Z. klin. Chem, u. klin. Biochem.

7. Jg., S. $404-426$, September 1969

\title{
Aminosäuren-Analyse in der klinischen Chemie
}

\author{
von A. Niederwieser und H.-Ch. Curtius \\ Medizinisch-Chemische Abteilung der Universitäts-Kinderklinik Zürich \\ (Direktor: Prof. Dr. A. Prader) \\ (Eingegangen am 9. Juni 1969)
}

Es werden die wichtigsten heute gebräuchlichen Methoden zur qualitativen, semiquantitativen und quantitativen Analyse von Aminosäuren in biologischem Material beschrieben.

\section{Amino acid analysis in clinical chemistry}

The foregoing paper describes the most important methods currently used for the qualitative, semi-quantitative and quantitative determination of amino acids in biological material.

Man kennt heute mehr als 60 angeborene Störungen des Aminosäure-Stoffwechsels (1-5). Davon wurden mehr als 40 erst in den vergangenen 10 Jahren mit Hilfe der modernen Techniken der Aminosäuren-Analyse entdeckt. Verschiedene der z. T. schweren Krankheiten, die sich in einer Hyperaminoacidurie äußern, haben Schwachsinn zur Folge und können sogar zum Tode führen.

Die Bedeutung einer sicheren Frühdiagnose ist groß, da bei verschiedenen Formen der Hyperaminoacidurie (z. B. Phenylketonurie) die Entwicklung des Schwachsinns verhindert werden kann, wenn von frühestem Säuglingsalter an die Aminosäure, die sich im Blut pathologisch anhäuft, von der Nahrung weitgehend ferngehalten wird. Die Erkennung einer Aminoacidurie ist aber auch dann noch wertvoll, wenn die Diagnose für eine wirksame Behandlung des betreffenden Individuums bereits zu spät ist: Die Ermittlung von Erbträgern (6), Familienberatung und schnellstmöglich einsetzende Behandlung von kranken Neugeborenen aus der betreffenden Familie können weiteres Leid vermeiden.

Eine primäre Hyperaminoacidurie betrifft meist nur eine oder wenige Aminosäuren. Sie wird durch einen Enzym- oder Transportdefekt im Aminosäurestoffwechsel verursacht, der oft erblich ist. Man unterscheidet:

Úberlauf-Hyperaminoacidurien, bei denen sich eine oder mehrere Aminosäuren im Urin anhäufen und deshalb als solche oder als ihre Abbauprodukte auch vermehrt im Urin ausgeschieden werden. Die einzelnen Aminosäuren weisen eine unterschiedliche renale Clearance auf; diese kann so groß sein, daß die pathologische Konzentrationserhöhung der betreffenden Substanz nur im Urin, aber nicht im Plasma nachweisbar ist (Hyperaminoacidurie „ohne Nierenschwelle").

Renale Hyperaminoacidurien, bei denen infolge eines defekten tubulären Rückresorptionsmechanismus für bestimmte Aminosäuren ebenfalls eine Hyperaminoacidurie ohne Aminosäureanstieg im Blut vorliegt. Teilweise ist auch die intestinale Resorption der gleichen Aminosäuren gestört.

Während das äußere Erscheinungsbild dieser "schweren Krankheiten zumeist wenig Charakteristika aufweist, gelingt die Diagnose in der Regel rasch durch eine Aminosäuren-Analyse von Urin und Serum.

Die große Zahl der bisher bekannt gewordenen Aminoacidurien (Tab. 1) darf nicht darüber hinwegtäuschen, $\mathrm{da} ß$ die meisten dieser Krankheiten extrem selten be-

Tab. 1. Hyperaminoacidurien

\begin{tabular}{|c|c|c|c|c|c|c|c|c|c|}
\hline Nr. & Aminosäure & $\begin{array}{c}\text { Konzen } \\
\text { erhöl } \\
\text { 茎 } \\
\text { d }\end{array}$ & $\begin{array}{l}\text { ntration } \\
\text { jht in } \\
\text { 돈 } \\
\text { 站 }\end{array}$ & Krankheit & Typ*) & Symptome & Defekt & $\begin{array}{c}\text { Therapie bzw. Diät } \\
\text { arm an } \begin{array}{c}\text { Zugabe } \\
\text { von }\end{array}\end{array}$ & Literatur \\
\hline
\end{tabular}

\begin{tabular}{|c|c|c|c|c|}
\hline 1. & $\begin{array}{l}\text { Alanin siehe } 9 \mathrm{~b}, 24 \\
\beta \text {-Alanin }\end{array}$ & + & + & $\begin{array}{l}\text { Hyper- } \beta \text {-alanin- } \\
\text { ämie }\end{array}$ \\
\hline & $\beta$-Aib, $\gamma$-Aib, Тau & & + & \\
\hline 2. & $\begin{array}{l}\beta \text {-Aminoisobuttersäure } \\
\text { siehe auch } 1 .\end{array}$ & + & + & $\begin{array}{l}\beta \text {-Aminoiso- } \\
\text { buttersäure- } \\
\text { ausscheidung }\end{array}$ \\
\hline
\end{tabular}

A Schlafsucht, Krämpfe ver-
mehrte $\gamma$ Abu mehrte $\gamma \mathrm{A}$
im Gehirn

A Keine a) genetischer
Polymorphis
mus (hohe Ausscheidung)

b) Index von Leberfunktion und Gewebe-
$\beta$-Alanin-aminotransferase
(EC 2.6.1.18) D-(--)- $\beta$-Aminoisobuttersäure 
Tabelle 1 (Fortsetzung)

\begin{tabular}{|c|c|c|c|c|c|c|c|c|c|c|}
\hline Nr. & Aminosäure & 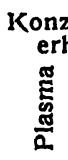 & $\begin{array}{l}\text { entra } \\
\text { oht } \\
5 \\
5\end{array}$ & 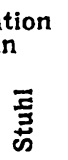 & Krankheit & Typ*) & Symptome & Defekt & $\begin{array}{c}\text { Therapie bzw. Diät } \\
\text { arm an } \begin{array}{c}\text { Zugabe } \\
\text { von }\end{array}\end{array}$ & Literatur \\
\hline
\end{tabular}

3. Argininobernsteinsäure $+\underset{(+)}{(+)} \begin{gathered}\text { Argininobern- } \\ \text { steinsäureurie } \\ \text { (Harnstoffcy- } \\ \text { kluskrankheit) }\end{gathered}$

4. Citrullin

siehe auch 3.
$+\quad+\quad \begin{gathered}\text { Citrullinämie, } \\ \text { Citrullinurie }\end{gathered}$ (Harnstoffcy kluskrankheit)

5. Cystathionin

$+\quad+\quad$ Cystathioninurie
6. Cystin
Arg, Lys, Orn
(sonst keine Amino-
säuren vermehrt!) siehe auch $14 \mathrm{c}, 26$

7a. Glycin

7b. Glycin

(
$+\quad+\quad \begin{gathered}\text { Nichtketotische } \\ \text { Hyperglycin- }\end{gathered}$ Hyperglycin-

$+\quad+\quad \begin{gathered}\text { Ketotische Hy- } \\ \text { perglycinämie }\end{gathered}$

$$
++ \text { Cystinurie }
$$$$
\text { perglycinämi }
$$

7c. Glycin

7d. Glycin

Phosphat

7e. Glycin Phosphat, Glucose

7f. Glycin Glucose

$+\quad$ Hyperglycinurie

$+\quad$ Dent-Typ

$+\quad$ Scriver-Typ

$+\quad$ Kaeser-Typ

7g. Glycin Pro
siehe auch 12, 17a-c

8. Glutamin

siehe auch $14 \mathrm{a}, \mathrm{b}$

$\stackrel{+}{+}+$

$\stackrel{+}{+}+$

Hyperammon-
amie (Harn-
stoffcyklus-
krankheit)

9a. Histidin

9b. Histidin

9c. Histidin Methylhistidin, Carnosin, Anserin

Homoarginin siehe $14 \mathrm{~b}$

10. Homocystin 5-Adenosyl-homo-
cystein, Homolan-
thionin

Methionin Homocystein

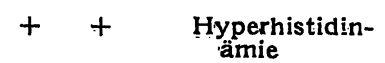

$$
\begin{aligned}
& +\quad \text { Hyperhistidin- } \\
& +\quad \text { Sonderform der } \\
& \begin{array}{l}
\text { juvenilen } \\
\text { Idiotie }
\end{array}
\end{aligned}
$$

+
+
$+(+)$

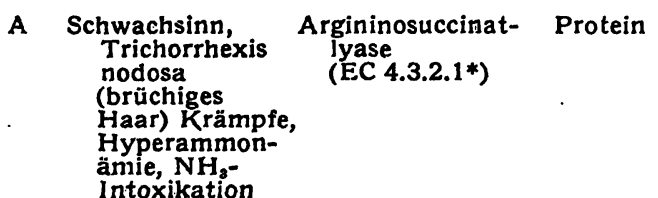

A Schwachsinn, Argininosuccinat- Protein

Trichorrhexis lyase

nodosa

(brüchiges

(EC 4.3.2.1*)

Haar) Krämpfe,

Hyperammon-

ämie, $\mathrm{NH}_{3}-$

$(8,9)$

A Erbrechen, Argininobern- Protein

$(10,11)$ Krämpfe, Hy-
pérammonämie,
steinsäure-Syn-
thetase (EC Hepatomegalie, 6.3.4.5) Schwachsinn

\section{$\Lambda$ Scher} $\begin{array}{ll}\text { Hypopsinn, } & \text { Mangelhafte } \\ \text { Bypophysen- } & \text { Bindung von } \\ \text { Psychosen, } & \text { Pyridoxalphos- } \\ \text { krankheit, } & \text { phat an Cysta- } \\ \text { Thrombopenic, } & \text { thionase (EC }\end{array}$

4.2.1.15)

B Cystinsteine
Diaminomono- carboxyl- und portsystem

A Schwachsinn, Apathie, Coma Glycin-" Oxi-
dase" oder
Glycin-Trans-
aminase (EC 2.6.1.4)
A massive Ketose, Erbrechen,
Neutropenie,
Thrombocyto-
penie, Apathie,
Coma, Hypo-
gammaglobu-
Schwachsinn

u. Tod

B Cálciumoxalat- Transportsystem steine, offenbar Vererbung

B Vitamin D-re- nichtkompetive $\begin{array}{ll}\text { sistente } & \text { Transport- } \\ \text { Rachitis } & \text { hemmung }\end{array}$

Dominante Vererbung, keine Symptome

B Hereditäre Taubheit, Nephropathie, Hyperprolinạmie
A Erbrechen, Hepatomega- lie, Schwach-

a) Carbamylphosphat-Synthetase

b) Ornithin-carba moyltransferase (EC 2.1.3.3)

A Sprachstörung, Manchmial

Histidase (EC 4.3.1.3)

Histidin

viel Pyri-
doxal-

phosphat

D-Penicil-

viel Flüs-

sigkeit,

Alkali

Histidase

(EC 4.3.1.3)

Histidin

Schwachsinn, Krämpfe, Erblindung, $\mathrm{Ce}$ rebromaculare Degeneration

Protein

A Ectopia lentis, Schwachsinn, schlaffe Ligamente, Arach-

nodactylic, ge-

rötete Wangen, blonde

Haare, Linsen-

luxation,

Thromboembolische Phänomene

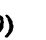


Itaballo I (Portsotzong)

\begin{tabular}{|c|c|c|c|c|c|c|c|c|c|c|c|}
\hline $\mathrm{Nr}$. & Amlinsanime & $\begin{array}{c}\text { ICuni: } \\
\text { eri } \\
\frac{6}{6}\end{array}$ & $\begin{array}{l}\text { tivitit } \\
\text { liblit } \\
\text { 量 }\end{array}$ & 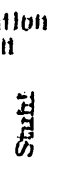 & Kinuklialt & (typl') & Syinptutno & Defekt & $\begin{array}{l}\text { "rlieraplo } \\
\text { arit afl } \\
1\end{array}$ & $\begin{array}{l}\text { b'sw, Diat } \\
\text { Zugabe } \\
\text { von }\end{array}$ & Literatur \\
\hline 11. & $\begin{array}{c}\text { - Jydrnkybultersaure } \\
\text { Mel, Ile, Leu, Val }\end{array}$ & & 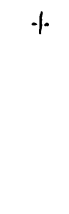 & + & $\begin{array}{l}\text { Metliluitlilemals } \\
\text { nusurptluit }\end{array}$ & U & 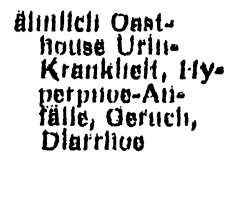 & 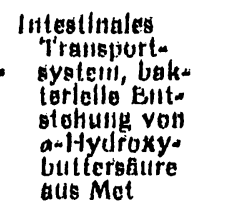 & Met & & $(0,47)$ \\
\hline 12. & 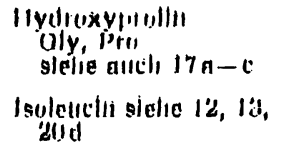 & 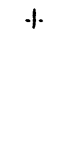 & $\stackrel{+1}{(t)}$ & & $\begin{array}{l}\text { Ifydruxyproblitim } \\
\text { diinle }\end{array}$ & $\mathbf{A}$ & $\begin{array}{l}\text { Buliwaclisline, } \\
\text { Mikfoliailias } \\
\text { turlo }\end{array}$ & 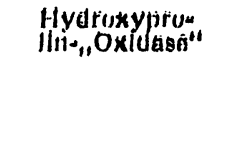 & & & $(48,49)$ \\
\hline 13. & 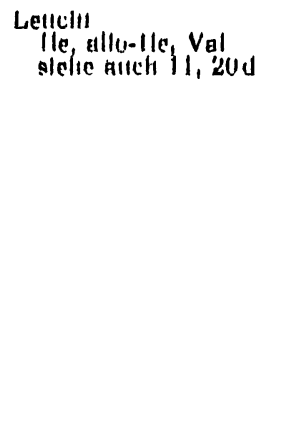 & + & $+t$ & & 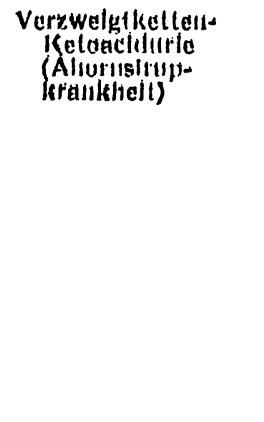 & $\boldsymbol{\Lambda}$ & 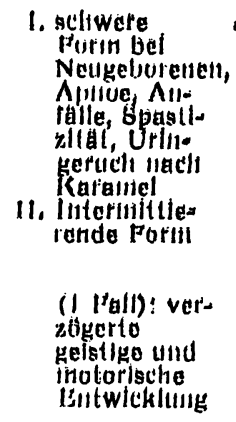 & 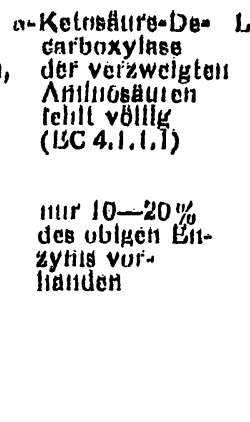 & $\begin{array}{l}\text { Lell, Ila, } \\
\text { Val }\end{array}$ & & $(50-6)$ \\
\hline 14a. & $\begin{array}{c}\text { Lysil1, } \\
\text { Aty, Oril }\end{array}$ & + & :t & & 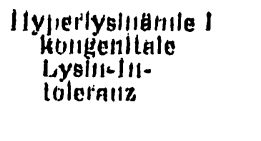 & 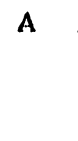 & 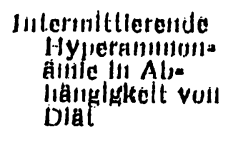 & " & Prolein & & $(65-60)$ \\
\hline $14 b$. & $\begin{array}{l}\text { Lysll1 } \\
\text { Oril, Arg } \\
\text { Olit } \\
\text { Hulloalce }\end{array}$ & $\left(\begin{array}{c}+ \\
+ \\
+1\end{array}\right)$ & $\begin{array}{l}+r \\
+r \\
+\end{array}$ & & Iyptarlysluanile II & $\Lambda$ & 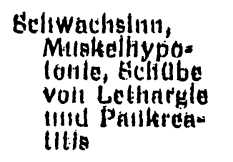 & " & Lys & & $(67-5 y)$ \\
\hline $14 c$ & $\begin{array}{l}\text { Lysin OrH, Art } \\
\text { siclie allicli } 0\end{array}$ & & + & & 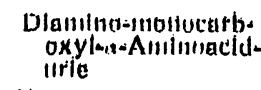 & is & 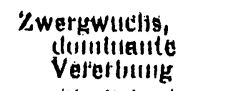 & 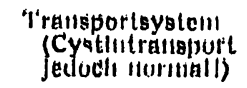 & & & (204) \\
\hline Iti. & 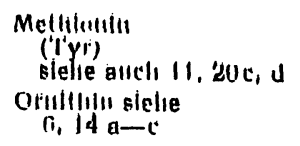 & $\nLeftarrow$ & -1 & & $\begin{array}{l}\text { Hyperinathilu= } \\
\text { illibitile }\end{array}$ & $\Lambda$ & $\begin{array}{l}\text { gewblumlieli als } \\
\text { liulge akuler } \\
\text { Leliererititail. } \\
\text { klulig }\end{array}$ & $p$ & & $\begin{array}{l}\text { Lobelor- } \\
\text { krankility } \\
\text { beliatidelii }\end{array}$ & (5) \\
\hline $18 \theta_{1}$ & t'lenylalaniln & +1 & + & & Pliellylkelonutie & $\boldsymbol{\Lambda}$ & 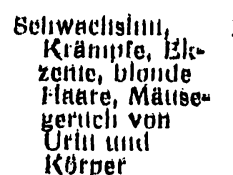 & 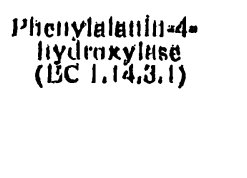 & $\begin{array}{l}\text { Mlienyl. } \\
\text { alaiili }\end{array}$ & & $(\theta 0-0 j)$ \\
\hline 166. & $\begin{array}{l}\text { Plienylalanili } \\
\text { slefie allcli zod }\end{array}$ & +1 & + & & $\begin{array}{l}\text { Hypetpluenyl- } \\
\text { alaillitale }\end{array}$ & $\mathbf{A}$ & 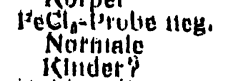 & $?$ & & & $(04,03)$ \\
\hline 17 a. & $\begin{array}{l}\text { Prolln } \\
\text { Oly, Hyjuro }\end{array}$ & + & tr. & & $\begin{array}{l}\text { Hyperpionlin- } \\
\text { anile }\end{array}$ & $\Lambda$ & $\begin{array}{l}\text { Uniklare zu- } \\
\text { salinilenlliang } \\
\text { inll heredifiarer } \\
\text { Neplisupatio }\end{array}$ & 1.-1Prulili-Oxidase & & & $((i 5) \underset{49)}{-07}$ \\
\hline $17 \mathrm{~b}$ & Prolin & + & + & & $\begin{array}{l}\text { Hypeiprolilis } \\
\text { ilile II }\end{array}$ & $\Lambda$ & $\begin{array}{l}\text { Seliwacliolint } \\
\text { und Kräinpfe }\end{array}$ & 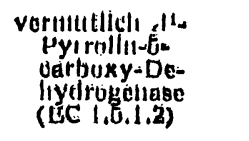 & & & $(4(4)$ \\
\hline $17 c$ & $\begin{array}{l}\text { Prolin } \\
\text { oly, Hypro } \\
\text { sielic auch 12 }\end{array}$ & + & +1 & $\phi$ & 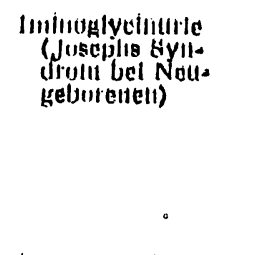 & $\mathbf{B}$ & 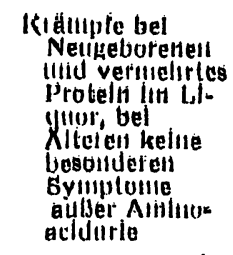 & Traheportsystent & & & $\left(\cos _{67} 40\right.$ \\
\hline 16. & 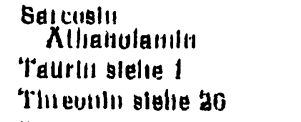 & + & + & & Bencuslitämle & $\mathbf{A}$ & Mirskelliynutullie & 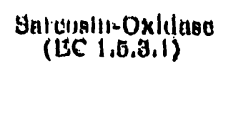 & . & & $(60)$ \\
\hline $19 \mathrm{a.}$ & $\begin{array}{l}\text { Tiypluplian } \\
\text { Plidulueilvale }\end{array}$ & & + & + & $\begin{array}{l}\text { IJlue difiper } \\
\text { sylidiume }\end{array}$ & U) & 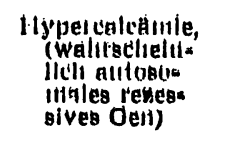 & $\begin{array}{l}\text { IIItrsllinales } \\
\text { framspoft. } \\
\text { systeni }\end{array}$ & ; & & (b) \\
\hline
\end{tabular}


Talselle I (Portsetzung)

\begin{tabular}{|c|c|c|c|c|c|c|c|c|c|c|c|}
\hline \multirow[t]{2}{*}{$\mathrm{Nr}$, } & \multirow[t]{2}{*}{ Allilnosture } & \multicolumn{3}{|c|}{$\begin{array}{c}\text { Knnzentration } \\
\text { erliblit lil }\end{array}$} & \multirow[t]{2}{*}{ Krankhoit } & \multirow[t]{2}{*}{ 'Тур*) } & \multirow[t]{2}{*}{ Symplome } & \multirow[t]{2}{*}{ Detelut } & \multirow{2}{*}{\multicolumn{2}{|c|}{$\begin{array}{c}\text { Theraple brw. Diat } \\
\text { arni all Zilgalie } \\
\text { vinl }\end{array}$}} & \multirow[t]{2}{*}{ lallaralur } \\
\hline & & 至 & $\stackrel{g}{5}$ & 蛋 & & & & & & & \\
\hline $10 \mathrm{~b}$, & Tryptoplian & + & & & $\begin{array}{l}\text { Hypertrypto- } \\
\text { phananite }\end{array}$ & A & $\begin{array}{l}\text { Zwergwichs, } \\
\text { Schwachisinn } \\
\text { Liclitempflid. } \\
\text { Heit, A taxio }\end{array}$ & $\begin{array}{l}\text { PTryploplian- } \\
\text { Pyirrilase oder } \\
\text { Porniylase }\end{array}$ & & $\begin{array}{l}\text { PNicollon- } \\
\text { andild }\end{array}$ & $(B O \mathrm{a})$ \\
\hline 20 n. & Tyrosin & + & + & & Tyrosinose & $A$ & $\begin{array}{l}\text { Tyrosylurle, } \\
\text { Myssthemia } \\
\text { gravis (I Pall } \\
\text { bekanint) }\end{array}$ & $\begin{array}{l}\text { Tyrnsin-Trans- } \\
\text { annlinase? } \\
\text { (\&:C } 2,(i, 1,5)\end{array}$ & & & 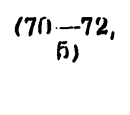 \\
\hline $20 \mathrm{~b}$. & 'Pyrasin & + & + & & $\begin{array}{l}\text { Ilyperiyrosili- } \\
\text { Ginle I bel } \\
\text { Priiligeburten } \\
\text { (Tyrosylurie) }\end{array}$ & $\mathbf{A}$ & $\begin{array}{l}\text { Tyrusylurle, in } \\
\text { schweren } \\
\text { FHilen Vens. } \\
\text { Depressiol }\end{array}$ & $\begin{array}{l}\text { Paraliyidroxy- } \\
\text { pheinylibrenz- } \\
\text { traubunsäure- } \\
\text { Oxidase ist :ell- } \\
\text { weise inaktiv }\end{array}$ & & $\begin{array}{c}\text { Ascourbin- } \\
\text { sắure }\end{array}$ & $(7: 3-7 \pi$ \\
\hline $20 c$. & $\begin{array}{l}\text { Tyrosin } \\
\text { (1ind Mel) } \\
\text { Tyrosylverbindungen }\end{array}$ & + & $\begin{array}{l}+ \\
+\end{array}$ & & $\begin{array}{l}\text { Hypertyrosill- } \\
\text { amie II } \\
\text { (erbllcli) }\end{array}$ & $A$ & $\begin{array}{l}\text { Leberclrrlinse, } \\
\text { Raclififs, } \\
\text { Rcliwaclisinn, } \\
\text { Babers Byn= } \\
\text { lirom hei } \\
\text { älteren Kindern }\end{array}$ & $\begin{array}{l}\text { Paraliydroxy- } \\
\text { phenylhrenz- } \\
\text { pralibensalire- } \\
\text { Oxidase }\end{array}$ & $\begin{array}{c}\text { Tyrosin } \\
\text { rolie }\end{array}$ & & $\begin{array}{l}776,77 \\
71,72 ;\end{array}$ \\
\hline $20 \mathrm{~d}$, & $\begin{array}{l}\text { Tyrosin } \\
\text { Jle, J,eu, Met, Phe, } \\
\text { Val } \\
\text { slelie auch } 15\end{array}$ & + & $t$ & & $\begin{array}{l}\text { Hypertyrosin- } \\
\text { Amle JJ } \\
\text { "Oąt-House" } \\
\text { Urin-Kranklielt }\end{array}$ & $\mathbf{A}$ & $\begin{array}{l}\text { Scliwachsinn, } \\
\text { Krämpfe, } \\
\text { Odenie, weilse } \\
\text { Haare, Oeruch }\end{array}$ & $\begin{array}{l}\text { vielleiclit wie } \\
\text { lyyp II }\end{array}$ & & & $(47,7 K)$ \\
\hline 21. & $\begin{array}{l}\text { Valin } \\
\text { slelie aucli 11, 13, } \\
20 \mathrm{~d}\end{array}$ & $t$ & + & & Hypervallnämie & $A$ & $\begin{array}{l}\text { 1.rhrechen, } \\
\text { Reizbarkeli, } \\
\text { Schwachsinin }\end{array}$ & $\begin{array}{l}\text { Valin-ox-|Kalri- } \\
\text { Isovalerian- } \\
\text { sänre-franis- } \\
\text { aminase (I-en- } \\
\text { kocyten) }\end{array}$ & Val & & (7fsa, 5) \\
\hline 22. & $\begin{array}{l}\text { Monoamino-monocar- } \\
\text { boxyl-a-Amina- } \\
\text { acidurie }\end{array}$ & & + & + & $\begin{array}{l}\text { HartnupeKrank- } \\
\text { heil }\end{array}$ & B & $\begin{array}{c}\text { zeitwellig pella- } \\
\text { graähilliche } \\
\text { Zustände mit } \\
\text { Psychosen, } \\
\text { Ataxie, } \\
\text { Schwachsinn }\end{array}$ & $\begin{array}{l}\text { Transportsystem, } \\
\text { unvollstänoliga: } \\
\text { Pesorption, } \\
\text { auej iim } \\
\text { Jejunum }\end{array}$ & & $\begin{array}{l}\text { Picostin- } \\
\text { amida }\end{array}$ & $(7 !), 8(1))$ \\
\hline 23. & $\begin{array}{l}\text { Allgemeine Aininn- } \\
\text { acidurie }\end{array}$ & - & + & & Pranconi-Syndronı & B & $\begin{array}{l}\text { Kombinationen } \\
\text { mil. Olycns- } \\
\text { urie, Hypo- } \\
\text { pliospliaturie, } \\
\text { Osteromalacie } \\
\text { (meist mit } \\
\text { clironiselier } \\
\text { Acidosis), Hy- } \\
\text { pokaliammie, } \\
\text { Hypouricamie }\end{array}$ & $\begin{array}{l}\text { erworbene Alb- } \\
\text { normität } 4, B, \\
\text { durcil Tetra- } \\
\text { cycline, } \\
\text { Schwermetalle, } \\
\text { Salicylal.e, } \\
\text { Vitamin-D. } \\
\text { Mangel }\end{array}$ & $\begin{array}{l}\text { frailizeilige } \\
\text { tigung des } \\
\text { bzw. Behs } \\
\text { Mane }\end{array}$ & $\begin{array}{l}\text { Besei- } \\
\text { êxins } \\
\text { el)ung des } \\
\text { gels }\end{array}$ & $(8)-(3: 3)$ \\
\hline 24. & $\begin{array}{l}\text { Allgemelne Amino- } \\
\text { acidurie } \\
\text { (vor allem Ala, Oly, } \\
\text { Ser, Thr, Oin, Val) } \\
\text { Oalaktose }\end{array}$ & & + & & $\begin{array}{c}\text { Itereditäre Ga- } \\
\text { laktosämie }\end{array}$ & B & $\begin{array}{l}\text { Scliwaclosinn, } \\
\text { Katarakst, Gelb, } \\
\text { suclit }\end{array}$ & $\begin{array}{c}\text { nichttkompelitive } \\
\text { Transport- } \\
\text { hemmung }\end{array}$ & Salakiose & & $(B A-F(S)$ \\
\hline 26. & $\begin{array}{l}\text { Allgemeine Amino- } \\
\text { acidurie } \\
\text { Phospliat }\end{array}$ & & + & & $\begin{array}{l}\text { Oculncerephrore- } \\
\text { nailes Syndrom }\end{array}$ & $\mathbf{B}$ & $\begin{array}{l}\text { Renale Tubuläre } \\
\text { Acidose, Hy- } \\
\text { potonie, } \\
\text { Schwachsinn }\end{array}$ & $\begin{array}{l}\text { nichterompetitive } \\
\text { Transport- } \\
\text { hemmung } \\
\text { Defekt. in } \mathrm{NHH}_{3} \\
\text { Syntliest }\end{array}$ & & & (E) \\
\hline 26. & $\begin{array}{l}\text { Allgemeine Amino- } \\
\text { qcidurie } \\
\text { bes. (Cys), Thr }\end{array}$ & & + & & $\begin{array}{l}\text { Hepalolenti- } \\
\text { culare De- } \\
\text { generation } \\
\text { Wileon'sche } \\
\text { Kranklielt }\end{array}$ & B & $\begin{array}{l}\text { Lebercirriuose, } \\
\text { Tremnr, } \\
\text { Kaysert } \\
\text { Fleischer } \\
\text { Ringe, } \\
\text { Kupferab- } \\
\text { lagerung im } \\
\text { Oewebe }\end{array}$ & $\begin{array}{l}\text { permindertes } \\
\text { cermingerisiplas- } \\
\text { min Niteren- } \\
\text { ochadigung } \\
\text { verantworlich } \\
\text { fïr Amino- } \\
\text { acidurie }\end{array}$ & $\begin{array}{l}\text { Penicill- } \\
\text { amin }\end{array}$ & & $(\$ 7$, fH) \\
\hline 27. & Alle Plasınaaminosäuren & & + & & Cystinose & B & $\begin{array}{l}\text { Vitamin-D-re- } \\
\text { sistente Ra- } \\
\text { clitis, Zwerg- } \\
\text { wuclis, Acidrisis, } \\
\text { Dehydratation, } \\
\text { inelat tödlich }\end{array}$ & & $\vdots$ & & $\begin{array}{l}\text { (fs2, fig, } \\
\text { in) }\end{array}$ \\
\hline
\end{tabular}

") A: Uberlauf-Amincacidurle mit normaler tubulärer Reabsorntion.

3: Renale Hyperaminoaciudurie, verringerte tubulare Reabsorption.

merkt werden. Es ist aber anzunchmen, dars sich dieses Bild ändert, wenn in der Zukunft alle Neugeborenen auf Aminoacidurien untersucht werden. Wahrscheinlich sterben heute noch viele Säuglinge an unerlsannten Aminosăure-Stoffwechselstbrungen. Bereits in mehreren Jandern sind Anshtze vorhanden, Neugeborene routinemaßBig auf solche Stoffwechselanomalien zu untersuchen: vgrl, z. B. (90-93). Um den Aufwand filir diese Analyeen ertrăglich zu halten, werden yunächst efnfache und preiswerte Screening-Tests angewendet. Bin positives Drgebnis dleser 'Tests (94) muß in der Regel durch elise quantitative Aminosăuren-Analyse tiberprifi: werden. Um falsch-negative Besultate y, vermeiden, sollten Proben von Neugeborenen eral nach 3-5thglger Pat- 
terung mit Milch gesammelt werden. Physiologische Faktoren, welche die Interpretation von Screening-Tests beeinflussen, wurden u. a. von SCRIver diskutiert (95). Weitere Anwendungsgebiete der Aminosäuren-Analyse betreffen z. B. Jodaminosäuten, die in Zusammenhang mit Schilddrüsenerkrankungen zunehmendes Interesse finden (siehe auch unter III), Kollagenstoffwechselstörungen und Kontrollen bei lang dauernder parenteraler Ennährung.

\section{Orientierende chemische Urinproben auf Stoffwechselstörungen}

Zur groben Auslese des Untersuchungsmaterials stehen zahlreiche Tests zur Verfügung (vgl. z. B. 3, 96-98), die aber alle unspezifisch sind und für eine endgültige Diagnose nicht ausreichen. In unserem Laboratorium werden u. a. folgende Proben durchgeführt:

\section{Dinitrophenylbydrazin-Probe auf Ketonkörper}

Positiv bei Ahorn-Sirup-Krankheit, Phenylketonurie, Histidinämie. Schwach positiv bei Acetonausscheidung, gelegentlich auch beim Lowe-Syndrom.

$1 \mathrm{ml}$ frischen, klaren Urin (evtl. Trübung und Färbung durch Zusatz von etwas Kieselgur und Zentrifugation beseitigen), mischen mit $1 \mathrm{ml}$ Reagens (2 g 2,4-Dinitrophenylhydrazin in $1 l$ 2N HCl). Das Gemisch 30 Min. bei Zimmertemperatur (evtl. kurz erwärmen) stehenlassen. Die Probe ist positiv, wenn eine gelbe Trübung oder ein Niederschlag auftritt. (Ein durch Aceton erzeugter Niederschlag löst sich durch kurzes Aufkochen.)

\section{Eisencblorid-Probe}

Grüne Farbe bei Phenylketonurie und Histidinämie. Falsch-positive Resultate werden von Salicylaten und anderen Medikamenten erhalten. Windeltest (Reagens auf feuchte Windel tropfen) ist möglich.

Zu $1 \mathrm{~m} /$ frischem, klarem Urin langsam 6-10 Tropfen 10 proz. Eisen-[III]-chloridlösung in $1 \mathrm{~N} \mathrm{HCl}$ geben. Phenylbrenztraubensäure, $p$-Hydroxyphenylbrenztraubensäure, Imidazolbrenztraubensäure geben sofort eine Grünfärbung. Die Farbe erreicht nach etwa 1 Min. ihr Maximum und wird in kurzer Zeit wieder gelb. Phenistix der Firma Ames beruhen auf demselben Prinzip.

\section{Nitroprussid-Probe (Brand-MeYer) auf Cystin und Homo- cystin}

Positiv bei Cystinurie, Homocystinurie und massiven allgemeinen Aminoacidurien.

Zu 5 Teilen Urin gibt man 1 Teil 5 proz. wäßr. NatriumcyanidLösung (Vorsicht: schweres Giftl) und läßt 10 Min. stehen. Man fügt dann einige Tropfen einer frisch hergestellten 1 proz. wäßr. Natriumnitroprussid-Lösung (hellrot) zu. Positiv bei Purpurfärbung des Urins, die längere Zeit bestehenbleibt, während ein falsch-positives Resultat schnell in Braun umschlägt.

\section{Nitroprussid-Probe nach BARBER auf Homocystin}

Bei positivem Nitroprussid-Test wird der folgende Doppel-Test zur Unterscheidung von Cystin und Homocystin angewendet:

a) $5 \mathrm{ml}$ Urin werden mit festem $\mathrm{NaCl}$ gesättigt. Man gibt $0,5 \mathrm{ml}$ einer Lösung von 1 proz. Silbemitrat in 3 proz. Ammoniak zu, mischt und läßt 1 Min. stehen. Man gibt $0,5 \mathrm{~m} l$ einer frisch hergestellten 1 proz. Natriumnitroprussid-Lösung zu und dann $0,5 \mathrm{ml}$ 0,7 proz. Natriumcyanidlösung (Vorsicht: Giftl). b) genau wie unter a), jedoch verwendet man 3 proz. Ammoniaklösung anstelle von ammoniakalischer Silbernitrat-Lösung.

Sofortige Rotfärbung der Probe a) bedeutet Homocystin. Eine langsame Reaktion beruht auf Cystin oder einer anderen Verbindung. Eine Reaktion in Probe b) wird nicht von Homocystin verursacht.

\section{$\alpha-N i t r o s o-\beta$-naphtbol-Test auf Tyrosylurie}

Positive Reaktion durch $p$-Hydroxyphenylbrenztraubensäure, $p$-Hydroxyphenylmilchsäure, $p$-Hydroxyphenylessigsäure. Negativ mit o-Hydroxyphenylessigsäure sowie mit Tyrosin.

$1 \mathrm{~m} l$ 2,6N Salpetersäure, 1 Tropfen 2,5 proz. wäßr. Natriumnitritlösung, 10 Tropfen 0,1 proz. $\alpha$-Nitroso- $\beta$-naphthol in 95 proz. Äthanol und 3 Tropfen Urin werden gemischt und 2-3 Min. stehengelassen. Positiv bei orange/rot-Färbung.

\section{Mikrobiologische Screening-Tests}

Mikrobiologische Verfahren gestatten es, eine einzelne Aminosäure gleichzeitig in einer großen Reihe von Proben zu bestimmen. Pro Arbeitskraft können bis zu 100 Proben in einem Ansatz bearbeitet werden. Solche Tests sind daher im allgemeinen billig und eignen sich zur Massenuntersuchung. Die größte Verbreitung fand der Agardiffusionstest nach GUTHRIE und SUSI $(99,100)$. Dieser semiquantitative Test wird in großem Umfang zur Früherkennung der Phenylketonurie, Höomocystinurie und Verzweigtketten-Ketoacidurie (Ahorn-SirupKrankheit) eingesetzt. Als Probe dient ein mit dem zu testenden Blut getränktes Filterpapier, das in getrocknetem Zustand aufbewahrt und zur Untersuchung an ein Zentrallabor geschickt werden kann.

Aus der getränkten Papierzone werden kleine Scheibchen (Testblättchen) gestanzt, sterilisiert und auf die Oberfläche einer dünnen Agar-Agar-Schicht, die ein Minimal-Nährmedium nach DemaIN, einen für die zu bestimmende Aminosäure spezifischen Antimetaboliten sowie Bakteriensporen enthält. Beim Bebrüten können nur dort Bakterien wachsen, wo die Wachstumshemmung des Antimetaboliten durch die aus dem Testblättchen herausdiffundierte Aminosäure aufgehoben wird. Der Durchmesser des sich bildenden Wachstumshofs ist bei stañndardisierter Durchführung ein $\mathrm{Maß}$ für die Konzentration der betreffenden Aminosäure im Blutt. Zur Bestimmung von Phenylalanin, Homocystin und Leucin dient als Antimetabolit $\beta$ (2-Thienyl)alanin bzw. L-Methionin-DI-sulfoximin bzw. Methylleucin (über Aminosäuren-Antagonisten siehe MEISTER (100a)). Ës kommen Sporen z. B. von Bacillus subtilis 6633 ATCC zur Anwendung. Als Standard dient eine Reihe von Testblättchen, die mit Blut von zunehmender Aminosäurekonzentration getränkt sind.

Über quantitative mikrobiologische Aminosäurebestimmungen siehe unter IV.

III. Qualitative und semiquantitative elektrophoretische und chromatographische Verfahren ${ }^{1}$ )

Im Hinblick auf die zahlreichen möglichen Formen von Aminosäurestoffwechselstörungen (siehe Tab. 1) ist es

1) Vgl. die Úbersicht von Patakr, diese Z. 2, 129 (1964). 


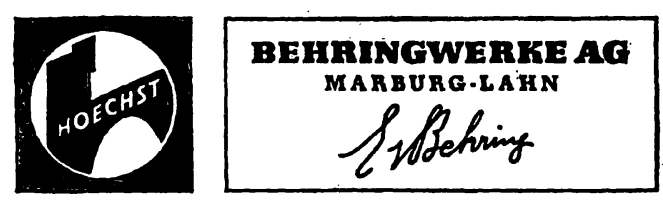

\section{PTT-Reagenz}

Reagenz zur Bestimmung der partiellen Thromboplastin-Zeit

Einfacher Suchtest zur

präoperativen Diagnostik

von Gerinnungsstörungen
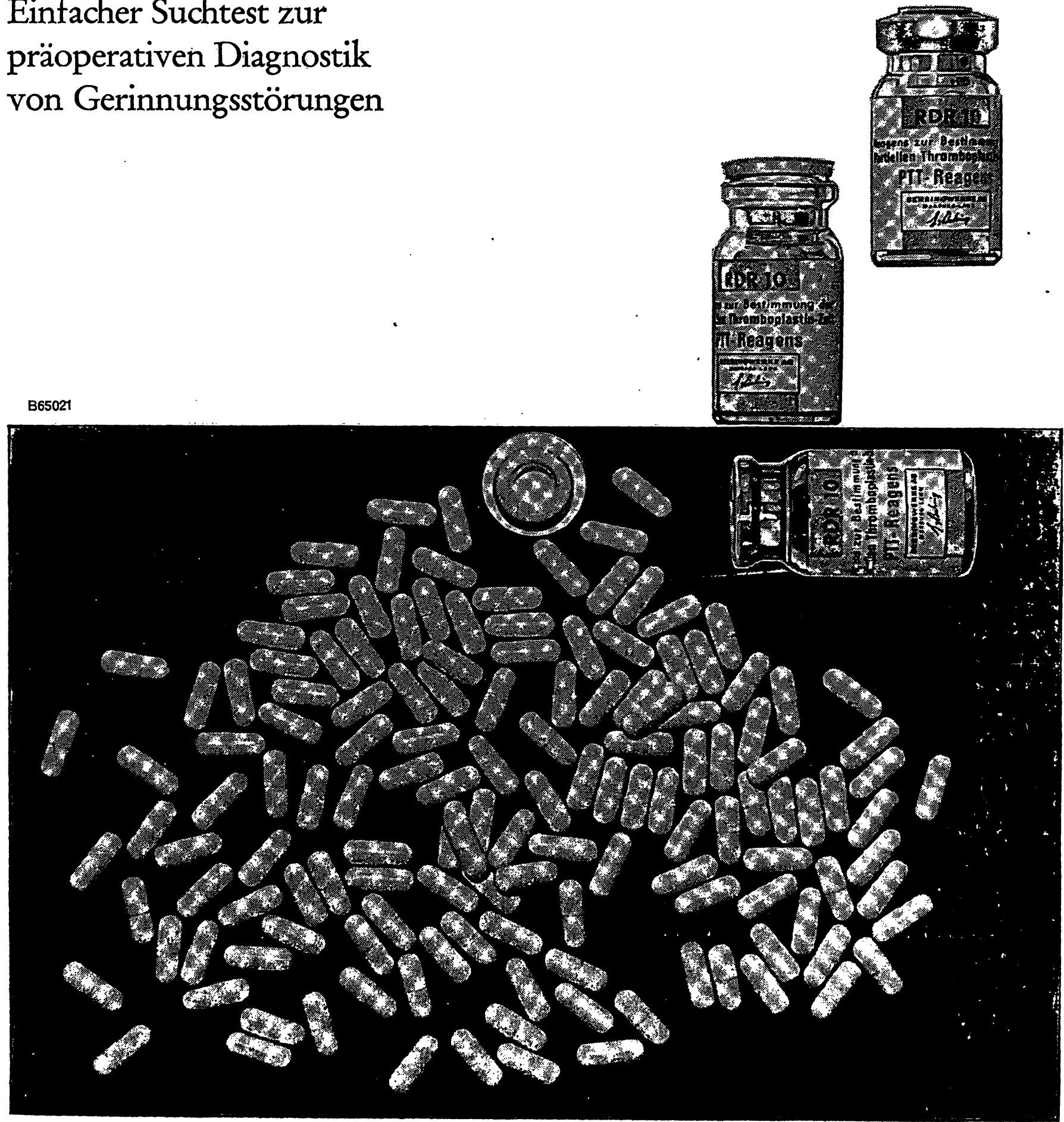
Für schnelle. Konzentrierung, Reinigung und Fraktionierung von biologischen Flüssigkeiten

\section{Dar \\ MAEMBRAN ULTRAFILTRATION}

DIAFLO Membranen, in AMICON UItrafiltrationszellen eingesetzt, konzentrieren verdünnte Proteinlösungen innerhalb kurzer Zeit 10 bis 1000-fach. Eine vollständige Beseitigung der Salze oder anderer kleiner Moleküle kann innerhalb der gleichen Zeit mittels Diafiltration erzielt werden.

DIAFLO Membranen verstopfen nicht und sind wieder verwendbar. Jeder Membrantyp besitzt eine bestimmte chemische Beständigkeit und charakteristische physikalische Eigenschaften. Alle Membranen sind nicht denaturierend und biologisch inert.

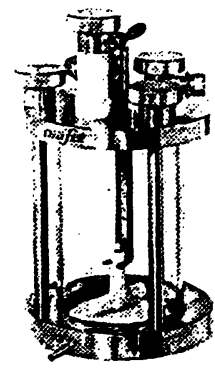

AMICON

ULTRAFILTRATIONS-

ZELLEN erlauben das

Arbeiten mit biologischen

Flüssigkeiten von

1 ML BIS ZU 20 LITERN

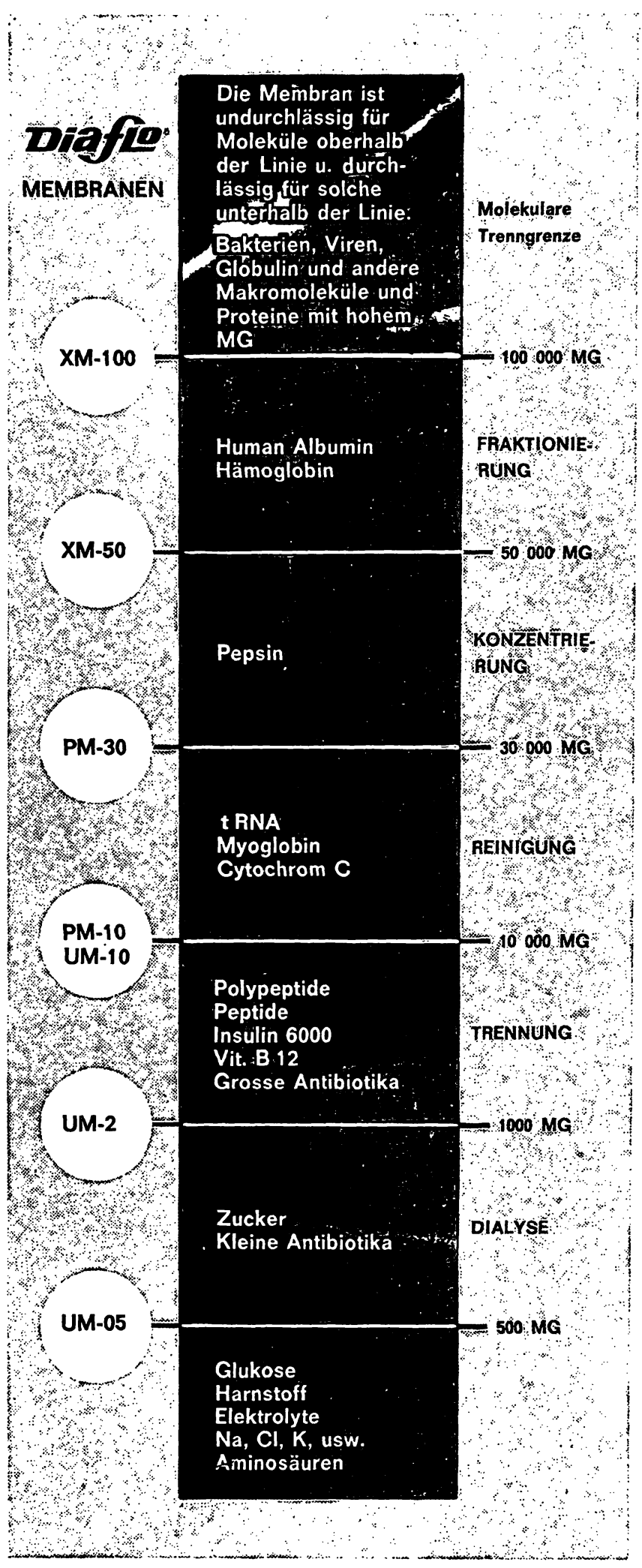

Amicon bietet ausserdem grössere industrielle Anlagen für kontinuierliche Verfahren.

Abt.: 05

AMICON N.V. Heemskerckstraat 43 In den U.S.A.: 27 Hartwell Ave.

DEN HAAG
Lexington

HOLLAND Ruf : (070) 642820 MASS. 02173 
von Nachteil, daß die bisher genannten Tests nur auf eine einzige (Guthrie-Tests) oder auf wenige Aminosäuren spezifisch sind. Man kann damit zwar die zahlenmäßig häufigsten Aminoacidurien mit relativ geringem Aufwand erfassen, doch bleiben die selteneren Krankheiten unerkannt. Hingegen sind elektrophoretische und chromatographische Trennmethoden in der Lage, jede nennenswerte Veränderung des normalen Aminosäuren„Spektrums" zu erfassen. Da eine vollständige Trennung aller Komponenten und eine sichere Identifizierung zunächst nicht nötig ist, wurden bereits viele einfache und billige Screening-Verfahren auf dieser Basis ausgearbeitet. Diese Verfahren scheinen uns insofern einander weitgehend äquivalent $\mathrm{zu}$ sein, als sie gestatten, eine Unregelmäßigkeit irgendwelcher Art aufzudecken. Bei den relativ wenigen aus dem Rahmen fallenden Fällen ist eine genauere, wenn möglich sogar quantitative Analyse anzuschließen. Als Pionier auf diesem Gebiet wirkte zweifellos DENT (101-103), der sehr früh den Vorteil der Papierchromatographie zur Untersuchung von Aminosäuren im Urin erkannte. Fast alle chromatographischen Methoden wurden seitdem für solche
Zwecke verwendet. Im Falle von Urin wird zweckmäßigerweise zunächst $\alpha$-Aminostickstoff oder Kreatinin bestimmt und ein auf den betreffenden Gehalt bezogenes Volumen zur Analyse eingesetzt.

\section{Hochspannungs-Elektrophorese von Urin}

Hochspannungs-Elektrophorese ist ein rasches Trennverfahren. Es eignet sich besonders zur Untersuchung von Aminosäuren im Urin, da die anwesenden Salze im Gegensatz zur Chromatographie - in der Regel nicht stören. Eiweißhaltige Proben sollten vor der Analyse enteiweißt werden. Hochspannungs-Elektrophorese auf Papier wurde von zahlreichen Autoren eindimensional (z. B. (104-106)) und in Kombination mit Papierchromatographie (z. B. (105, 107-109)) verwendet. Für technische Details verweisen wir auf die hervorragende Übersicht von EFroN (110) sowie auf Handbücher (z. B. (111-113)). In unserem Laboratorium wird nach dem unten angegebenen Verfahren gearbeitet. Mit eindimensionaler Elektrophorese können bis zu 100 Analysen pro Tag von einer Person bewältigt werden. Zeigt sich auf dem eindimensionalen Pherogramm eine deutliche

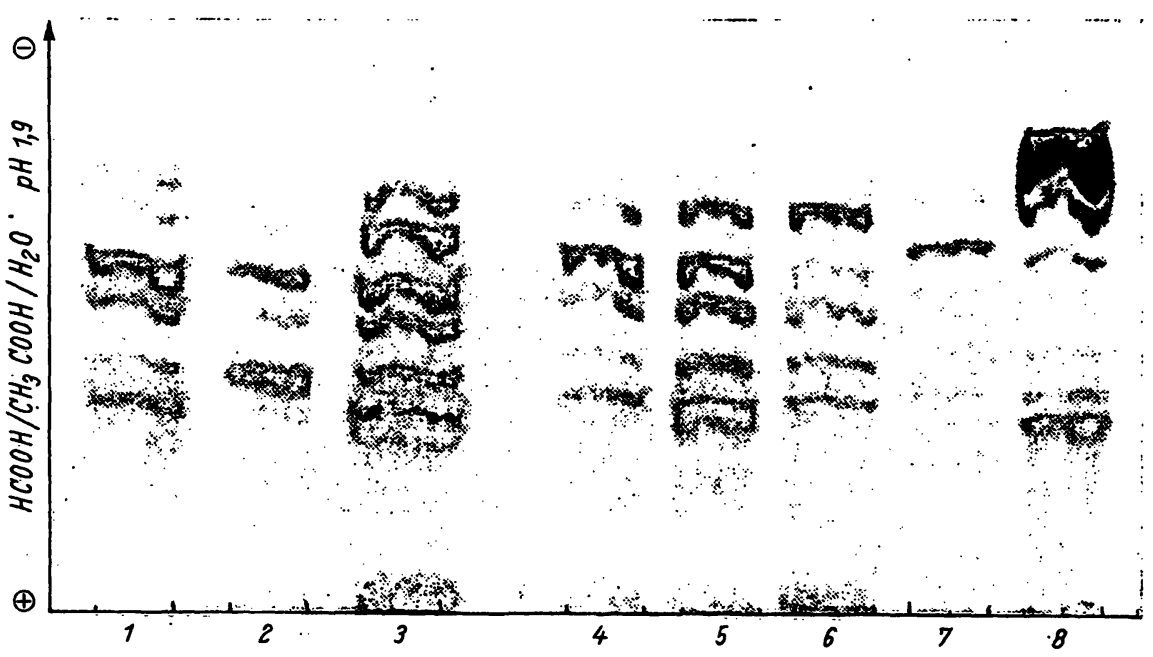

Abb. 1

Hochspannungselektrophorese von normalen und pathologischen Urinen auf Schleicher \& Schüll Nr. $2043 \mathrm{~b}$ in Essigsäure/A meisensäure/ Wasser $(26+120+854, v+v), \mathrm{pH} 1,9$ bei $100 \mathrm{~V} / \mathrm{cm}$ (siehe Text).

1: Mischurin, 2 Wochen - 6 Monate;

2: Verzweigtketten-Ketoacidurie, 3 Monate; 3: Generelle Aminoacidurie, 6 Monate;

4: Mischurin, 2-5 Jahre;

5: Phenylketonurie, 3,5 Jahre

6: Histidinämie, 2 Jahre;

7: Mischurin, 10-20 Jahre; 8: Cystinurie, 14 Jahre
Abb. 2

Kombination von Hochspannungselektrophorese und Papierchromatographie. Fleckenmuster zur Identifizierung von Urinaminosäuren a) Elektrophorese allein (vgl. Abb. 1) b) Kombination von Elektrophorese (vgl. a) und Papierchromatographie n-Butanol/Eisessig/Wasse $(4+1+5, v+v)$

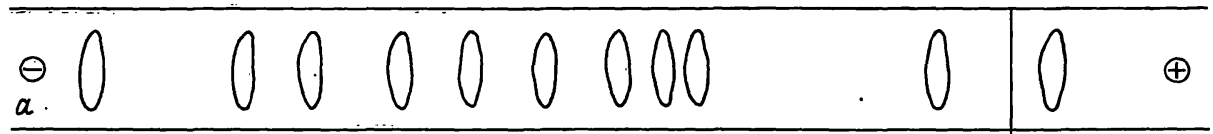

$\oplus$

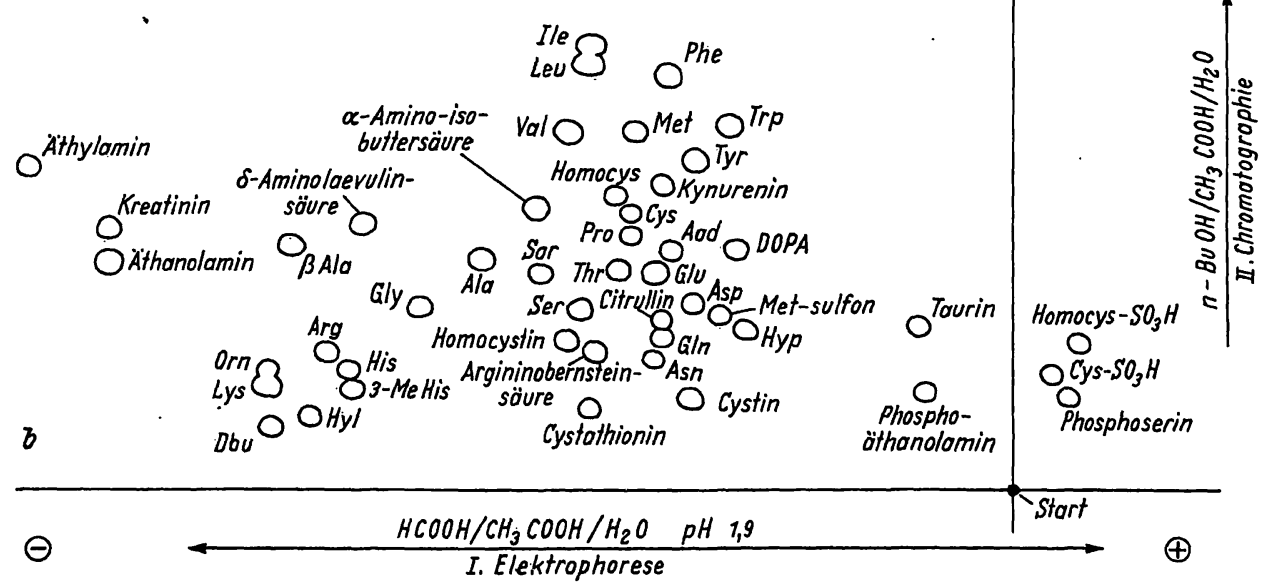


Konzentrationserhöhung einer oder mehrerer Banden (Abb. 1), so kombinieren wir die Elektrophorese mit Papierchromatographie in der zweiten Dimension. Dies erlaubt eine weitgehende Identifizierung der betreffenden Komponente. Eine solche zweidimensionale Trennung ist in Abbildung 2 dargestellt.

\section{Eindimensionales Pherogramm}

Auf Schleicher \& Schüll-Papier Nr. $2043(20 \times 40 \mathrm{~cm})$, das mit Puffer pH 1,9 $(120 \mathrm{~m} l$ Eisessig, $26 \mathrm{ml}$ Ameisensäure ad $1000 \mathrm{~m} l$ mit dest. Wasser) getränkt ist, werden die Proben als $2 \mathrm{~cm}$ lange Streifen aufgetragen $(10 \mathrm{~cm}$ vom schmalen, der Kathode zugewandten Seitenrand entfernt, in gegenseitigem Abstand von $1 \mathrm{~cm}$ ). Das jeweils aufzutragende Volumen in $\mu l$ ergibt sich aus 1500

$\mathrm{mg} / 100 \mathrm{~m} /$ Kreatinin

Kreatinin. Als Standard wird je nach Altersklasse ein Mischurin mitaufgetragen $(0-1 ; 1-5 ; 5-10$ bzw. $10-20 \mathrm{Jahre})$. In einer Elektrophoreseapparatur der Firma $\mathrm{Camag}^{2}$ ) wird $20 \mathrm{~min}$ bei 200 Watt $(100 \mathrm{~V} / \mathrm{cm})$ im obigen Puffer $\mathrm{pH} 1,9$ getrennt. Das Pherogramm wird $10 \mathrm{~min}$ bei $110^{\circ}$ getrocknet, in NinhydrinReagens nach MofFat und LYTLE [114] getaucht und 4 min auf $110^{\circ}$ erwärmt. Es entstehen polychromatische Zonen, die aufgrund ihrer Position und Farbe identifiziert werden können. Das Ninhydrin-Reagens besteht aus:

Lösung I: $1 \mathrm{~g}$ Ninhydrin, $500 \mathrm{~m} l$ Äthanol abs., $100 \mathrm{~m} l$ Eisessig, $20 \mathrm{~m} / 2,4,6$-Collidin.

Lösung II: $1 \% \mathrm{Cu}\left(\mathrm{NO}_{3}\right)_{2} \cdot 3 \mathrm{H}_{2} \mathrm{O}$ in abs. Alkohol. Unmittelbar vor Gebrauch werden $150 \mathrm{~m} /$ Lösung I mit $10 \mathrm{~m} l$ Lösung II gemischt.

\section{Kombination von Elektrophorese mit Cbromatograpbie}

Zur Elektrophorese wird die Probe $10 \mathrm{~cm}$ vom schmalen, der Kathode zugewandten Seitenrand und $1 \mathrm{~cm}$ von einem langen Rand punktförmig sowie $15 \mathrm{~cm}$ vom langen Rand entfernt strichförmig ( $1 \mathrm{~cm}$ lang) aufgetragen. $17 \mathrm{~cm}$ vom langen Rand entfernt wird daneben Standard-Mischurin aufgetragen. Man trennt wie oben. Das getrocknete Pherogramm wird zu einem Zylinder gerollt, mit einer Plastikbüroklammer oben zusammengehalten, mit dem punktförmigen Startfleck nach unten in einen mit der oberen Phase des Fließmittels n-Butanol/Eisessig/Wasser $(4+1+5$ $v+v)$ beschichteten Chromatographiertank gestellt, und $14 \mathrm{~cm}$ hoch chromatographiert ( $3-4 \mathrm{~h})$. Das Chromatogramm wird getrocknet und wie oben gefärbt.

\section{Papier-und Dünnschicht-Chromatographie}

Die Pionierleistung von DeNT auf dem Gebiet der Papierchromatographie (PC) von Aminosäuren im Urin (101-103) wurde bereits erwähnt. Seitdem wurden zahlreiche papierchromatographische Methoden zur Trennung von Aminosäuren in biologischen Flüssigkeiten ausgearbeitet. Eine Übersicht geben Brgwood und Mitarbeiter (115) und SMITH (116). Heute wird in der Regel die Dünnschichtchromatographie (DC) gegenüber der PC wegen ihrer Schnelligkeit, ihres größeren Trennvermögens und bequemeren Handhabung vorgezogen (vgl. BrenNER und Mitarbeiter (117) und PATAKI $(118,119))$.

Urin und Serum enthalten beträchtliche Mengen an Fremdstoffen wie Salze bzw. Proteine, welche die PC oder die DC stören können, wenn die Aminosäuren in freier Form chromatographiert werden. Gewöhnlich

2) Andere ebenso brauchbare Fabrikate sind erhältlich z. B. bei den Firmen L. Hormuth (Heidelberg-Wiesloch), Shandon (London). müssen diese Störsubstanzen vor der Chromatographie durch Entsalzung bzw. Enteiweißung entfernt werden (siehe unten). Je nach der verwendeten Technik treten dabei z.T. beträchtliche Verlúste von bestimmten Aminosäuren auf (120). Serumaminosäuren können aber auch ohne vorherige Enteiweißung chromatographiert werden (121). Störungen von Begleitsubstanzen sind besonders gering, wenn die Aminosäuren in Derivate umgewandelt und als solche chromatographiert werden. Dazu bieten sich in erster Linie die intensiv gelb gefärbten Dinitrophenylderivate an, die sich sehr leicht von Salzen und Proteinen extrahieren und ausgezeichnet chromatographieren lassen. Die Trennung als DansylDerivate wurde ebenfalls versucht (122), doch ist diese Methode trotz der nahezu 100fach größeren Empfindlichkeit wegen Artefaktbildung (123) gegenwärtig nicht zu empfehlen.

\section{Entfernung von Salzen, Proteinen und Koblenbydraten}

a) Nach Harris und Mitarbeitern (124) (Modifikation). Taurin, Cysteinsäure und Phosphoäthanolamin gehen mit dem Waschwasser verloren.

Dowex 50-X 8 Ionenaustauscher (200-400 mesh) wird durch mehrmaliges aufeinanderfolgendes Waschen mit $1 \mathrm{~N} \mathrm{NaOH}, \mathrm{H}_{2} \mathrm{O}$, 1N HCl, $\mathrm{H}_{2} \mathrm{O}$ gründlich gereinigt, $5 \mathrm{~cm}$ hoch in eine Säule mit innerem $\varnothing 6 \mathrm{~mm}$ gefüllt und mit $\mathrm{H}_{2} \mathrm{O}$ gewaschen. Man läßt $1 \mathrm{ml}$ der auf $\mathrm{pH} 2-2,5$ angesäuerten Probe (Serum oder Plasma mit gleichem Volumen Wasser verdünnen!) durchlaufen und wäscht mit $3 \mathrm{ml} 0,5 \mathrm{~N}$ Esșigsäure und $2 \mathrm{~m} l \mathrm{H}_{2} \mathrm{O}$ nach. Die Aminosäuren werden mit $2 \mathrm{~m} / 2 \mathrm{~N}$ Ammoniak eluiert und das Ëluat eingedampft. Man bestimmt den Kreatiningehalt der ursprünglichen Probe und löst den Rückstand des Eluats in soviel $\mathrm{m} / \mathrm{H}_{2} \mathrm{O}$, daß eine Kreatininkonzentration von $1 \mathrm{mg} / \mathrm{m} /$ entsteht.

b) Nach KraffCzyK und Helger (125) auf einer Zweischichten-Dünnschichtplatte.

Diese Entsalzungsmethode ist besonders für Routine$z$ wecke geeignet. Man kann die Proben aber anschließend nur eindimensional chromatographieren. Ein Beispiel ist in Abbildung 3 wiedergegeben.

Stark saurer Ionenaustauscher, z. B. Dowex 50-X 8400 mesh $(<60 \mu)$ wird mit 1N Salzsäure, Wasser, Methanol und Äther gewaschen und an der Luft getrocknet. $5 \mathrm{~g}$ Austauscher und $45 \mathrm{~g}$ Cellulose für DC werden mit $180 \mathrm{ml}$ einer 0,05proz. Carboxymethylcellulose in $\mathrm{H}_{2} \mathrm{O}$ homogenisiert. $10 \mathrm{ml}$ dieser Ionenaustauscher-Streichmasse werden neben $80 \mathrm{ml}$ normaler CelluloseStreichmasse (z. B. $50 \mathrm{~g}$ Cellulose SF $+200 \mathrm{ml} \mathrm{H} \mathrm{H}_{2} \mathrm{O}$ ) in ein geeignetes Mehrschichten-Streichgerät gefüllt und in $0,25 \mathrm{~mm}$

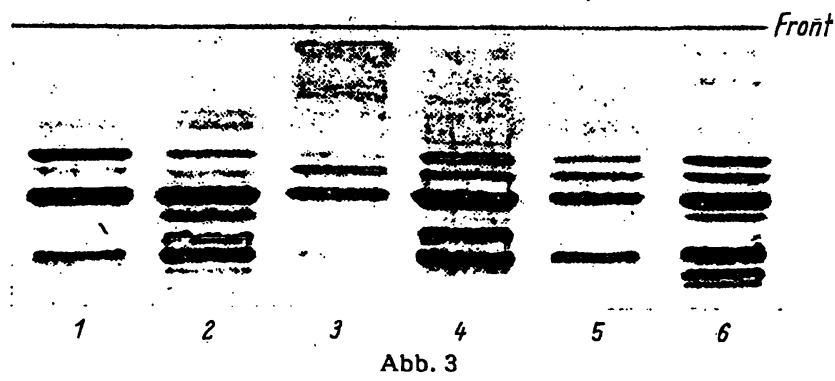

Dünnschicht-Chromatogramm von Harnaminosäuren auf einer Zweischichtenplatte nach KRAFFCZYK und HELGER [125]. Die Entsalzung erfolgt am Start auf einem Schichtstreifen von saurem Ionenaustauscher, die Chromatographie erfolgt auf der anschließenden Cellu1: Fanconi-Syndrom; 2: Normalurin; 3: Verzweigtketten-Ketoacidurie; 4: Homocystinurie; 5: Normalurin; 6: behandelte PKU (Anmerkung: Nach unserer Meinung könnte Probe 1 Normalurin und Probe 2 Fanconi-Syndrom darstellen) 
Tab. 2. Fließmittel zur Papier- und Dünnschicht-Chromatographie von Aminosäuren im Urin. a) und b) bezeichnen Fließrnittelkombinationen für die zweidimensionale Technik

Fließmittel DC PC Schichtmaterial Lauf- $\quad$ Literatur

1. a) wassergesättigtes Phenol

b) 2,6-Lutidin/Wasser $(2+1)$

2. a) Lutidin/Pyridin/n-Butanol/Wasser $(8+7+7+13)$

b) Phenol/Wasser $/ 10 \% \mathrm{NH}$ usatz von $5 \mathrm{mg} 8$-Hydroxychinolin zu $1000 \mathrm{~g}$ als Stabilisator

3. a) Butanol/ $\mathrm{CH}_{3} \mathrm{COOH} / \mathrm{H}_{2} \mathrm{O}(4+1+1 \mathrm{v}+\mathrm{v})+$ Kieselgel G b) $\mathrm{Phenol} / \mathrm{H}_{2} \mathrm{O}(75+25 \mathrm{v}+\mathrm{v})$

4. a) $\underset{(2+2+1 \mathrm{~V}+\mathrm{V})}{\mathrm{C}} \mathrm{Cl}_{3} / \mathrm{Methanol}^{2} \mathrm{~N} \mathrm{NH}_{3}$

b) $\mathrm{Phenol} / \mathrm{H}_{2} \mathrm{O}(75+25 \mathrm{~g}+\mathrm{g})$ 5. a) Pyridin/Aceton $/ 58 \% \mathrm{NH}_{3} /$ Wasser
$(45+30+5+20 \mathrm{v}+\mathrm{V})$

b) Isopropanol/Ameisensäure/Wasser $(75+12,5+12,5 v+v)$

6. a) Äthanol/Wasser $(83+17) 3 \times 8 \mathrm{~cm}$ hoch

b) t-Butanol/Äthylmethylketon/conc. $\mathrm{NH}_{3} / \mathrm{H}_{2} \mathrm{O} /$ Diäthylamin $(50+30+10$ $+20+0,3 v+v)$

7. a) Aceton/Eisessig/Wasser

b) Phenol,15\% wäßr. Ameisensäure $(75 \mathrm{~g}+25 \mathrm{ml}) 1 \times 8 \mathrm{~cm}$ hoch

8. 1. mit $\mathrm{H}_{2} \mathrm{O}$ waschen

2. mit Methanol/conc. $\mathrm{NH}_{3} / \mathrm{H}_{2} \mathrm{O}$ $(15+50+35) 2 \times 1,5 \mathrm{~cm}$ über Ionenaustauscher-Chromatographie

3. Butanol/Aceton/Eisessig/ $\mathrm{H}_{2} \mathrm{O}$ $(35+35+10+20) 2 \times 7,5 \mathrm{~cm}$ 9. a) Pyridin/Aceton/conc. $\mathrm{NH}_{2} /$ Wasser
$(45+30+5+20 \mathrm{v}+\mathrm{v})$

b) Isopropanol/ $\mathrm{HCOOH} / \mathrm{H}_{2} \mathrm{O}$ $(75+12,5+12,5 \mathrm{v}+\mathrm{v})$
+ z. B. Whatman No. 1

+ Whatman No. 1

$8-15$ DENT $(102,103)$

8-15 WADMAN und Mitarbeiter (128)

15

1,5 BRENNER und NIEDERWIESER (129)

2,5 OPIENSKA-BLAUTH und Mitarbeiter (130) Und BARON Und ECONOMIDIS (131)

1 BRENNER und Mitarbeiter (132) und 2,5

1,5 White (134)

$+\quad \begin{aligned} & \text { Cellulose MN } 300 \\ & \text { (Macherey \& Nagel) }\end{aligned}$

$+\quad$ Cellulose (Merck) Vorbeschichtete Platten

$3 \times 1$ BREMER und Mitarbeiter (121) 1,5

$+\quad$ Cellulose (Merck) vorbeschichtete Platten

$2 \times 0,5$ BREMER und Mitarbeiter (121) 2

Ziweischichtenplatten:

I: stark saurer Ionenaus-

II: Cellulose SF (Merck)

Cellulose MN 300 (Macherey und Nagel)
KRAFFCZYK und HELgER (125)

1,5 WhITE (134) dicker Schicht ausgestrichen $(2-4 \mathrm{~cm}$ breiter Ionenaustauscherstreifen). Nach Trocknen bei $90^{\circ}$ sind die Platten gebrauchsfertig zur Chromatographie: Man trägt auf dem Ionenaustauscherstreifen $2 \mu l$ Urin in einem $2 \mathrm{~cm}$ langen Strich auf $(1,5 \mathrm{~cm}$ vom Plattenrand entfernt), chromatographiert mit $\mathrm{H}_{2} \mathrm{O}$ in die Celluloseschicht bis zum oberen Plattenrand, trocknet die Schicht und eluiert die Aminosäuren durch DC in Methanol/Wasser/conc. Ammoniak $(50+35+15 \nabla+\nabla)$ zweimal $1,5 \mathrm{~cm}$ weit über dem Austauscherstreifen in die Cellulose-Schicht. Nach Trocknung kann mit Fließmittel 8.3 (Tab. 2) chromatographiert werden.

\section{Zweidimensionale Cbromatographie von freien Aminosäuren}

Die allgemeinen Techniken der PC und der DC sind in einschlägigen Handbüchern beschrieben $(126,116) \mathrm{bzw}$. (118, 119, 127). Zur Dünnschichtchromatographie trägt man in einer Ecke einer Dünnschichtplatte jewweils $1,5 \mathrm{~cm}$ von den Rändern entfernt $1 \mu \mathrm{l}$ einer entsalzten Urinlösung entsprechend $1 \mu \mathrm{g}$ Kreatinin oder $5 \mu l$ unenteiweißtes Serum auf ${ }^{3}$ ) und chromatographiert $10 \mathrm{~cm}$ weit in beiden Dimensionen. Bewährte Fließmittelkombinationen für die zweidimensionale $P C$ und $D C$ von Aminosäuren in biologischem Material sind in Tabelle 2 zusammengestellt; siehe aber auch (269). Die fertigen Chromatogramme werden $10 \mathrm{Min}$. bei $110^{\circ}$ getrocknet und die Aminosäuren mit 0,2proz. Ninhydrin in n-Butanol/Eisessig $(95+5 \mathrm{v}+\mathrm{v})$ einfarbig oder besser mit dem Moffat-Lytle Reagens ((114) siehe S. 410) polychro-

3) Die einfachen Microcap Mikropipetten eignen sich am besten für diesen Zweck. Erhältlich bei Drummond Scientific Company, Broomall, $\mathrm{Pa}$, USA. matisch nachgewiesen. Die Identifizierung der Flecken erfolgt anhand eines Fleckenmusters, das durch Chromatographie einer Standardmischung erhalten wurde, sowie aufgrund der Fleckenfarbe. Abbildung 4 zeigt ein

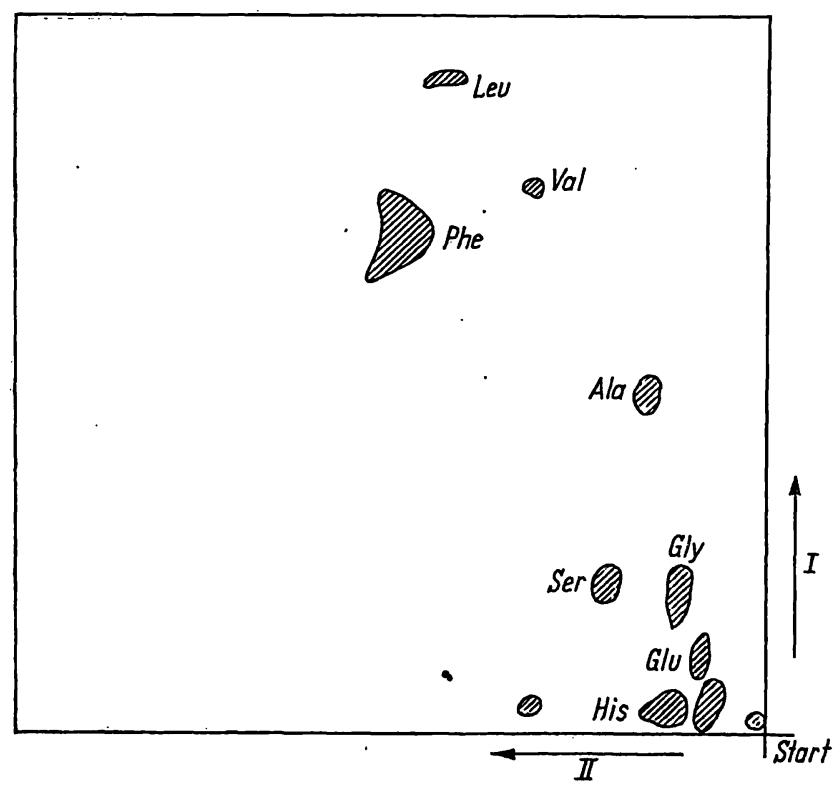

Abb. 4

Dünnschicht-Chromatogramm yon Aminosäuren im Urin bei einer Phenylketonurie nach BREMER und Mitarbeiter (121)

Laufrichtung I (3 mal): Athanol $\mathrm{H}_{2} \mathrm{O}(83+10, \mathrm{v}+\mathrm{v})$ Laufrichtung II: t-Butanol/Methyläthylketon/25\% $\left.\mathrm{NH}_{3} / \mathrm{H}_{3} \mathrm{O}\right)$ 'Diäthyl-
amin $(50+30+10+20+0,3, \mathrm{v}+\mathrm{v})$ 
Tab. 3

Konzentration von freien Aminosäuren im Blutplasma und Serum von Neugeborenen und Erwachsenen in $\mathrm{mg} / 100 \mathrm{ml}$ )

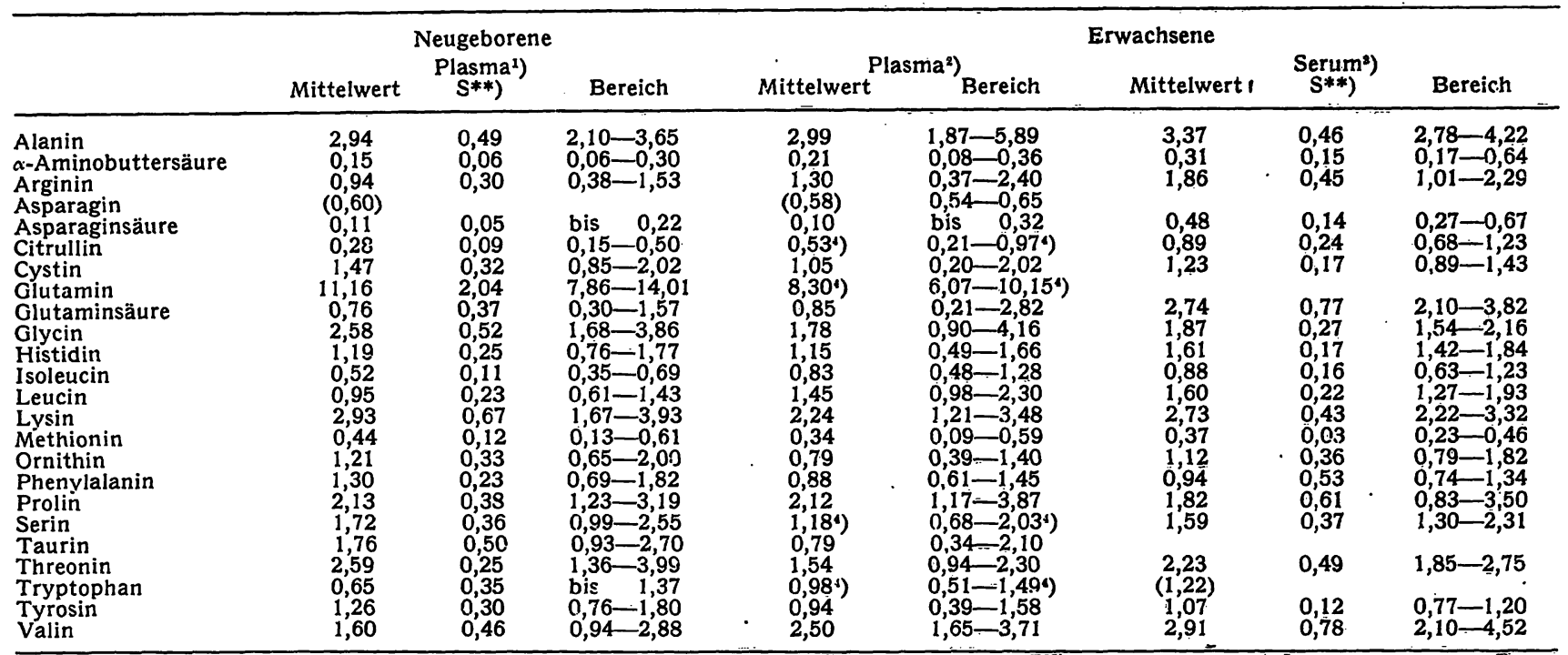

*) Normalwerte weiterer Altersgruppen sind in unserem Labor in Vorbereitung.

**) Standardabweichung.

1) Werte von 9, Knaben und 16 Mädchen nach HAMILton aus (213).

2) Daten aus 9 Laboratorien von 39 Männern und 37 Frauen, zusammengestellt von HAMILTON (213)

3) Nüchternseren von 7 Normalpersonen, enteiweißt mil $5 \%$ Salicylsäure, Daten nach BREUER und Mitarbeiter (249).

6 Werte von 3 Männern und 5 Frauen nach HAMILTON aus (213).

Beispiel. Die Dünnschichtchromatographie kann auch mit Elektrophorese kombiniert werden (135-140), wobei eine besonders gute Trennung von sauren, neutralen und basischen Aminosäuren erreicht wird.

\section{Chromatograpbie von Aminosäuren als DNP-Derivate}

2,4-Dinitrophenyl-(DNP-)Derivate wurden von SANGER zur Bestimmung der $\mathrm{N}$-terminalen Aminosäure in Proteinen eingeführt (141). Es zeigte sich, daß sich die DNP-Aminosäuren durch Papierchromatographie (142) und Dünnschichtchromatographie (143) ausgezeichnet trennen lassen. Durch bloße Extraktion kann man sie von Salzen und anderen wasserlöslichen Störsubstanzen ebenso wie von DNP-Aminen trennen. Während der Chromatographie kann man die intensiv gelben Farbstoffe mit bloßem Auge verfolgen. Wegen dieser günstigen Eigenschaften haben BRENNER und Mitarbeiter $(144,145)$ mit Erfolg versucht, Aminosäuren im Urin als DNP-Derivate durch DC nachzuweisen. Die Methode erwies sich auch in anderen Laboratorien erfolgreich (146-150a) und in bezug auf Trennwirkung und Empfindlichkeit den bisherigen Methoden überlegen (151, 149). Die Trennung von Aminosäuren beispielsweise im Blut (146), Sperma (152), Stuhl (in unserem Labor durchgeführt (153)) und im Meerwasser (hohe Salzkonzentration!) (154) zeigen den nahezu universellen Anwendungsbereich. Abbildung 5 zeigt die Trennung von Aminosäuren im Stuhl als DNP-Derivate. Leider eignet sich die bisherige Methode wenig für umfangreichere Routineuntersuchungen; ohne einen Extraktionsautomaten werden von einer Person nur etwa 20 Analysen pro Woche bewältigt.

Nachweis von Aminosäuren im Stuhl (153) und Utin $(144,149)$ als DNP-Derivate

Extraktion des Stubls: Man versetzt $10 \mathrm{~g}$ frischen Stuhl mit $100 \mathrm{ml}$ Wasser und homogenisiert die Mischung während $10 \mathrm{~min}$. Man zentrifugiert, dekantiẹrt und wäscht das Zentrifugat mit $100 \mathrm{ml}$ Wasser nach. Die vereinigten Extrakte werden filtriert und sofort weiterverarbeitet oder tiefgefroten.

Dinitrophenylierung von Stublextrakt: Man versetzt $20 \mathrm{ml}$ Stuhlextrakt mit $5 \mathrm{~N} \mathrm{NaOH}$ bis zur schwachen Rosafärbung vom Phenolphthaleinpapier, mit $5 \mathrm{ml}$ Puffer $\mathrm{pH} 8,8\left(8,4 \mathrm{~g} \mathrm{NaHCO}_{3}\right.$ in $100 \mathrm{~m} /$ Wasser lösen, mit $5 \mathrm{~N} \mathrm{NaOH}$ auf $\mathrm{pH} 8,8$ einstellen) sowie mit $2 \mathrm{ml}$ 10proz. Lösung vọ 2,4-Dinitrofluorbenzol in abs. Äthanol. Die Mischung wird in einer braunen Flasche im Wasserbad von $40^{\circ}$ während $1 \mathrm{~h}$ geschüttelt, dann abgekühlt und $3 \mathrm{mal} \mathrm{mit} \mathrm{je} 10 \mathrm{ml}$ Äther extrahiert (Extrakt verwerfen, enthält überschüssiges Reagens und DNP-Amine). Die wäßr. Lösung wird nun vorsichtig mit $6 \mathrm{~N} \mathrm{HCl}$ deutlich kongosauer gestellt $(\mathrm{pH}<2)$ und $5 \mathrm{mal}$ mit je $10 \mathrm{ml}$ Åther extrahiert. Die vereinigten Ätherextrakte werden über $\mathrm{Na}_{2} \mathrm{SO}_{4}$ sicc. getrocknet, filtriert und eingedampft. Dieser Extrakt 1 enthält die ,ätherlöslichen“ DNPAminosäuren. Er wird in $2 \mathrm{~m} l$ Aceton aufgenommen; davon werden $10 \mu l$ zur DC aufgetragen.

Die noch gelb gefärbte wäßr. Lösung wird nun $5 \mathrm{mal} \mathrm{mit} \mathrm{je} 10 \mathrm{~m} l$ sek-Butanol/Essigester $(1+1 v+v)$ extrahiert, die vereinigten Extrakte werden - in Abweichung von der Vorschrift (144, 153) - durch Zusatz von $\mathrm{CaCl}_{2}$ getrocknet (Salzphase im Scheidetrichter abziehen), filtriert und eingedampft. Dieser Extrakt 2 enthält die „säurelöslichen“ DNP-Aminosäuren. Er wird in $2 \mathrm{~m} /$ sek-Butanol/Essigester $\cdot(1+1)$ aufgenommen; davon .werden $40 \mu l$ zur DC aufgetragen.

Dinitrophenylierung von Urin nach (144): Man versetzt $25 \mathrm{~m} /$ frischen Urin tropfenweise mit $5 \mathrm{~N} \mathrm{NaOH}$ bis zur schwachen Rosafärbung von Phenolphthaleinpapier, filtriert durch einen trockenen Faltenfilter, versetzt $20 \mathrm{~m} l$ Filtrat mit $5 \mathrm{~m} /$ Puffer $\mathrm{pH} 8,8$ und $2 \mathrm{~m} /$ 10 proz. Dinitrofluorbenzol-Lösung in abs. Äthanol, und verfährt weiter wie oben bei Dinitrophenylierung von Stuhl beschrieben. Man trägt von Extrakt 1 und Extrakt 2 entsprechend 0,1-0,3 mg Kreatinin auf.

Zweidimensionale DC von DNP-Aminosäuren auf Kieselgel G (Merck):

Die ätherlöslichen DNP-Aminosäuren werden in der ersten Dimension $2 \mathrm{mal}$ chromatographiert in Toluol/2-Chloräthanol/Pyridin/ 25 proz. Ammoniak $(50+35+15+7 \mathrm{v}+\mathrm{v})(144)$, Zwischentrocknung $10 \mathrm{~min}$ im Luftstrom. Trócknung nach der zweiten DC: $10 \mathrm{~min}$ Luftstrom, $10 \mathrm{~min}$ Trockenschrank bei $60^{\circ}, 15 \mathrm{~min}$ Luftstrom. Danach folgt Chromatographie in der zweiten Dimen- 


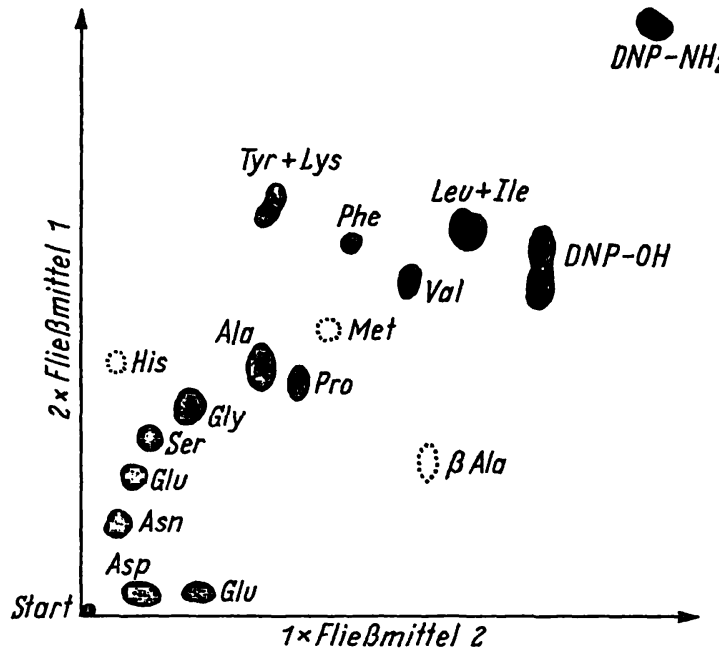

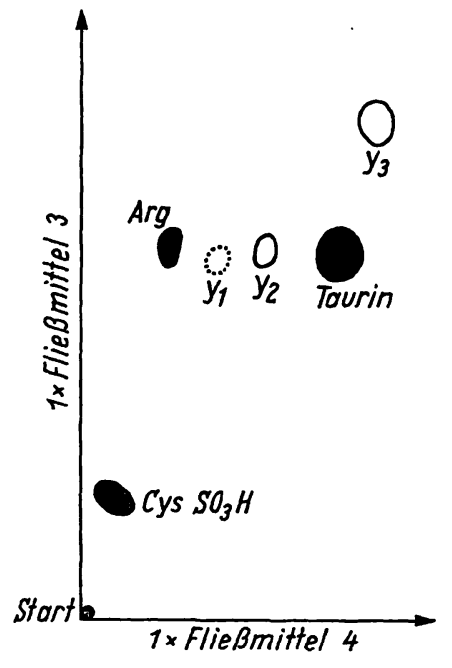

Abb. 5

Dünnschicht-Chromatogramme von Aminosäuren im Stuhl, chromatographiert als DNP-Derivate (153) Links ätherlösliche rechts säurelösliche DNP-Aminosäuren DNP-OH $=2$ 4-Dinitrophenol DNP-NH $=2.4$-Dinitroanilin sion im Fließmittel Chloroform/Benzylalkohol/Eisessig $(70+30$ $+3 v+v)(143)$.

Säurelösliche DNP-Aminosäuren: Es sind dies die Derivate von Arginin, Homoarginin, Citrullin, Homocitrullin, Taurin, Cysteinsäure, Homocysteinsäure und Histidin (letzteres nur zu etwa $50 \%$ ). Man chromatographiert in der ersten Dimension in Butanol/Eisessig/Wasser $(4+1+1 \mathrm{v}+\mathrm{v})$ und in der zweiten in sekButanol/25 proz. Ammoniak $(70+30 \mathrm{v}+\mathrm{v})$. Eine andere, sehr gute Fließmittelkombination ist Phenol/Wasser $/ 17 \mathrm{proz}$. Ammoniak $(80+20+2 v+v)$ (erste Dimension) und Toluol/2-Chloräthanol/Pyridin/20 proz. Ammoniak $(35+50+15+10 v \dot{\nabla})$ nach (149), siehe auch $(144,152)$.

\section{Nacbuveis von Jodaminosäuren im Plasma}

Die Hormone der Thyroidea, Thyroxin und Trijodthyronin, sind Aminosäuren. Diese und andere Jodaminosäuren spielen daher in der Kontrolle der Schilddrüsenaktivität eine große Rolle (155). Die Bestimmung des proteingebundenen Jods und der Jodbindungskapazität sind im Augenblick unersetzliche, aber doch recht summarische Tests, die nichts über das Konzentrationsverhältnis der einzelnen Jodaminosäuren aussagen. Nachdem es feststand, daß Jodotyrosine im Blut vorkommen (vgl. z. B. (156-158)), bestand ein Interesse für einfache Nachweismethoden. Diese Substanzen zeigen zwar keine Hormonwirkung, aber ihre Konzentrationen scheinen sich ähnlich der der Jodothyronine bei thyroidealen und extrathyroidealen Krankheiten zu ändern, so $\mathrm{da} B$ sich ein für die betreffende Krankheit charakteristisches Bild der Jodaminosäuren ergibt (159 bis 162). Zirkulierende phenolische Jodaminosäuren sind zumindest teilweise an Trägerproteine gebunden, von denen sie aber größtenteils durch Extraktion mit organischen Lösungsmitteln befreit (163) und dann mit Hilfe chromatographischer Methoden aufgetrennt werden können. Eine Fülle verschiedener Verfahren wurde beschrieben. Dünrischichtchromatographisch lassen sich Jodaminosäuren besonders gut trennen auf Cellulose $G$ in Ameisensäure/Wasser $(10+50 \mathrm{v}+\mathrm{v})(164)$, auf Cellulose $G$ in Aceton/0,5N Essigsäure $(20+80 v+v)$ (165) sowie auf Kieselgel $\mathrm{G}$ in Phenol/Aceton/1 $\mathrm{N} \mathrm{NaOH}$ $(2+7+1 \mathrm{v}+\mathrm{v})$ in $\mathrm{NH}_{3}$-Atmosphäre (166). Eine Ubersicht gibt ZAPPI (167), siehe auch (118, 119). Sofern die Substanzen nicht radioaktiv markiert sind, basiert der Nachweis und die quantitative Bestimmung zumeist auf der äußerst empfindlichen katalytischen Wirkung von Jod (Jod in Phenolen tauscht in Gegenwart von $\mathrm{Cl}^{\ominus}$ aus!) auf die Redoxreaktion Ce (IV)/As (III) (168, 169) bzw. Fe (III)/As (III) (170). Es bestehen aber Probleme hinsichtlich der Spezifität $(171,172)$, die durch ein Differenzverfahren beseitigt werden können $(173,174)$. Ein weiteres Nachweisverfahren besteht in der photochemischen Dejodierung und Nachweis des Jods mit Stärke (175).

\section{Quantitative Bestimmung}

Mikrobiologische Bestimmung von Aminosäuren

Diese Methode ergab lange Zeit die zuverlässigsten Werte von Aminosäurekonzentrationen im Blut. In abgewandelter Form (Hemmtest) wird sie heute zur semiquantitativen Massenuntersuchung nach Guthrie benutzt (siehe oben). Das Untersuchungsmaterial, z. B. enteiweißtes Serum, wird mit einem Nährmedium inkubiert, das alle notwendigen Nährstoffe außer der zu bestimmenden Aminosäure enthält, und mit einem geeigneten Mikroorganismus beimpft (als Beispiel siehe Bestimmung von Phenylalanin nach Prescotr und Mitarbeiter (176), Tyrosin nach GuNNEss und Mitarbeiter (177), Aminosäuren in Plasma und Urin nach HARPER und Mitarbeiter (263). Nach einer bestimmten Inkubationszeit wird die Zunahme von Mikroorganismen am einfachsten durch Turbidimetrie anhand einer Eichkurve gemessen, oder die metabolische Aktivität der Mikroorganismen durch pH-Messung (Lactobacillus casei (178)) oder Titration der produzierten Milchsäure bestimmt $(179,180)$. Es eignen sich Lactobacillus arabinosus 17/5 ATCC 8014 zur Bestimmung von Leucin, Isoleucin, Valin und Tryptophan; Leuconostoc mesenteroides P 60 ATCC 8042 für Histidin, Lysin, Penylalanin und Methionin; Streptococcus faecalis R. ATCC 9790 für Arginin und Threonin. Die Methode der Milchsäuretitration soll nach SCHIERDTFEgER (180) nahezu gleich gute Ergebnisse $(+4-6 \%$ ) liefern wie die automatische Ionenaustausch-Chromatographie nach STEIN und MOORE. 
Die mikrobiologische Methodik gestattet es, eine einzelne Aminosäure gleichzeitig in bis zu 20 Untersuchungsproben je Ansatz zu bestimmen. Die Ergebnisse werden stets auf eine jeweils neu aufgestellte Eichkurve bezogen und können durch Wuchs- oder Hemmstoffe (Antibiotika!) im Untersuchungsmaterial beeinflußt werden. Der apparative Aufwand ist gering, die Analysendauer relativ lang (etwa 6 Tage). Die Genauigkeit wird im allgemeinen mit $\pm 10-15 \%$ angegeben. Die Empfindlichkeit ist extrem hoch; die Methode eignet sich daher zur Spurenanalyse.

Eine Automatisierung mikrobiologischer Verfahren wurde bereits zur Untersuchung von Antibiotika ausgearbeitet $(180 \mathrm{a}, \mathrm{b})$. Da zahlreiche physiologische Parameter, wie z. B. $\mathrm{CO}_{2}$-Milchsäure Produktion, Glucose-, Aminosäure-Verbrauch, zur Messung der biologischen Aktivität herangezogen werden können, sollte es auch möglich sein, die mikrobiologischen Verfahren zur Aminosäuren-Analyse zu automatisieren. Entsprechende Arbeiten sind uns aber bis jetzt nicht bekannt geworden.

Kolorimetrische und enzymatische Bestimmungsmethoden

Es können hier nur einige -wichtige Bestimmungsmethoden erwähnt werden. Wir verweisen auf Handbücher wie z. B. (181-183).

\section{Phenylalanin}

Die häufig benutzte fluorometrische Bestimmung nach MCCAMAN und Robins (184), modifiziert von Wong und Mitarbeitern (185), vgl. auch Ambrose (185a) beruht auf der Fluoreszenzmessung des PhenylalaninNinhydrin-Kupferkomplexes in Gegenwart von L-Leucyl-L-alanin (186). Benötigt werden nur 5-25 $\mu l$ Serum, das mit Trichloressigsäure enteiweißt wird. Die stark $\mathrm{pH}$-abhängige relative Fluoreszenz wird bei $515 \mathrm{~nm}$ (Aktivierung bei $365 \mathrm{~nm}$ ) und pH 5,88 gemessen. Die Methode wurde von HrLl und Mitarbeitern (187) automatisiert, wobei die Enteiweißung mit Trichloressigsäure durch Dialyse ersetzt wurde. Mit dem TechniconAutoanalyzer können damit 60 Analysen pro h durchgeführt werden (Variations-Koeffizient etwa $\pm 10 \%$ ). Eine envymatische Bestimmungsmethode beschrieben la Du und Michael (188). Dabei wird Phenylalanin in Gegenwart von L-Aminosäure-oxidase (EC 1.4.3.2) aus Crotalus adamanteus Schlangengift durch Luftsauerstoff zu Phenylbrenztraubensäure oxydiert und das gebildete $\mathrm{H}_{2} \mathrm{O}_{2}$ durch Katalase zerstört. In $1 \mathrm{M}$ Natriumarsenat-Borat-Lösung bildet sich der Boratkomplex der Enolform von Phenylbrenztraubensäure, der bei $308 \mathrm{~nm}$ gemessen wird. Tyrosin und Tryptophan werden miterfaßt und können durch Differenzmessung bei 308,330 und $350 \mathrm{~nm}$ mitbestimmt werden. Serumprotein stört und wird z. B. durch Ultrafiltration entfernt. Phenylalanin kann im Ultrafiltrat bis $z u \quad 0,4 \mathrm{mg} / 100 \mathrm{~m} l$ erfaßt werden. Dazu werden etwa $0,4 \mathrm{~m} l$ Serum benötigt. Der Variationskoeffizient beträgt etwa $\pm 5 \%$ bei $2,2 \mathrm{mg}$ Phenylalanin $/ 100 \mathrm{~m} l$.

Ohne die vorgeschaltete enzymatische Oxidation können Phenylbrenztraubensäure und $p$-Hydroxyphenyl- brenztraubensäure direkt als Enol-Borat-Komplex (189) sowohl im Serum als auch im Urin bestimmt werden (190).

Nach Udenfriend und Cooper (193) kann Phenylalanin nach Decarboxylierung mit Phenylalanin-Decarboxylase aus Streptococcus faecalis als Phenäthylamin bestimmt werden. Das Amin wird aus stark alkalischem Milieu mit Chloroform-Amylalkohol-Mischung extrahiert. Die Lösung wird mit einer wäßr. Methylorange-Lösung geschüttelt und die optische Absorption der Chloroformphase gemessen. Die spezifische Methode weist aber größere technische Schwierigkeiten auf (194). Weitere, weniger spezifische Methoden siehe z. B. (194).

\section{Tyrosin}

Die fluorometrische Bestimmung von Tyrosin geht zurück auf die Gerngross-Reaktion (195). In einer Modifikation von WAALKES und UdENFRIEND (196) wird Tyrosin in Gegenwart von salpetriger Säure mit 1-Nitroso-2-naphthol zu einer gelben, fluoreszierenden Verbindung gekuppelt. Der Reagensüberschuß witd mit Methylenchlorid entfernt, und die relative Fluoreszenz bei $570 \mathrm{~nm}$ (Anregung bei $460 \mathrm{~nm}$ ) gemessen. Tyramin und ortho- und parasubstituierte Phenole reagieren ebenfalls. Die Methode wurde von Hochelia (197) für den Technicon-Auto-Analyzer umgearbeitet, wobei der Überschuß an 1-Nitroso-2-naphthol mit Natriumpyrosulfit beseitigt und Äthanol als Lösungsmittel durch Dimethylsulfoxid unter Zusatz von Röhm und Haas Surfactant 705 ersetzt wurde.

Tyrosin kann nach enzymatischer Oxidation auch als Enol-Borat-Komplex der $p$-Hydroxyphenylbrenztraubensäure neben Phenylalanin und Tryptophan bestimmt werden (LA Du und MrChaEL (188), siehe unter Phenylalanin).

\section{Hydroxyprolin}

Die Bestimmung von Hydroxyprolin ist wichtig u. a. zum Nachweis von metabolischen Knochenkrankheiten und des Kollagenumsatzes.

Zur kolorimetriscben Bestimmung von Hydroxyprolin wird die Probe im alkalischen Milieu mit $\mathrm{H}_{2} \mathrm{O}_{2}$ (NeumanN und LOGAN (198)) oder besser in schwach saurem Milieu mit Chloramin-T (StEgemanN $(199,200)$ ) oxydiert und anschließend in saurem Milieu mit $p$-Dimethylaminobenzaldehyd umgesetzt. Unspezifische Chromogene können nach Prockop und Udenfriend (201) am Anfang der alkalischen Oxidation extrahiert und die Spezifität der Reaktion kann durch Extraktion des am Ende vorliegenden Chromogens erhöht werden. Die Oxidation mit Chloramin- $T$ vermeidet die unangenehme Störung durch Tyrosin und Tryptophan und läßt sich technisch einfacher durchführen. Urin muß durch Ionenaustauschersäulen (Amberlite IRA 410- $-\mathrm{OH}^{\prime}$ ) zur Entfernung interferierender Substanzen vorbehandelt werden $(202,268)$, ebenso Plasma nach Enteiweißung (200). Eine Ubersicht der recht iempfindlichen $(0,5 \mu \mathrm{g})$ und genauen $( \pm 3 \%)$ Methode geben STEGEMANN und STALDER (200). 
Eine enzymatische Bestimmung von freiem Hydroxyprolin wurde von Rosano beschrieben (203). Ein adaptiertes Enzymsystem, isoliert aus Psezdomonas fluorescens A-312, baut Hydroxyprolin spezifisch zu $\mathrm{NH}_{3}$ bzw. zu einem primären Amin ab. Gemessen wird die AbsorptionsAbnahme der mit Ninhydrin in saurem Medium (204) erhaltenen Farbe der cyclischen Iminosäuren. Es können noch $0,5 \mu \mathrm{g}$ Hypro/Probe nachgewiesen werden.

\section{Cystin}

Kolorimetrisch wird Cystin zumeist nach der Methode von Sullivan, Hess und Howard $(205,206)$ oder einer der zahlreichen Modifikationen (vgl. z. B. (207, 208)) bestimmt, wobei es durch Cyanid in Cystein und Thiocyanat reduziert und das gebildete Cystein mit 1,2Naphthochinon-4-sulfonat in einen roten Farbstoff verwandelt wird. Dieser wird bei $500-520 \mathrm{~nm}$ gemessen. In einer Mikromethode (209) lassen sich damit noch $20 \mathrm{nMol} / \mathrm{ml}$ bestimmen. Die Cystinognost-Testpackung der Firma Heyl \& Co, Berlin 37, arbeitet nach dem gleichen Prinzip. Die Methode von Sullivan und Mitarbeitern wurde inzwischen auch für den Technicon Auto-Analyzer angepaßt (210). Damit können täglich bis zu 120 Doppelbestimmungen durchgeführt werden.

\section{Histidin}

Histidin wird mit Histidase (EC 4.3.1.3) in Gegenwart von Glutathion in Urocaninsäure gespalten. Die Bildung der Urocaninsäure wird im UV bei $277 \mathrm{~nm}$ kinetisch verfolgt $(210 \mathrm{a}, \mathrm{b})$, Serum wird mit $\mathrm{ZnSO}_{4}$ $+\mathrm{Ba}(\mathrm{OH})_{2}$ enteiweißt.

Eine von AMbrose und Mitarbeitern (265) kürzlich beschriebene Methode zur fluorometrischen Bestimmung von Histidin im Blut basiert auf der analogen Kondensation von Histamin mit o-Phthalaldehyd in stark alkalischem Milieu (266). Der im Fall von Histidin labile Fluorophor wird durch Ansäuern mit Phosphorsäure stabilisiert und bei $436 \mathrm{~nm}$ (Aktivierung bei $360 \mathrm{~nm}$ ) bestimmt. In einer Mikromodifikation genügen $100 \mu l$ Serum. Von 45 untersuchten Substanzen zeigen nur Histamin, DL- $m$-Tyrosin und L-Cystin eine nennenswerte Fluoreszenz (52 bzw. 9 bzw. 7\% der HistidinFluoreszenz bei gleicher Konzentration von $10 \mathrm{mg} /$ $100 \mathrm{~m} /$.

Säulenchromatographie an Ionenaustauschern ${ }^{4}$ ) Unter den quantitativen Analysenmethoden nimmt die Ionenaustauscher-Chromatographie bei weitem die wichtigste Stellung ein. Im allgemeinen werden Kationenaustauscher, in einigen Spezialfällen auch Anionenaustauscher benutzt. Neuderings spielt auch die Chromatographie an Chelat-Harzen eine wichtige Rolle.

\section{Prinzip}

Die Trennung von Aminosäuren mittels Ionenaustauscher erfolgt an 15-150 cm langen Kolonnen von $0,5-9 \mathrm{~mm} \mathrm{I}$. D. mit Hilfe von Ionenaustauschern. Die

4) Eine ausführliche Zușammenfassung geben Benson [211] und HamiLton [212, 213].
Aminosäuren werden mit Puffern verschiedener $\mathrm{pH}-$ Werte und verschiedener Ionenstärke eluiert, mit Ninhydrin-Reagens versetzt, auf $100^{\circ}$ erwärmt, photometrisch gemessen und die Extinktionen mit einem Recorder aufgezeichnet. Für die Güte und Schnelligkeit der Trennung sind die folgenden Parameter wichtig:

1. $\mathrm{pH}$ des Puffers

2. Ionenstärke des Puffers

3. Temperatur der Säule

4. Durchflußgeschwindigkeit

5. Säulenlänge

6. Säulenquerschnitt

7. Harz, Quervernetzung, Partikelgröße usw.

Das $\mathrm{pH}$ des Puffers muß auf die Art des verwendeten Ionenaustauschers abgestimmt sein. Um reproduzierbare Elutionszeiten und gute Trennungen der einzelnen Aminosäuren zu erhalten, sind genau eingestellte Puffer unerläßlich, wobei besonders $z u$ beachten ist, daß die Natriumkonzentration auf $\pm 0,001 \mathrm{Mol} / l$ und das $\mathrm{pH}$ auf $0,01 \mathrm{pH}$ Einheiten genau eingestellt werden müssen. Eine Erhöhung von Temperatur, Ionenkonzentration und $\mathrm{pH}$ führt zu einer größeren Geschwindigkeit der Analyse, die Trennung hingegen verschlechtert sich meist. Es ist daher von größter Bedeutung, die Parameter 1-3 maximal günstig einzustellen.

Ein Substanzpeak wird bei gegebenem Säulenquerschnitt um so breiter, je länger die Säule ist, je schlechter sie gepackt und je ungünstiger die Durchflußgeschwindigkeit gewählt wird. Wenn die Substanzen nicht getrennt werden können, bewirkt eine Säulenverlängerung eine Verbesserung der Trennung. Der Abstand der Maxima zweier Peaks wächst mit dem Elutionsvolumen (Vm), die Summe der Peakbreiten aber mit $\sqrt{\mathrm{Vm}}$, so daß theoretisch auch in ungünstigen Fällen eine vollständige Trennung erreicht werden kann. Bei Verkleinerung des Säulenquerschnittes und Konstanthalten aller übrigen Parameter werden die Peaks schmaler und damit die Empfindlichkeit größer. Von diesem Prinzip wird beim Mikroanalysator von Kirsten und Kirsten Gebrauch gemacht (214).

Auch die Korngröße des Harzes ist für die Trennfähigkeit von Bedeutung. Eine Verkleinerung der Korngröße führt zu einer Vergrößerung der Austauschkapazität; ein rundes Harzkorn verbessert die Dichte und Gleichmäßigkeit der Packung.

Die heutigen Geräte beruhen immer noch auf dem von Spackman, Stein und Moore erstmals beschriebenen Prinzip (215). Die meisten Apparate arbeiten vollautomatisch mit Programmierung von Temperaturwechsel, Pufferwechsel, Waschschritten und Probengebern. Die Probengeber (vgl. dazu z. B. $(215 \mathrm{a}, \mathrm{b}, \mathrm{c})$ ) sind in der Lage, 20 und mehr Proben automatisch auf die Kolonne aufzutragen. Zur Berechnung der Chromatogramme wird ein derartiger Vollautomat zweckmäßig mit einem Integrator ausgestattet.

\section{a) Trennung an Kationenaustauschern}

Die Kationenaustauscher bestehen im allgemeinen aus einem mit Divinylbenzol quervernetzten Polystyrolbarz, 
das $\mathrm{SO}_{3}^{\ominus}$-Gruppen trägt. Der Grad der Quervernetzung beeinflußt die Trenngüte und die mechanischen Eigenschaften des Harzes. Bei dem verwendeten $\mathrm{pH}$ liegen die meisten Aminosäuren als Kationen vor. Diese positiv geladenen Aminosäuren konkurrieren auf dem Austauscher mit den Kationen des Puffers. Je nach ihrer Ladung (isoelektrischer Punkt) werden sie verschieden schnell eluiert. Die Elution erfolgt hauptsächlich mit $\mathrm{Na}-$ Citratpuffern verschiedener Ionenstärken und verschiedener $\mathrm{pH}$-Werte, denen ein Netzmittel (Brij-35), ein Antioxidans (Thiodiglycol) und Caprylsäure zugesetzt werden. Zur Trennung von Glutamin und Asparagin können Li-Citratpuffer $(216,271)$ oder spezielle Temperaturprogramme (217) verwendet werden. Um Verluste von Glutamin infolge Cyclisierung und Hydrolyse zu vermeiden, soll die Säulentemperatur $35^{\circ}$ nicht überschreiten (272). Puffer mit Äthanol-Zusatz bewirken eine bessere Trennung zwischen Threonin und Serin. Das Eluat aus den Kolonnen wird mittels NinhydrinReaktion automatisch analysiert. Dem NinhydrinReagens, das sich aus Methylcellosolve, 4N Natriumacetat-Puffer $\mathrm{pH} 5,5$ und Ninhydrin zusammensetzt, wird im allgemeinen $\mathrm{SnCl}_{2}$ (215), Hydrindantin (218) oder Cyanid (219) zugesetzt. Diese Reagenzien sind im allgemeinen luft- und lichtempfindlich, und die Zubereitung und Lagerung muß unter hoch gereinigtem Stickstoff erfolgen.

Fast alle heute käuflichen Geräte benutzen einen diskontinuierlichen Pufferwechsel. Das anfänglich von Technicon benutzte Prinzip der Gradientenelution (220) ergab häufig Peakverschiebungen.

\section{b) Trennung an Anionenaustauschern}

Für die Auftrennung von stark sauren Aminosäuren ist die Anionenaustauscher-Chromatographie besser geeignet; so werden z. B. Aminosulfonsäuren und O-Phosphorylhydroxyaminosäuren an Kationenaustauschern nur schlecht zurückgehalten. Zur Auftrennung von SCarboxymethyl-Derivaten von Cystein, Homocystein und Penicillamin sowie von Monoaminodicarbonsäuren ist die Anionenaustauscher-Chromatographie ebenfalls besser geeignet. Ein solches Verfahren wurde von BORNER (221) und später von BURTIS und W WRREN (222) beschrieben. Als Harz fanden Austauscher vom Typ Dowex 1 und Natriumformiatpuffer pH 4,2 bzw. BioRad AG 1-X8 und Natriumacetatpuffer pH 4,4 Verwendung.

\section{c) Ligand-Austausch Chromatographie}

Diese Methode beruht auf der Komplexbildung der zu untersuchenden Substanzen mit schwach basischen Metallionen wie Nickel, Kobalt, Kupfer, Cadmium oder Zink (223-226) und Chromatographie der Komplexe an einem Kationenaustauscher. Die Metallionen bleiben dabei weitgehend an den Kationenaustauscher gebunden. Dieser kann speziell auf das betreffende Metallion wirkende Chelatgruppen - z. B. Iminodiessigsäuregruppen - aufweisen (227), welche das Schwermetallion besonders intensiv binden, oder aus einem konventionel- len Sulfonsäureharz bestehen (228). Der erstgenannte Harztyp verhindert ein Auswaschen des komplexierenden Ions durch konzentrierte Salzlösungen und eignet sich daher zur Konzentrierung, ivon Aminosäuren aus Salzlösungen. Der zweitgenannte Harztyp wurde von einer Forschungsgruppe der Firma Hitachi zur beschleunigten Aminosäuren-Analyse herangezogen ${ }^{5}$ ). Um ein Auswaschen des komplexierenden Ions zu verhindern, muß in diesem Fall das Metallsalz dem Elutionspuffer in der Gleichgewichtskonzentration zugesetzt werden. $\alpha$-Aminosäuren bilden daher sowohl in der Puffer- als auch in der Harzphase Kationenkomplexe von der Art

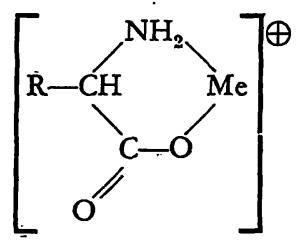

wobei die beiden noch freien Koordinationsstellen des Metallions $\mathrm{Me}^{++}$entweder vom Lösungsmittel oder von Ionenaustauschergruppen eingenommen werden. Die Affinität der Aminosäuren zum Ionenauustauschharz nimmt dadurch zu. Das Ausmaß der Komplexbildung wird bestimmt durch das $\mathrm{pH}$ und die jeweilige Stabilitätskonstante. Während beim normalen Ionenaustausch von freien Aminosäuren die jeweilige Aciditätskonstanten (isoelektrischer Punkt) neben Adsorptionseffekten die Trennung weitgehend bestimmen, kommt beim Ligand-Austauschverfahren der Komplexstabilitätskonstante eine ebenso wichtige Bedeutung zu. Bei Erhöhung des $\mathrm{pH}$ nimmt die Komplexbildung zu, während der Ionenaustauschvorgang abnimmt. Im mittleren pH-Bereich, der für die Chromatographie besonders interessant ist, kommen beide Vorgänge nebeneinander vor. Als besonders günstig haben sich die Zink-Komplexe erwiesen. Sie erlauben die Trennung von sauren und neutralen Aminosäuren aus physiologischen Flüssigkeiten innerhalb von $3,5 \mathrm{~h}$ und von basischen Aminosäuren innerhalb von 4,5 h (Abb. 6). Die Reihenfolge der Elution der Aminosäure-Komplexe ist ähnlich der Ionenaustauscher-Chromatographie von freien Aminosäuren (Cystin exšcheint infolge seines besonders stabilen Zink-Komplexes etwas später). Hervorzuheben ist die ausgezeichnete Trennung von Tyrosin und Phenylalanin; Hydroxyprolin und Asparaginsäure, Threonin und Serin und im basischen Bereich von Tryptophan und den für Histidin-Stoffwechselstörungen wichtigen Dipeptiden Anserin und Carnosin sowie den Histidinen. Hingegen trennen sich Glycin und Alanin nicht immer vollständig.

Weniger komplizierte Aminosäurengemische wie Proteinhydrolysate können sogar innerhalb von $2 \mathrm{~h}$ komplett analysiert werden, wobei zur Trennung von sauren und neutralen Aminosäuren ein einziger Puffer

5) Das Verfahren kann bei dem neúen automatischen Aminosäuren-Analysator KLA-3B von Hitachi-Perkin-Elmer verwendet werden. Vergleiche die diesbezüglichen Firmenschriften. 


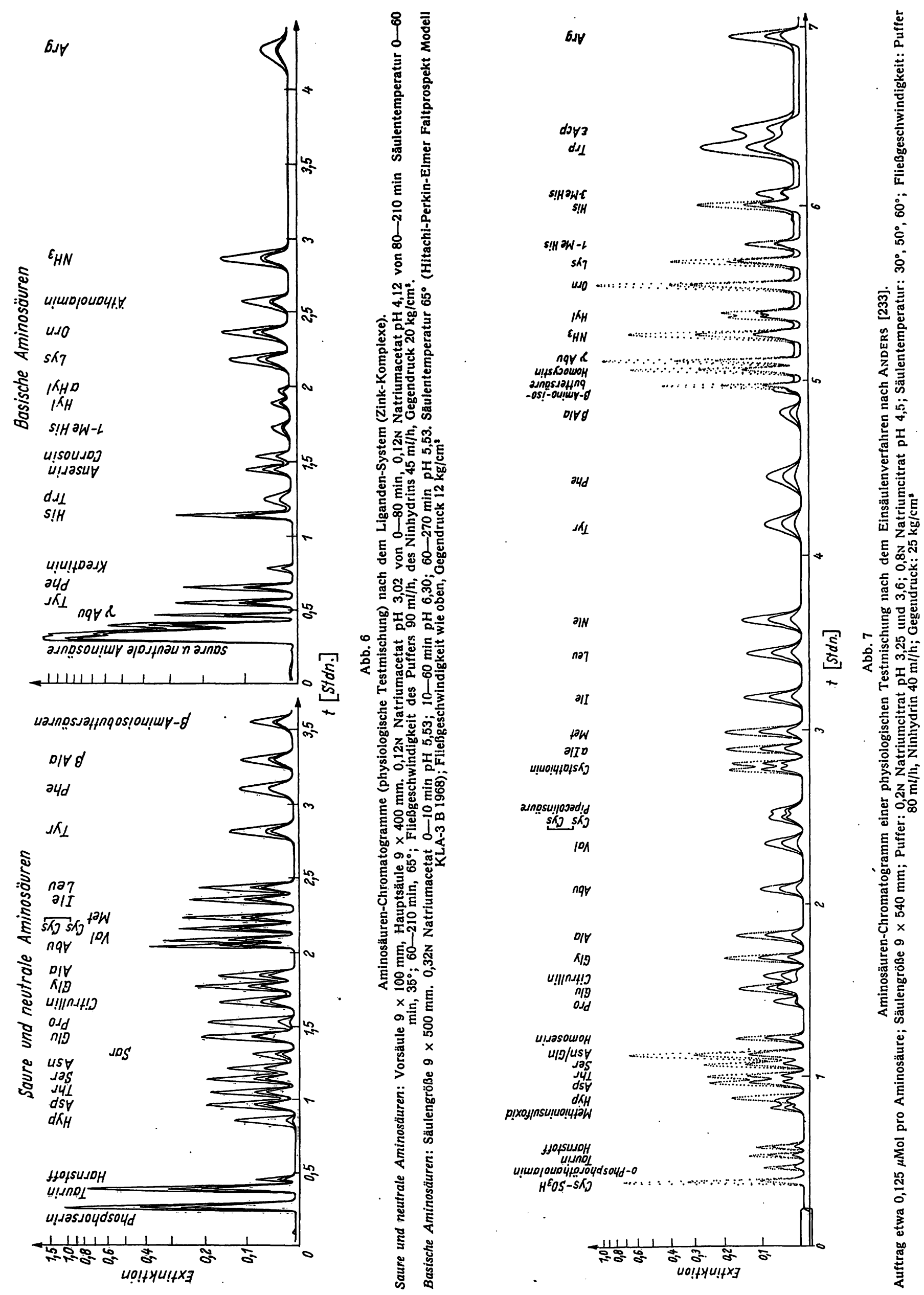


genügt $(55 \mathrm{~mm}$ Natriumacetat $\mathrm{pH} 4,10 ; 0,4 \mathrm{~mm}$ Zinkacetat; $6 \%$ Äthylalkohol; $55^{\circ}, 120 \mathrm{~m} / \mathrm{h}$ ).

Die Verwendung von Metall-Liganden in der Harzphase bringt auch einige rein technische Vorteile; so wird beispielsweise der Hydratationszustand des Ionenaustauschers durch die ständige Anwesenheit von Zink stabilisiert, was die mechanischen Eigenschaften der Säule verbessert. Geringe $\mathrm{pH}-$ Änderungen im Puffer wirken sich nicht mehr so stark auf die Trennung aus. Dagegen ist die Metallkonzentration im Puffer kritisch in bezug auf die Aufrechterhaltung des Gleichgewichts zwischen Harz und Puffer, und Fließgeschwindigkeit und Arbeitstemperatur müssen besonders gut kontrolliert werden, um reproduzierbare Ergebnisse zu erhalten (211). Die Regeneration der Säule kann leicht zu einer Störung des oben erwähnten Gleichgewichts führen.

\section{Vorbereitung des biologischen Materials}

\section{a) Blutplasma}

Zur Bestimmung der Aminosäurekonzentration im Blut wählen die meisten Untersucher heparinisiertes Plasma; die Serumwerte liegen etwas höher (228a). Nach dem Abkühlen des Blutes wird das Plasma durch Zentrifugieren abgetrennt. Die Aufbewahrung von Vollblut bewirkt eine starke Veränderung der Aminosäurekonzentration; ebenso ist eine hämolytische Plasmaprobe für die quantitative Aminosäurenanalyse nicht geeignet. Eine Lagerung nicht enteiweißter Plasmaproben ist ebenfalls nicht zu empfehlen, da die Werte von Asparaginsäure und Glutaminsäure zunehmen, während diejenigen von Cystin jedoch abnehmen.

Zur Enteiweißung kommen die unten aufgeführten Methoden in Betracht, wobei die Sulfosalicylsäure-, Pikrinsäure-Enteiweißung und die Ultrazentrifugation die gebräuchlichsten sind.

Sulfosalicylsäure-Enteinveißung: $1 \mathrm{ml}$ Plasma wird mit $4 \mathrm{ml} 3$ proz. Sulfosalicylsäure versetzt, geschüttelt und abzentrifugiert. Ein Aliquot des Überstandes wird mit Puffer $\mathrm{pH} \mathrm{2,2}$ auf ein bestimmtes Volumen gebracht $(5 \mathrm{~m} l)$, ein Teil dieser Lösung kann ohne weitere Behandlung auf die Säule aufgetragen werden.

Pikrinsäure-Enteiveißung: $1 \mathrm{~m} l$ Plasma wird mit $5 \mathrm{ml}$ einer 1 proz. Pikrinsäurelösung versetzt, einige Sekunden geschüttelt und anschließend zentrifugiert. Ein Aliquot des Uberstandes wird auf eine kleine Anionenaustauschersäule (Harzhöhe $3 \mathrm{~cm}$ ) in der Chloridform gegeben (Dowex $2 \times 8 ; 200-400$ mesh) und mit $0,02 \mathrm{~N}$ Salzsäure eluiert. Das Eluat wird eingeengt, auf $\mathrm{pH} 8,0$ gebracht und $4 \mathrm{~h}$ zur Oxydation von Cystein zu Cystin stehengelassen. Anschließend wird der $\mathrm{pH}-\mathrm{Wert}$ mit $2 \mathrm{~N} \mathrm{HCl}$ auf 2,0 bis 2,2 eingestellt und die Probe mit Puffer $\mathrm{pH} 2,2$ auf ein bestimmtes Volumen gebracht.

Ultrazentrifugation $(229,230): 1 \mathrm{ml}$ Plasma oder Serum wird mit $1 \mathrm{~m} l$ internem Standard (siehe Seite 419) gemischt und mit $0,2 \mathrm{~N}$ Citratpuffer $\mathrm{pH} 2$ auf $10 \mathrm{~m} l$ gebracht. Man läßt dịe Probe $30 \mathrm{~min}$ im Kühlschrank stehen und zentrifugiert dann 30-40 min bei $50000 \mathrm{~g}$ oder $20 \mathrm{~min}$ bei $78000 \mathrm{~g}$. Man saugt die Lipidschicht ab und entnimmt das benötigte Volumen aus der mittleren Schicht. Gelfiltration: Zur Abtrennung von Aminosäuren, Proteinen und größeren Peptiden ist auch die Gelfiltration gut geeignet. Sie ist jedoch zeitlich und apparativ etwas anspruchsvoller als die vorher beschriebenen Methoden. Das Plasma $(1-2 \mathrm{~m} l)$ wird z. B. auf eine Biogel-P4-Säule $(40 \times 1,5 \mathrm{~cm})$ aufgetragen, welche mit $0,05 \mathrm{M}$ Phosphatpuffer $\mathrm{pH} 7,5$ äquilibriert ist. Nach Einsickern der Probe wird mit Wasser eluiert. Die Proteinfraktion, welche am Anfang die Säule passiert, wird verworfen und die anschließenden nichtmolekularen Fraktionen gesammelt, vereinigt und eingeengt. Das Konzentrat wird auf $\mathrm{pH}$ 2,2 gebracht und mit Puffer $\mathrm{pH}$ 2,2 auf z. B. $5 \mathrm{~m} l$ aufgefüllt. Es empfiehlt sich, in einem Vorversuch ein Vergleichsplasma zu analysieren und mit Hilfe der Ninhydrinfärbung und mit einem Protein-Reagens (z. B. Folin-Ciocalteu) die genauen Positionen von Proteinfraktionen und AminosäureFraktionen zu lokalisieren (Tüpfelreaktion).

Tricbloressigsäure-Enteiweißung: $1 \mathrm{~m} /$ Plasma wird mit $1 \mathrm{ml} 10$ proz. Trichloressigsäure-Lösung versetzt, geschüttelt und abzentrifugiert. Der Uberstand wird zur Entfernung von überschüssiger Trichloressigsäure $5 \mathrm{mal}$ mit je $5 \mathrm{ml}$ Ăther ausgeschüttelt, die wäßr. Phase eingeengt und mit Puffer $\mathrm{pH} \mathrm{2,2} \mathrm{auf} \mathrm{ein} \mathrm{bestimmtes}$ Volumẹn gebracht.

Ultrafiltration: Eine weitere Möglichkeit zur Enteiweißung ist die Ultrafiltration, welche unter Druck und in kalter Umgebung durchgefüht wird. Man erhält ein eiweißfreies Filtrat. Die nachteilig lange Filtrationsdauer kann durch ein Schüttelgerät wesentlich verkürzt werden.

\section{b) Urin}

Zur quantitativen Aminosäuren-Analyse sollte ausschließlich 24 Stdn. Urin verwendet werden, der bei $+4^{\circ}$ gesammelt wurde. Sollte kein Kühlschrank zur Verfügung stehen, so müssen Zusätze von Toluol, Chloroform oder Thymol zugegeben werden. Ein. Aliquot von $50 \mathrm{~m} l$ Urin wird tiefgefroren. Um das genaue Auftragsvolumen zu ermitteln, bestimmt man im allgemeinen den $\alpha$-Aminostickstoff (231). Enthält der Urin Eiweiß, so wird nach einer der vorher beschriebenen Methoden enteiweißt. Wird der eiweißfreie Urin nur zur Bestimmung auf neutrale und saure Aminosäuren verwendet, so trägt man den Urin nach pH Einstellung auf 2,0-2,2 sofort auf die Säule auf; für die basischen Aminosäuren muß der Ammoniak entfernt werden:

Man versetzt $5 \mathrm{ml}$ der Urinprobe mit $2 \mathrm{~N} \mathrm{NaOH}(\mathrm{pH}$ 11) und dampft im Exsikkator über konz. $\mathrm{H}_{2} \mathrm{SO}_{4}$ ein. Anschließend wird die trockene Probe mit $2 \mathrm{~N} \mathrm{HCl}$ auf $\mathrm{pH} 2,2$ eingestellt und mit Puffer pH 2,2 auf ein bestimmtes Endvolumen $(10 \mathrm{~m} l)$ gebracht. Die Auftragsmenge tichtet sich weitgehend nach der Empfindlichkeit des Gerätes.

\section{c) Liquor}

Der durch Lumbalpunktion erhaltene Liquor wird zentrifugiert und der Überstand mit einer der obigen Methoden enteiweißt. Eine Enteiweißung ist aber nicht unbedingt erforderlich.

\section{d) Gewebeextrakte}

Für die Erfassung der freien Aminosäuren aus biologischem Gewebe ist die Enteiweißungsmethode von großer Bedeutung. Die Aufbearbeitung muß raschmöglichst erfolgen. Praktisch wird so verfahren, da $\beta$ man das Gewebe mit dem Enteiweißungsmittel, z. B. Pikrinsäure, direkt homogenisiert. Man verwandelt Glutathion zu Glutathion-S-Sulfonat (231 a), welches zu Beginn der Analyse erscheint. Bei dieser Reaktion werden Cystin und Cystein ebenfalls verändert.

\section{e) Erytbrocyten}

Die Erythrocyten werden 3-4 mal in eiskalter 0,9 proz. $\mathrm{NaCl}-\mathrm{Lösung}$ gewaschen und zentrifugiert. Die anschließende Hämolyse wird wie folgt durchgeführt: Der 

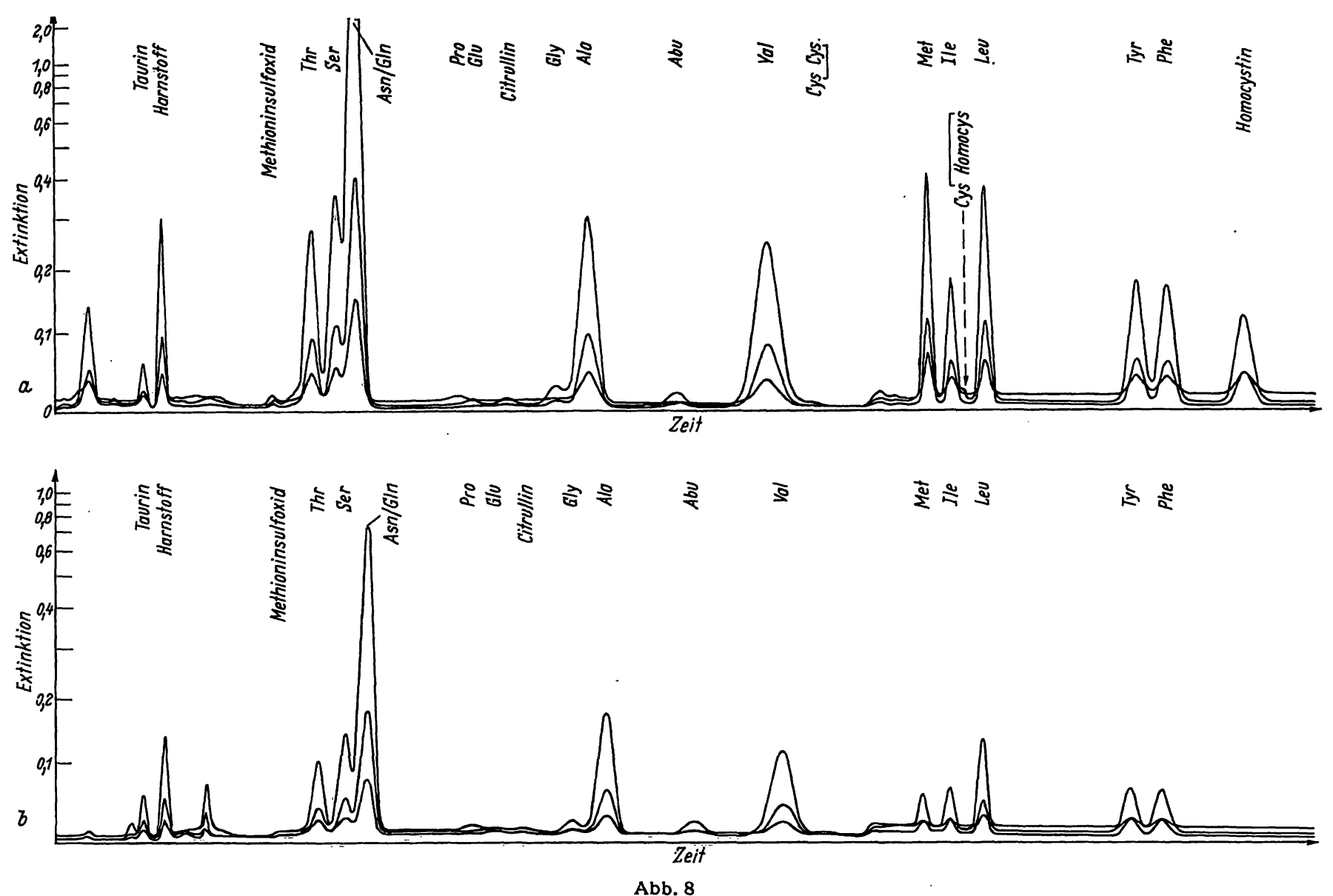

Aminosäuren-Chromatogramm vom Augenkammerwasser a) eines Homocystinurie-Patienten (oben) und b) eines Kontrollfalls (unten) nach (236).

Erythrocytenbrei wird mit dem doppelten Volumen von kalter $0,1 \mathrm{~N} \mathrm{HCl} 24 \mathrm{~h}$ bei $4^{\circ}$ stehengelassen. Durch Osmose erfolgt die Zellsprengung. Andere Möglichkeiten sind die mechanische Zerstörung durch Homogenisieren der Zellen in der Kälte oder wiederholtes Tieffrieren auf etwa $-30^{\circ}$ und rasches Auftauen (Kältehämolyse). Die Zellreste sind durch Zentrifugation aus dem tiefroten Hämolysat $z u$ entfernen. Anschließend wird nach einer der vorher beschriebenen Methoden enteiweißt.

Die quantitative Aminosäuren-Analyse erfordert die vortherige Messung des Gesamtvolumens der Blutprobe sowie die Bestimmung des Hämatokritwertes.

\section{Ausfübrung der Analyse an Kationenaustauschern}

Die Analyse von biologischem Material stellt größere Ansprüche an die Trennleistung als die einfache Analyse von Proteinhydrolysaten. Während bei der Analyse von Hydrolysaten im allgemeinen nur 20 Aminosäuren zu bestimmen sind, müssen bei physiologischen Flüssigkeiten mehr als 50 Komponenten voneinander getrennt werden. Wir unterscheiden dabei 2 Methoden: das Einsäulenverfabren und das Zweisäulenverfabren.

\section{Das Einsäulenverfahren}

PIEz und Morris empfahlen eine Einsäulen-Gradientenelution für die Analyse der sauren, neutralen und basischen Aminosäuren in einem Lauf (220). Von diesem Verfahren machte das System von Technicon Gebrauch.
Mit Lithiumcitrat-Puffern läßt sich damit eine hervorragende Trennung von Aminosäuren aus physiologischem Material in $21 \mathrm{~h}$ erzielen (270). Hamilton benutzt einen diskontinuierlichen Pufferwechsel (232) und führt eine Analyse in $20 \mathrm{~h}$ durch. Mit einem speziellen, $65 \mathrm{~h}$ dauernden Verfahren konnte HAmrLton in einem Chromatogramm von $0,5 \mathrm{ml}$ Urin insgesamt 175 Peaks nachweisen (213). Neuerdings ist es auch möglich, physiologische Materialien im Einsäulenverfahren mit diskontinuierlichem Pufferwechsel in $7 \mathrm{~h}$ mit 3 Puffern durchzuführen (233) (Abb. 7).

\section{Zweisäulenverfahren}

Das ursprüngliche Verfahren von Spackman, Stein und Moore (215) benntzt zur Trennung der sauren und neutralen Aminosäuren an einer $150 \times 0,9 \mathrm{~cm}$ Kolonne zwei Puffer, die in der Mitte der Analyse gewechselt werden. Ein dritter Puffer mit höherer Ionenstärke und $\mathrm{pH}$ wird für die Analyse der basischen Aminosäuren mit einer zweiten Kolonne von $50 \times 0,9 \mathrm{~cm}$ durchgeführt. Zur Analyse von physiologischen Flüssigkeiten benutzten schon SPACKMAN, STEIN und MOore (215) einen Pufferwechsel bei den sauren und neutralen und einen bei den basischen Aminosäuren sowie einen Temperaturwechsel bei beiden Läufen. Die Analyse benötigte etwa $22 \mathrm{~h}$. Die Einführung sphärischer Ionenaustauscher und die Verwendung hoher Drucke gestattet in neuerer Zeit eine drastische Kürzung der Kolonnenlänge und der Analysenzeit (211, 212, 234). 

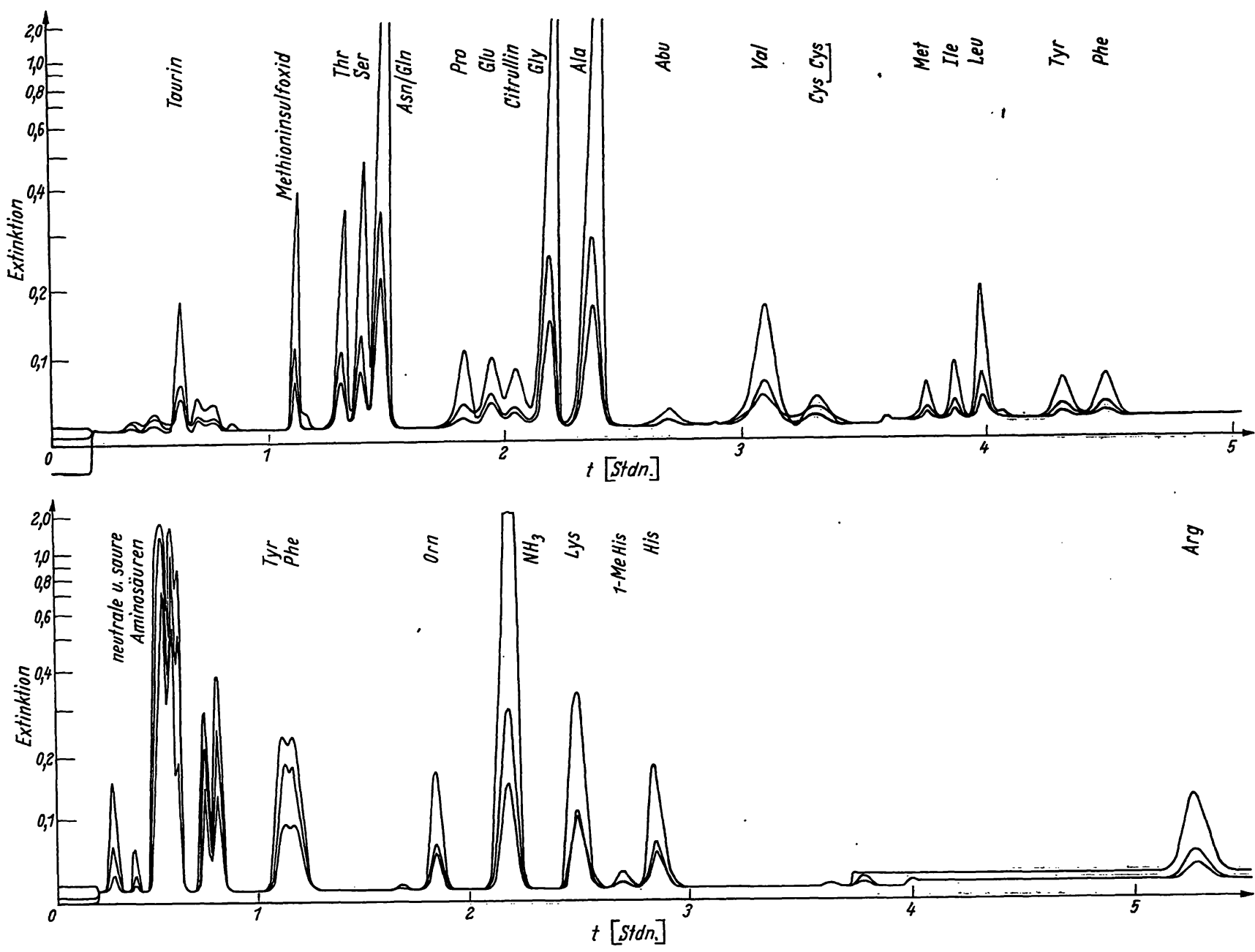

Abb. 9

Aminosäuren-Chromatogramme von sauren und neutralen (oben) sowie basischen Aminosäuren (unten) (233)

Saure und neutrale Aminosäuren: Säulenlänge $56 \mathrm{~cm}$; Beginn $\mathrm{pH} \mathrm{3,25}$ während $2,5 \mathrm{~h}$, Natriumkonzentration $0,2 \mathrm{~N}$; pH 4,25 bis $6 \mathrm{~h}$ Natriumkonzentration $0,2 \mathrm{~N}$; Temperaturwechsel von $30^{\circ}$ auf $55^{\circ}$ nach $2 \mathrm{~h}$; Fließgeschwindigkeiten: $50 \mathrm{ml}$ Puffer, $25 \mathrm{ml}$ Ninhydrin pro h. Basische Aminosäuren: Säulenlänge $20 \mathrm{~cm}$; Beginn pH 4,26 während $3 \mathrm{~h}$, Natriumkonzentration $0,35 \mathrm{~N}$; pH 5,28 bis $6 \mathrm{~h}$, Natriumkonzentration $0,38 \mathrm{~N}$; Temperaturwechsel von $30^{\circ}$ auf $55^{\circ}$ nach $2,5 \mathrm{~h}$; Fließgeschwindigkeit: $50 \mathrm{ml}$ Puffer, $25 \mathrm{ml} \mathrm{Ninhydrin}$ pro h.

Während die Empfindlichkeit der Analyse früher bei $10 \mathrm{nMol}$ pro Aminosäure lag, können heute durch Verwendung von Mikroküvetten und durch Spreizung des Schreiberbereiches mit Hilfe von Expandern noch 1-2 Nanomol pro Aminosäure nachgewiesen werden (235, 212, 211); vgl. dazu auch Abbildung 8 (236). Die Reproduzierbarkeit dieser Art von Analysen liegt bei $\pm 5 \%$, während diejenige normaler Analysen zwischen $\pm 1 \%$ und $\pm 3 \%$ liegt.

Zur Verminderung des Fehlers verwenden einige Untersucher einen internen Standard, z. B. Homocitrullin (Norleucin ist weniger geeignet) für saure und neutrale Aminosäuren und $\alpha$-Amino- $\gamma$-guanidinobuttersäure für die basischen Aminosäuren (229).

Eine gewöhnliche komplette Aminosäuren-Analyse von physiologischen Flüssigkeiten dauert immer noch $10 \mathrm{~h}$ (Abb. 9). Bei gewissen angeborenen Stoffwechselkrankheiten wie Phenylketonurie, Tyrosinose, Histidinämie, Verzweigtketten-Ketoacidurie, Homocystinurie und Hyperprolinämie ist es für die Klinik erforderlich, die Aminosäuren-Analysen häufig durchzuführen. Hierfür stehen heute sogenannte Kurzprogramme zur Verfügung (vgl. z. B. $(237,238,213)$ ), die es gestatten, nur

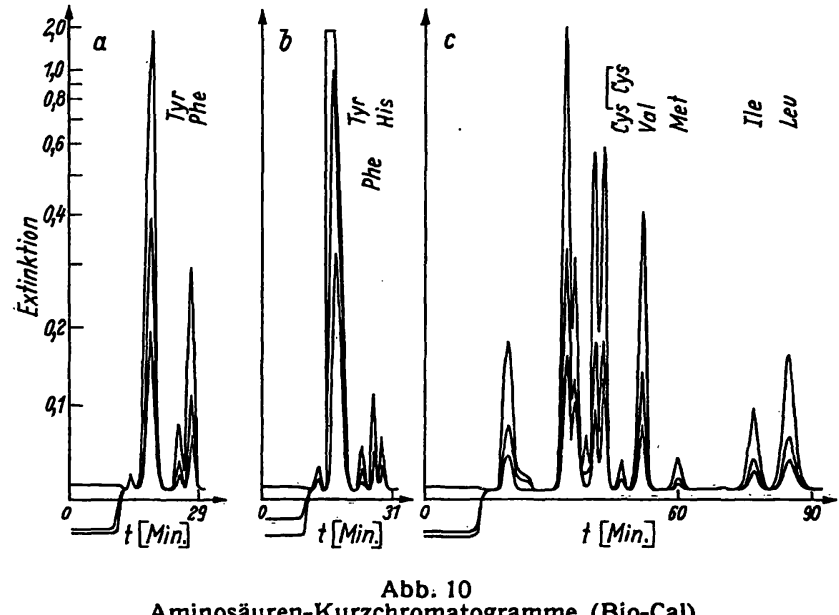

Aminosäuren-Kurzchromatogramme (Bio-Cal)

A: Kurzprogramm für Phenylketonurie und Tyrosinämie: Säule $9 \times$ $400 \mathrm{~mm}$, Harzhöhe $220 \mathrm{~mm}$; Auftrag: 0,2 ml Plasma eines Gesunden nach $1 \mathrm{~h}$ oraler L-Phenylalanin-Belästung $(100 \mathrm{mg} / \mathrm{kg}$ Körpergein $0,38 \mathrm{~N}$ Natriumcitrat pH 5,28 , $\mathrm{NaOH}, 15-41 \mathrm{~min}$ Puffer $\mathrm{pH} 5,28$. Säulentemperatur $57^{\circ} ; 80 \mathrm{ml} / \mathrm{h}$ Puffer und $40 \mathrm{ml} / \mathrm{h}$ Ninhydrin. $B$ : Kurzprogramm für Histidinämie

Auftrag: $0,2 \mathrm{ml}$ Plasma eines Frühgeborenen; Säule, Temperatur und Durchlaufgeschwindigkeit siehe $A ; 0-9$ min $0,38 \mathrm{~N}$ Natriumcitrat pH 6,$5 ; 9-17 \mathrm{~min} \mathrm{0,4N} \mathrm{NaOH,} \mathrm{17-44} \mathrm{min} \mathrm{Puffer} \mathrm{pH} \mathrm{6,5}$

c: Kurzprogramm für Hypervalinämtie, Verzweigtketten-Ketoacidurie

Auftrag: $0,4 \mathrm{ml}$ Plasma eines Gesunden. Säule, Temperatur und Auftrag: 0,4 ml Plasma eines Gesunden. Säule, Temperatur und $\mathrm{pH} 3,15 ; 65-80 \mathrm{~min} 0,4 \mathrm{~N} \mathrm{NaOH} ; 80-110 \mathrm{~min}$ Puffer $\mathrm{pH} 3,15$ 
wenige oder eine Gruppe von Aminosäuren in kürzerer Zeit quantitativ zu erfassen. Einige wesentliche Kurzprogramme sind in Abbildung 10 dargestellt.

\section{Auswertung der Chromatogramme}

Die Auswertung der Chromatogramme erfolgt im allgemeinen nach der Methode "Halbwertsbreite $\times$ Höhe“ und Multiplikation mit einem Eichfaktor, der sich aus cinem Testlauf ergibt. Zur Auswertung eines kompletten Chromatogramms benötigt man etwa $1 \mathrm{~h}$. Zur Erleichterung der Auswertung wurde ein Nomogramm beschrieben (239). Zur Ermittlung der Peakfläche werden häufig Integratoren eingesetzt. Man unterscheidet mechanische (nicht sehr genaue) und elektronische Integration. Die Peakflächen werden entweder ausgedruckt oder in einem Computer weiterverarbeitet. Eine Zusammenfassung gibt Hrrs $(240,241)$.

Gaschromatographische Bestimmung von Aminosäuren

Die Gaschromatographie (GC) besitzt gegenüber der Flüssig-Chromatographie nach wie vor zahlreiche Vorteile: Die Nachweisgrenze liegt bei Verwendung eines Flammenionisationsdetektors bei $1 \mathrm{pMol}$ und bei einem Massenspektrometer-Detektor sogar noch tiefer. Die Analysendauer kann meistens auf weniger als $30 \mathrm{~min}$ herabgesetzt werden. Ein Gaschromatograph ist preiswerter als ein hoch-spezialisierter Aminosäuren-Analysator und bleibt jederzeit universell einsetzbar.

Es hat daher in der Vergangenheit nicht an Versuchen gefehlt, die GC auch für die Aminosäuren-Analyse einzusetzen (vgl. die Reviews (242-245)).

\section{Derivate}

Aminosäuren können in freier Form nicht gaschromatographiert werden, sondern müssen dazu in Derivate umgewandelt werden. Eine Fülle verschiedener Derivate wurde vorgeschlagen, darunter die Reaktionsprodukte der Ninhydrin-Reaktion, $\alpha$-Chloroaminsäuremethylester, 2,4-Dinitrophenylmethylester, Phenylthiohydantoinaminosäuren, N,N-Dimethylaminosäuremethylester, $\alpha$ Methoxymethylester, Trimethylsilyl-aminosäuren und Acylaminosäureester. Hinsichtlich der Derivatisierung bestehen erhebliche Ansprüche: Sie soll bei allen in
Frage kommenden, chemisch sehr heterogenen Aminosäuren sehr gut reproduzierbat, rasch und möglichst quantitativ verlaufen und soll Verbindungen ergeben, die unzersetzt chromatographiert und vollständig voneinander getrennt werden können. Es dürfen auch keine Nebenprodukte gebildet werden, die die Trennung beeinträchtigen. Von den oben genannten Derivaten erfüllen im Augenblick die Acylaminosäureester die meisten dieser Bedingungen.

Systematische Untersuchungen zeigten (242), daß Acylaminosäureester höherer Alkohole bessere Chromatogramme ergeben. So werden heute bevorzugt N-Acetylaminosäurebutylester oder N-Trifluoracetylaminosäurebutylester verwendet. Die Veresterung erfolgt zwcckmäßig in zwei Schritten: Man bildet zunächst die Methylester (HCl-Gas-Katalyse) und schließt eine Umesterung mit Butanol an. Relativ schwierig zu verestern sind Lysin, Histidin und Cystin. Die Butylester werden anschließend acyliert. Dabei machten besonders Arginin und Tryptophan.Schwierigkeiten. Arginin kann indessen vor der Analyse mittels Arginase in Ornithin verwandelt (246) und Histidin durch Ozonspaltung in Asparaginsäure überführt $(246,242)$ und durch Analyse von behandelter und unbehandelter Probe bestimmt werden.

\section{Stationäre Phasen}

Nahezu 100 verschiedene stationäre Phasen wurden bercits zur gaschromatographischen Trennung von Aminosäurederivaten untersucht. Aufmerksamkeit ist indessen nicht nur der flüssigen Phase, sondern auch dem Trägermaterial zu schenken. Für Trifluoracetyl-aminosäuremethylester eignet sich eine gemischte Phase $(2,5 \%$ auf desaktiviertem Diatoport S) von XE-60, QF-1 und MS-200 im Verbältnis $46+27+27$ (g/g) (247), wobei sich 22 Aminosäurederivate einschließlich Arginin trennen lassen. Trifluoracetyl-aminosäure-n-butylester können besonders gut mit Äthylenglycoladipat (EGA) auf Chromosorb W getrennt werden. Bei Änderung der Beladung von $0,5-2 \%$ wurden indessen Peak-Verschiebungen beobachtet (248) (optimale Trennung bei $0,65 \%$ Beladung). Für die polaren Aminosäurederivate eignet sich nach GeHRKE (243) eine Säule von 1,5\% g/g OV-17 auf Chromosorb G (Abb. 11).
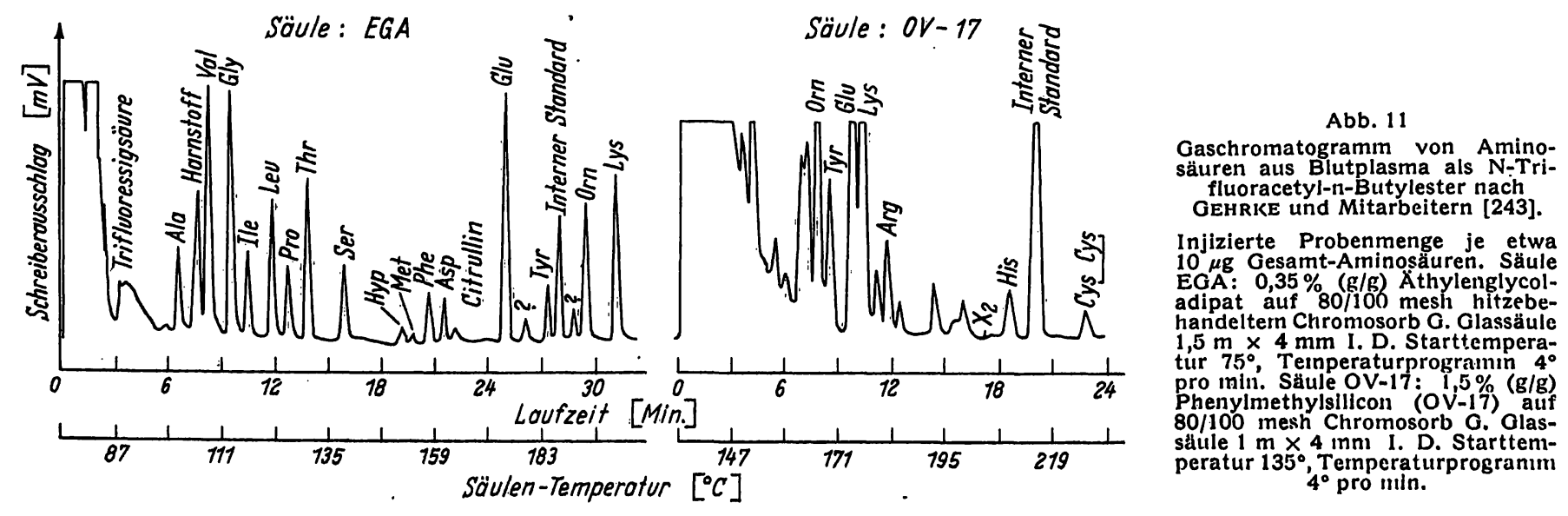


\section{Quantitative Bestimmung}

Die Anzeige des für analytische Gaschromatographie in der Regel eingesetzten Flammenionisationsdetektors ist sehr unspezifisch. Dies ist gegenüber der Flüssig- Chromatographie mit anschließender Ninhydrin-Reaktion von Nachteil. Bei der Analyse von biologischem Material ist daher zu erwarten, daß die Anwesenheit einer Fülle von nicht interessierenden Substanzen die quantitative Auswertung des Aminosäuren-Chromatogramms unmöglich macht. Biologisches Material ist deshalb vor der Derivatisierung vorzureinigen. Die Aminosäuren werden dazu zweckmäßig an einer kurzen Säule von stark saurem Ionenaustauscher (z. B. Amberlite IR-120 H) adsorbiert und nach Waschen mit Wasser anschließend mit Ammoniak eluiert (vgl. S. 410, Entsalzung, siehe auch (243)). Gegebenenfalls sind noch weitere Reinigungsschritte (z. B. Extraktion der Aminosäurederivate) der gaschromatographischen Analyse vorauszuschicken.

Um Fehler durch Verluste während der vorbereitenden Operation und Derivatisierung sowie bei der Injektion möglichst klein zu halten, muß der Probe ein interner Standard - z. B. n-Butylstearat - zugefügt werden.

Die molare Ansprechbarkeit des Flammenionisationsdetektors variiert bei den verschiedenen Aminosäuren. Für jede Aminosäure ist daher eine separate Eichkurve anzufertigen, die aber im Arbeitsbereich praktisch linear verläuft. 5-10 nMol Aminosäuren können noch bestimmt werden (242). Der Arbeitsbereich liegt bei 0,1 bis $35 \mu \mathrm{g}$ pro Aminosäure (243) bei einem Fehler von etwa $\pm 2 \%$. Semiquantitative Analysen können bei Anwendung einer Submikrotechnik noch mit weniger als $200 \mathrm{ng}$ Aminosäuremischung durchgeführt werden.

\section{Diskussion}

Die Aminosäure-Analyse spielt außer für biochemische Probleme, wie Sequenzanalyse von Peptiden, Proteinen, Enzymen etc. auch für die klinische Chemie eine immer größere Rolle. Klinisch chemische Anwendungen sind vor allem heriditäre Aminosäure-Stoffwechselstörungen und renale Hyperaminoacidurien. Eine vermehrte Ausscheidung von Hydroxyprolin zeigt sich häufig beim Marfan-Syndrom und bei Kollagenosen. Einzelne interessante Untersuchungen liegen auch bei MammaCarcinom (250), Myocard-Infarkt (251) und Psoriasis (252) vor.

Grundsätzlich sollten bei allen hospitalisierten Patienten, bei denen eine Aminosäure-Stoffwechselstörung in Frage käme, orientierende qualitative Urinanalysen auf Aminosäuren bzw. deren Metabolite durchgeführt werten. Bei positivem Ausfall einer der unter I aufgeführten Proben muß eine semiquantitative oder eine quantitative Analyse erfolgen; auch ein unter Umständen negatives Resultat sollte bei fortbestehender unklarer Diagnose mittels semiquantitativer Analyse weiter verfolgt werden. Quantitative Analysen aller Aminosäuren sind zur endgültigen Diagnose (evtl. Belastungstest) bei gewissen Stoffwechselstörungen zur Kontrolle der Behandlung und zur rechtzeitigen Erkennung diätbedingter Störungen des Aminosäurespiegels erforderlich. Die qualitativen Proben sind in der Regel sehr unspezifisch. Die Dinitrophenylhydrazin-Probe ist stark $\mathrm{pH}$ - und temperaturabhängig ' und daher trotz guter Spezifität heikel durchzuführen. Sie spricht auf alle Ketosäuren an, so auch auf die beim Gesunden vorhandene 2-Oxoglutarsäure und Brenztraubensäure, die allerdings erst bei längerer Inkubationsdauer ausfallen. Die Analysenvorschrift ist daher auch zeitlich genau einzuhalten. Die Eisenchlorid-Probe ist sehr unspezifisch und spricht nicht nur auf Aminosäure-Metaboliten, sondern auch auf zahlreiche andere Substanzen, auch Arzneimittelmetaboliten an. Bei der Phenylketonurie (PKU) wird der Test häufig erst dann positiv, wenn der Zeitpunkt für eine wirksame Behandlung bereits überschritten ist. Für eine Frühdiagnose der PKU kommt daher nur eine Bestimmung des Phenylalanins im Blut in Betracht.

Die Nitroprussid-Probe ist spezifisch auf SH- und Disulfid-Gruppen und ist daher bei Cystin und Homocystin positiv. Eine positive Probe kann aber nur mit einiger Erfahrung von unspezifischen Reaktionen, wie z. B. von Kreatinin, unterschieden werden. Entsprechendes gilt auch für die Probe auf Homocystin nach BARBER.

Das heute am meisten durchgeführte Screeningverfahren ist der semiquantitative mikrobiologische Test auf PKU nach Guthrie und SusI $(99,100)$. Wesentliche Vorteile sind: die Blutproben können auf Filterpapier eingetrocknet versandt werden, der Test ist relativ billig, einfach und in großen Serien durchführbar. Der Test kann auch auf andere Substanzen angewandt werden, z. B. Methionin, Leucin, Galaktose etc. Nachteile des Verfahrens sind: es ist ein spezialisiertes Labor erforderlich die Analysendauer ist lang und es wird jeweils nur eine Substanz, erfaßt, ein positives Resultat muß durch eine quantitative Methode bestätigt werden. Es ist zu erwarten, daß die semiquantitativen mikrobiologischen Tests in absehbarer Zeit weitgehend durch quantitative, automatische Verfahren ersetzt werden (vgl. hierzu $(180 a, b))$.

Bei der fluorometrischen, automatischen PhenylalaninBestimmung mittels Autoanalyzer (187) können hingegen 40-60 Proben pro $h$ analysiert werden. Dabei bleibt der Vorteil der eingetrockneten Blutflecken auf Filterpapier erhalten und es werden quantitative Resultate erzielt. Dasselbe gilt für Bestimmung von Tyrosin (197).

Alle bisher genannten Analysenverfahren beziehen sich jeweils nur auf eine oder wenige Aminosäuren. Der Vorteil der chromatographischen Verfahren liegt vor allem darin, daß jede Art von Aminosäure-Stoffwechselstörungen bemerkt wird. Der Guthrie-Test könnte unseres Erachtens am ehesten durch Dünnschicht-Chromatographie abgelöst werden, mit der bei vergleichbarem Aufwand eine semiquantitative Analyse auf alle Aminosäuren durchgeführt werden kann. Es ist allerdings nicht möglich, das Verfahren der eingetrockneten Blutflecken ohne Modifikationen zu übernehmen (vgl. dazu auch (267)). Untersuchungen über die Verwendbarkeit von Blutproben in Kunststoffkapillaren sind noch im Gange. Bei Urinanalysen müssen die Proben vor der 
Chromatographie entsalzt werden, was einen zusätzlichen Aufwand erfordert. Die Einführung der Zweischichten-Platte durch KRAFFCZYCK und HeLGER (125) stellt hier einen großen Fortschritt dar.

Die Aminosäuren-Analyse als DNP-Derivate nach BRENNER und Mitarbeitern $(144,145)$ ist wegen der guten Trennung und Extraktion besonders geeignet für die Untersuchung heterogener Gemische wie z. B. Stuhl (153), sowie für spezielle wissenschaftliche Aufgabenstellungen. Für Massenuntersuchungen ist die Methode aber zu arbeitsaufwendig. Die anfänglich von DENT für klinisch-chemische Routine-Analysen eingeführte Papierchromatographie wird zwar in USA noch häufig verwendet, ist aber als überholt anzusehen. Dies gilt sicher nicht für die Hochspannungselektrophorese, die sehr rasch durchführbar ist, aber doch einen zusätzlichen apparativen Aufwand erfordert. Sie ist besonders für die salzhaltigen Urinproben vorteilhaft.

Die spezifischen enzymatischen und kolorimetrischen Methoden finden nur in Einzelfällen Verwendung. Die quantitativen mikrobiologischen Verfahren waren früher von Bedeutung und erzielten eine beachtliche Spezifität und Genauigkeit. Die Ergebnisse bleiben aber mit einer Unsicherheit behaftet, da Wuchsstoffe oder Antibiotika in den untersuchten Proben zu beachtlichen Fehlern führen können. Durch den großen Erfolg der chromatographischen Verfahren sind die mikrobiologischen Methoden in den Hintergrund getreten.

Unter den quantitativen chromatographischen Analysenmethoden spielt heute zweifellos die Säulenchromatographie im Zweisäulenverfahren an Kationenaustauschern bei weitem die größte Rolle. Mit modernen, vollautomatischen Geräten kann heute eine Genauigkeit von $1-2 \%$ erzielt werden. Mit Hilfe von Mikroküvetten, Skalenexpandern und Verringerung des Säulenquerschnitts wurde eine Empfindlichkeitssteigerung auf $1 \mathrm{nMol}$ pro Aminosäure erzielt. Die heutigen Mikroanalysatoren mit extrem reduziertem Säulenquerschnitt dürften sich aber weniger für Routine- als vielmehr für spezielle wissenschaftliche Fragestellungen eignen. Durch Verwendung neuer Harze konnte bei zunehmender Analysengeschwindigkeit auch die Trennleistung wesentlich gesteigert werden: Die ursprüngliche Analysenzeit für physiologisches Material wurde inzwischen von $22 \mathrm{~h}$ (215) auf $10 \mathrm{~h}$ und im Einsäulenverfahren sogar auf $7 \mathrm{~h}$ reduziert. Mehrkolonnensysteme (253, 254) sowie automatische Probengeber $(215 \mathrm{a}, \mathrm{b}, \mathrm{c})$ gestatten eine wesentlich rationellere Ausnützung der Analysengeräte. Wie im ursprünglichen Verfahren wird auch heute noch mit $\mathrm{SnCl}_{2}$ stabilisiertes Ninhydrin verwendet. Es gelang bisher nicht, ein Reagenz zu finden, das ähnlich empfindlich und spezifisch auf Aminoverbindungen ist, aber nicht seine Nachteile (Oxydationsempfindlichkeit) aufweist. Vom zeitweilig verwendeten Gradienten-Elutionsverfahren wurde in $z$ wischen wieder abgegangen. Die AnionenaustauscherChromatographie ergänzt bei speziellen Fragestellungen die Kationenaustauscher-Chromatographie. Der Ligandenaustausch könnte in der Zukunft eine größere Bedeutung erlangen. Im Augenblick liegen vor allem in Europa noch zu wenig Erfahrungen vor.

Bei automatischer Probenaufgabe ist der Einsatz von elektronischen Integratoren zur Flächenermittlung fast unerläßlich. Bei kleiner Anzahl von AminosäureAnalysatoren benötigt jedes Gerät einen eigenen Integrator, wobei die Umrechnung von Flächenwerten in Konzentrationswerte mit einem Tischrechner erfolgt. Bei großen Einheiten wird sich in Zukunft die Frage stellen, ob ein zentraler Integrator mit Computeranschluß und entsprechendem Tape oder Lochstreifeneinheiten an den einzelnen Getäten vorzuziehen ist.

Die Gaschromatographie von Aminosäuren aus physiologischen Flüssigkeiten ist zwar heute noch nicht für Routineanalysen brauchbar. Schwierigkeiten liegen in der Derivatbildung und der Unspezifität des Detektors. Die wesentlich kürzere Analysendauer, der geringere appatative Aufwand und die hervorragende Trennleistung berechtigen zu weiteren Versuchen. Die Möglichkeit der Kombination mit Radiogaschromatographie $(255,256)$ und Massenspektrometrie (257-262) eröffnen neue Wege zur Untersuchung von Stoffwechselstörungen z. B. mit Hilfe von Zellkulturen. Diese Kombinationen wären auch von Vorteil bei der Identifizierung der zahlreichen, in physiologischen Flüssigkeiten nachgewiesenen (213) unbekannten Substanzen.

Herrn Prof. Dr. T. Gerritsen danken wir für wesentliche Hinweise und Diskussionen zu dieser Arbeit, Frau Dr. R. Hernandez für Hilfe bei der Literaturbeschaffung und Fräulein C. Loosen für Mithilfe bei der Abfassung des Manuskripts.

\section{Literatur}

1. Detrerbeck, F. J. und M. S. Thests, Mich. State University (1969), in Vorbereitung. - 2. NYHAN, W. L., „Amino Acid Metabolism and Genetic Variation "c, McGraw-Hill Book Comp., New York (1967). - 3. Stanbury, J. B., J. B. WyngaARDEN und D. S. Fredrickson, "The Metabolic Basis of Inherited Disease“, McGraw-Hill Book Comp., New York, 2nd Ed. (1966). 4. Hsra, D. Y. und T. INOUYE, "Inborn Errors of Metabolism", Year Book Med. Publ., Chicago (1966). - 5. Scriver, C. R., in Cecil Loeb, Textbook of Medicine, S. 1219-1226 (Editors P. B. Beeson, W. McDermott), 12th Ed. Saunders, Philadelphia (1967).6. Hsis, D. T., Birth Defects Orig. Art. Ser. 4, 92 (1968). 7. Scriver, C. R., S. Purschel und E. Davies, N. England J. Med. 274, 636 (1966). - 8. EFron, M. L., in 3, S. 393-408.
9. Moser, H. W., M. L. Efron, H. Brown, R. Diamond und C. G. NeumanN, Amer. J. Med. 42, 9 (1967). - 10. McMurray, W. C., J. C. Rathbun, F. Mohynddin und S. J. Koegler, Pediatrics Springfield 32, 347 (1963). - 11. Mohrnddin, F., J. D. Rathoun und W. C. McMurray, Amer. J. Dis. Child. 113, 152 (1967). - 12. Harris, H., L. S. Penrose und D. H. Thomas, Amer. Human Genet. 23, 442 (1959). - 13. Frimter, G. W., A. Haymovitz und M. Horwith, N. England J. Med. 268, 333 (1963). - 14. Frimter, G. W., in 3, S. 409. - 15. Wollaston, W. H., Philos. Transact. Roy. Soc. London, Biol. Sc. 100, 223 (1810). - 16. Stein, W. H., Proc. Soc. Exper. Biol. Med. 78, 705 (1951). - 17. Dent, C. E. und G. A. Rose, Quart. J. Med. 20, 205 (1951). - 18. KNox, W. E., in 3, S. 1262. - 19. GrRRIT- 
Sen, T., E. Kaveggia und H. A. Waisman, Pediatrics Springfield 36, 882 (1965). - 20. Nyfian, W. L., T. Gerritsen und T. Ando, in 2, S. 255. - 20a. RAMpini, S., D. Vischer, H.-Ch. Curtius, P. W. Anders, F. TANCredi, W. Frischknecht und A. Prader, Helv. paediatr. Acta 22, 135 (1967). - 21. Childs, B., W. L. Nyhan, M. Borden, L. Bard und R. E. Cooke, Pediatrics Springfield 27, 522 und 539 (1961). - 22. ChILDS, B. und W. L. NyHaN, Pediatrics Springfield 33, 403 (1964). - 23. SCHreIER, K. und W. MǘlER, German Medical Monthly 9, 437 (1964). 24. de Vries, A., S. Kochwa, J. Lazebnik, M. Frank und M. DJaldetr, Amer. J. Med. 23, 408 (1957). - 25. WYNGAARDEN, J. B. und S. Segal, in 3, S. 341. - 26. Dent, C. E. und H. HarRIS, J. Bone Joint Surg. 38 B, 204 (1956). - 27. SCRIver, C. R., R. B. Goldbloom und C. Roy, Pediatrics Springfield 34, 357 (1964). - 28. Kaeser, H., P. Cottier und I. Antener, J. Pediatr. S. Louis 61, 386 (1962). - 28a. FuhrmanN, W., Z. Kinderhk. 82, 514 (1959). - 29. Levin, B., Amer. J. Dis. Child. 113, 142 (1967). - 30. Russell, A., B. Levin, V. G. Oberholzer und L. Sinclatr, Lancet London 1962/II 699. - 31. Ghadimi, H., M. W. Partington und A. Hunter, New Eng. J. Med. 265, 221 (1961). - 32. Ghadimi, H., M. W. Partington und A. Hunter, Pediatrics Springfield 29, 714 (1962). - 33. LA Du, B. N., R. R. Howell, G. A. Jacoby, J. E. Seegmiller, E. K. Sober, V. G. ZanNoni, Ji P. Canby und L. K. Ziegler, Pediatrics Springfield 32, 216 (1963). - 34. LA Du, B. N., in 3, S. 366. - 35. GHADrMI, H. und R. ZischKa, in 2, S. 133. - 36. Auerbach, V. H., A. M. DiGeorge und G. G. Carpenter, in 2, S. 145. - 37. Bessman, S. P. und R. BALDwiN, Science Washington 135, 789 (1962). 38. LeVEnson, J., K. Lindahl-KIESSLING und S. Rayner, Lancet London 1964 II 756. - 39. Toccr, P. M. und S. P. Bessman, in 2, S. 161-168. - 40. Gerritsen, T., J. G. Vaughn und H. A. Waisman, Biochem. Biophys. Res. Commun. 9, 493 (1962). 41. Gerritsen, T. und H. A. Waisman, Pediatrics Springfield 33, 413 (1964). - 42. Carson, N. A. und D. W. Neill, Arch. Dis. Child. London 37, 505 (1962); 38, 425 (1963). - 43. WERDER, E. W., H.-Ch. Curtius, F. Tancredi, P. W. Anders und A. PraDER, Helv. paediatr. acta 21, 1 (1966). - 44. PERRY, T. L., S. Hansen, L. McDougall und P. D. Warrington, Clin. Chim. Acta Amsterdam 15, 409 (1967). - 45. Gerritsen, T. und H. A. Waisman, in 3, S. 420. - 46. Perry, T. L., in 2, S. 279-296. 47. Smrth, A. J. und L. B. Strang, Arch. Dis. Child. London 33, 109 (1958). - 48. Efron, M. L., E. M. Bixby, L. G. PalattAo und C. V. Pryles, New Eng. J. Med. 267, 1193 (1962). 49. Efron, M. L., in 3, S. 376. - 50. Menkes, J. H., P. L. Hurst und J. M. Craig, Pediatrics Springfield 14, 462 (1954). 51. Westall, R. G., J. Dancis und S. Miller, Amer. J. Dis. Child. 94, 571 (1957). - 52. Dancis, J., M. Levitrz, S. Mrller und R. G. Westall, Brit. Med. J. 1, 91 (1959). - 53. Dancis, J. und M. Levitz, in 3, S. 353. - 54. SNYDERMaN, S. E., in 2, S. 171. - 54a. Dancis, J., J. Hutzler und T. Rokkones, New Eng. J. Med. 276, 84 (1967). - 55. Colombo, J. P., R. Richterich, A. Spahr, A. Donath und E. Rossi; Lancet London 1964 I 1014. - 56. Ghadimi, H., P. Kottmeier, R. Achs, R. Prabhu und B. Jaffe, Proc. Soc. Pediatr. Res. 35th Annual Meeting, S. 33, Philadelphia (1965). - 57. Woody, N. C., J. HurzLER und J. Dancis, Amer. J. Dis. Child. 112, 577 (1966). 58. Ghadimi, H., V. I. Binnington und P. Pecora, New Eng. J. Med. 273, 723 (1965). - 59. GHADimr, H. und R. ZissChKA, in 2, S. 227. - 60. Fölling, A., Hoppe-Seyler's Z. physiol. Chem. 227, 169 (1934). - 61. Jervis, G. A., R. J. BLOCK, D. Bolling und L. Kanze, J. biol. Chemistry 134, 105 (1940). 62. Knox, W. E., in 3, S. 258. - 63. AlLeN, R. J., L. Flemine und R. Spirito, in 2, S. 69. - 64. Auerbach, V. H., A. M. DiGeorge und G. G. CARPENTER, in 2, S. 11. - 65. Schäfer, I. A., C. R. Scriver und M. L. Efron, New Eng. J. Med. 267, 51 (1962). - 66. SCRrver, C. R., I. A. SCHÄFER und M. L. EFroN, Nature London 192, 672 (1961). - 67. SCRIVER, C. R., in 2, S. 327. - 68. Joseph, R., M. Ribierre, J. C. Job und M. Girault Arch. franç. pédiatr. 15, 374 (1958). - 69. Gerritsen, T. und H. A. Waisman, New Eng. J. Med. 275, 66 (1966). - 69a. TADA, K. H., Ito, Y. Wada und T. Arakawa, Tohoku J. Exper. Med. 80, 118 (1963). - 70. Medes, G., Biochem. J. 29, 917
(1942). - 71. LA Du, B. N., in 3, S. 295. - 72. Shear, C. S., W. L. NyHaN und P. M. Tocci, in 2, S. 97. - 73. Levine, S. Z., E. Marples und H. H. Gordon, J. Clin. Invest. 20, 199 (1941). 74. Levine, S. Z., H. H. Gordon und E. Marples, J. Clin. Invest. 20, 209 (1941). - 75. HsIA,' 'D. Y., M. LITwACK, M. O. FLYNN und S. Jaxovcic, New Eng. J. Med. 267, 1067 (1962). 76. Gentz, J., R. Jagenburg und R. Zetrerström, J. Pediatr. S. Louis 66, 670 (1965). - 77. Kogout, M. D., K. N. SHAW und G. N. Donnelt, Amer. J. Dis. Child. 113, 47 (1967). - 78. Jepson, J. B., A. J. Smith und L. B. Strang, Lancet London 1958 II 1334. - 78a. TAdA, K., Y. Wada und T. Arakawa, Amer. J. Dis. Child. 113, 64 (1967). - 79. Baron, D. N., C. E. Dent, H. Harris, E. W. HART und J. B. Jepson, Lancet London 1956 II 421. - 80. Jepson, J. B., in 3, S. 1283. - 81. FAnconI, G., Jber. Kinderhk. 147, 229 (1936). - 82. DETONr, G., Ann. paediatr. Basel 187, 42 (1956). - 83. LEAF, A., in 3, S. 1205. - 84. IsseLBACHER, K. I., in 3, S. 178. - 85. HsIA, D. Y., S. GREeN, M. KAY und S. S. Gellis, Amer. J. Dis. Child. 88, 258 (1954). - 86. Cusworth, D. C., C. E. Dent und F. V. FlynN, Arch. Dis. Child. London 30, 150 (1955). - 87. Stein, W. H., A. G. BEARN und S. Moore, J. Clin. Invest. 33, 410 (1954). - 88. BeArN, A. G., in 3, S. 761. - 89. Harrison, H. E., J. Chron. Dis. 7, 346 (1958). 90. MCCREADY, R. A. und M. G. HuSSEY, Newborn phenylketonuria (PKU) detection program in Massachusetts: progress report. Presented at American Public Health Association Convention, Kansas City, Kansas, Nov. 12, 1963. - 91. Scriver, C. R., Canad. Med. Assoc. J. 92, 1360 (1965). - 92. SCriver, C. R., Ped. Clin. N. Amer. 12, 807 (1965). - 93. Thalmammer, O., Mschr. Kinderhk. 117, 37 (1969). - 94. SCrrver, C. R., Pediatriçs Springfield 39, 764 (1967). - 95. Scriver, C. R., in „Progress in Medical Genetics". (A. Bearn and A. G. Steinberg, Eds.), Grune \& Stratton, New York, Vol. 2, 83 (1962). - 96. P. M. Toccr, in 2, S. 480. - 97. Berky, H. K., Clin. Chem. New York 5, 603 (1959). 98. Perry, T. L., S. Hansen und L. McDougarl, Canad. Med. Assoc. J. 95, 89 (1966). - 99. Guthrie, R. und A. Susi, Pediatrics Springfield 32, 338 (1963). - 100. Guthrie, R., Birth Defects Orig. Art. Ser. 4, 92 (1968). - 100a. Merster, A., Biochemistry of the Amino Acids, Academic Press, New York (1965), Vol. I, S. 231-268. - 101. DeNT, C. E., Iancet London 1947/I 637. - 102. Dent, C. E., Biochem. J. 41, 240 (1947). - 103. Dent, C. E., Biochem. J. 43, 169 (1948). - 104. MABRY, C. C. und W. R. TodD, J. Laborat. Clin. Med. S. Louis 61, 146 (1962). - 105. SAmuels, S., Arch. Neurol. 10, 322 (1964). - 106. JuUl, P., Scand. J. Clin. Laborat. Invest. 18, 629 (1966). - 107. EFron, M. L., New Engl. J. Med. 72, 692 (1959). - 108. in 4, Vol. 2, S. 60. - 109. Botromlx, S. S., Analytic Biochem. 18, 472 (1967). 110. Efron, M., in I. Smith, Chromatographic and Electrophoretic Techniques Vol. II, S. 159-189, Interscience Pub., New York (1960). - 111. Hannig, K., in Biochemisches Taschenbuch (H. M. Rauen, Editor), Band 2, S. 938, Springer-Verlag Heidelberg (1964). - 112. Clotren; R. und A. Clotren, Hochspannungselektrophorese, Georg Thieme Verlag, Stuttgart (1962). 113. Stevens, K. M., in Electrophoresis, A Practical Laboratory Manual (S. T. Nerenberg, Editor), C. A. Davis Comp., Philadelphia (1966), S. 147. - 114. Moffat, E. D. und R. I. LYTLE, Analytic. Chem. 31, 926 (1959). - 115. Bigwood, E. J., R. CRocart, E. Schramm, P. Soupart und H. Vis, Adv. Clin. Chem. 2, 201 (1959). - 116. SMrrH, I., Chromatographic and Electrophoretic Techniques, Interscience Publ. Inc., New York (1962). 117. Brenner, M., A. Niederwiesér und G. Pataki, in E. Stahl, Dünnschichtchromatographie, S. 403, Springer-Verlag, Heidelberg (1962). - 118. Patakr, G., Techniques of Thin-Layer Chromatography in Amino Acid and Peptide Chemistry, Ann Arbor Science Publ. Inc., Ann Arbor, Michigan (1968). - 119. PatAKr, G., Dünnschicht-Chromatographie in der Aminosäureund Peptid-Chemie, Walter de Gruyter \& Co., Berlin (1966). 120. Oepen, H. und I. Oepen, Klin. Wschr. 41; 921 (1963). 121. Bremer, H. J., W. Nützenader und H. Bickex, Mschr. Kinderhk. 117, 32 (1969). - 122. CRowshaw, K., S. J. Jessup und P. W. Ramwell, Biochem. J. 103, 79 (1967). - 123. Neadle, D. J. und R. J. Pollitt, Biochem. J. 97, 607 (1965). - 124. HARris, C. K., E. Trgane und G. S. Hanes, Canad. J. Biochem. 39. 

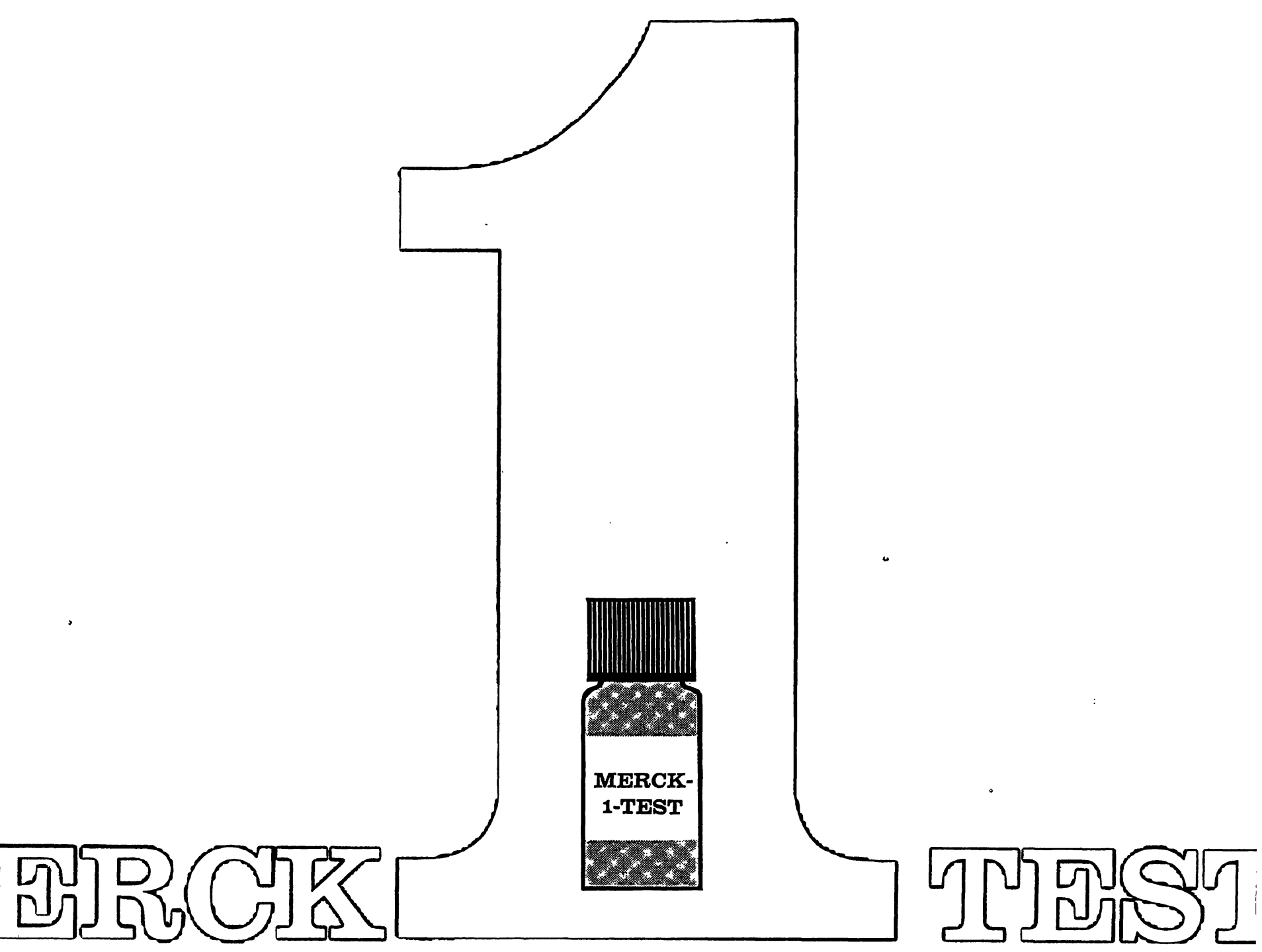

\section{Ein Test in einem Gla}

Cholinesterase

GOT (UV)

GPT (UV)

HBDH (UV)

LDH (UV)

Eine neue Konzeption für Sicherheit

und Zeitersparnis in Klinik- und

Praxislabor

Öffnung der 1-Test-Gläser

im Handumdrehen

Lösungsmittel in der Packung enthalten; daher kein destilliertes

Wasser notwendig

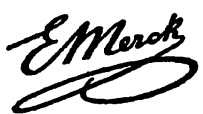

E. MERCK AG - DARMSTADT 


\section{Eine Frage \\ Haben Sie hoffenunglose Tremprobleme? \\ an den \\ Biochemiker: \\ „Dann versuchen Sie es doch einmal mit der, Quickfit“ Gegenstrom- verteilung! - Sie wollen nicht literweise mit Lösungsmitteln herum- \\ plantschen? - Keine Angst! Unsere Maschine ist vollautomafisiert, auch die Zugabe und Entnahme der Lösungsmittel".}

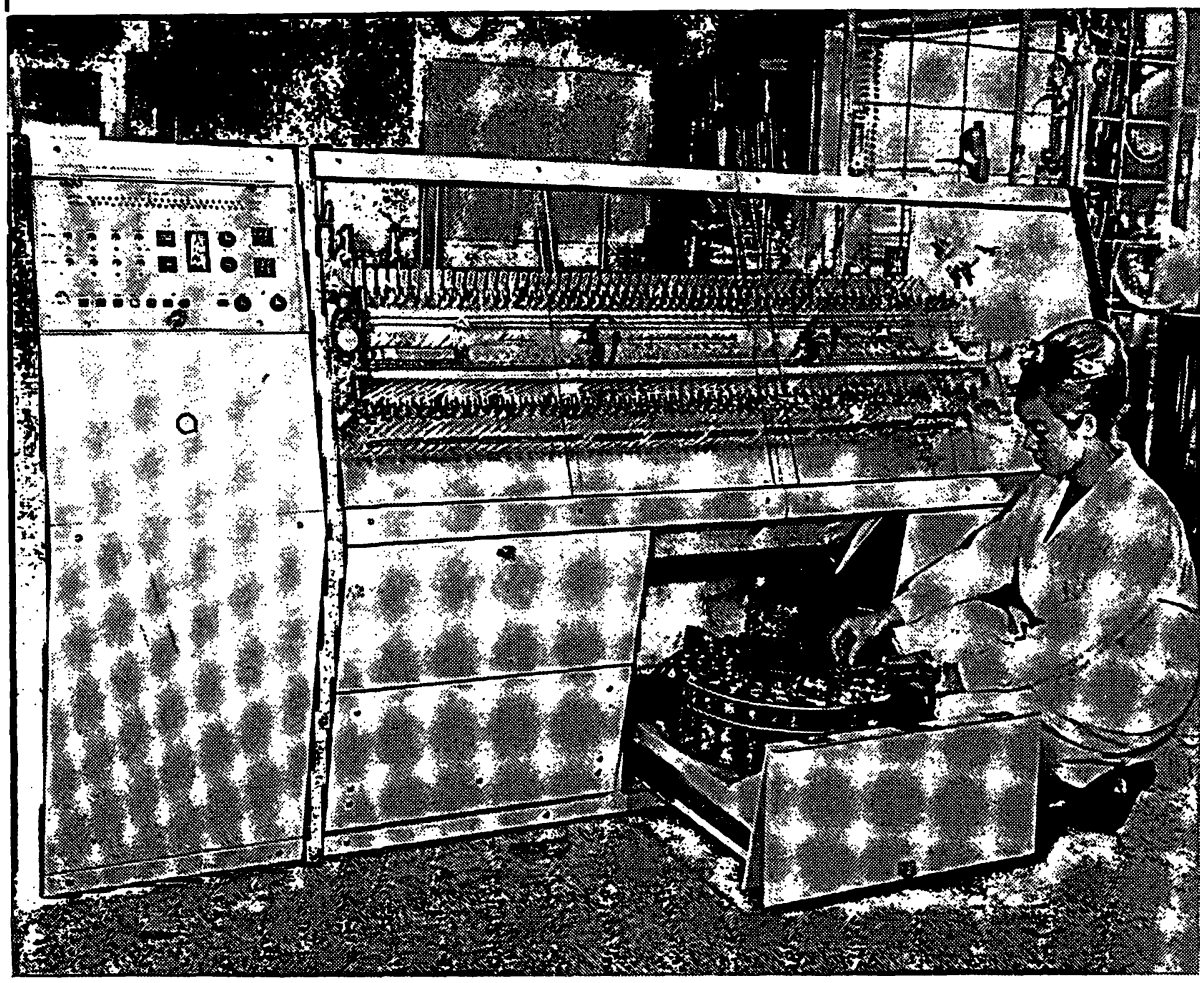

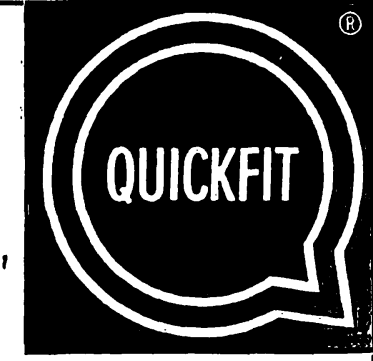

\section{Gegenstrom-} Verteilmaschine

mit zwei beweglichen

Phasen;

programmierbar von

$\frac{\text { Oberphase }}{\text { Unterphase }}=\frac{1}{24}$ bis $\frac{24}{1}$;

daher auch

Konzentrierungen möglich.

QUICKFIT LABORGLAS GMBH

Wiesbaden-Schiernstein. HüHtenstraße 8 Telefon (06121) 64091 . FS 04186503

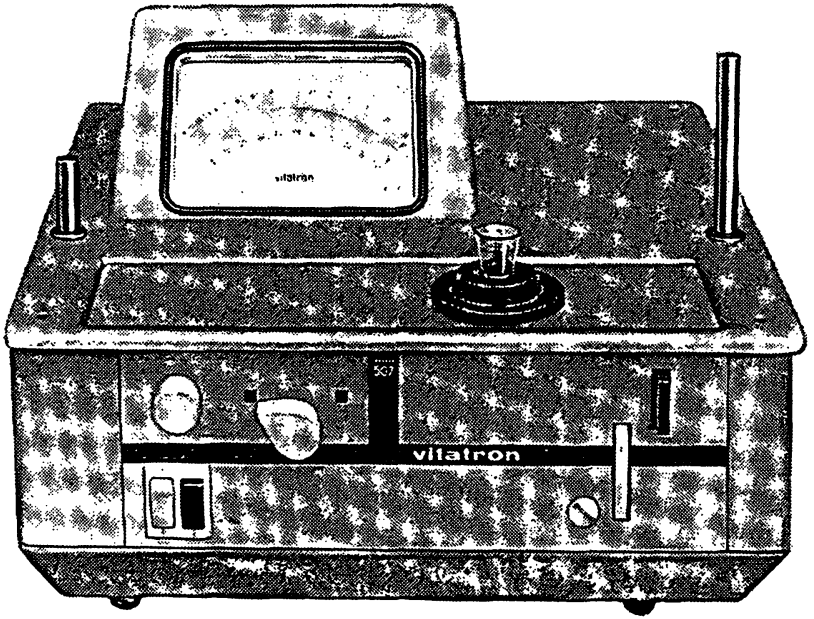

Es hat die Stabilität und Linearität eines

Doppel-Strahl Monochromator-Gerätes, kostet aber weniger als die Hälfte.

Wir können Ihnen hier nicht all seine Vorzüge beschreiben. Aber wenn Sie in Ihrem Labor ein wenig Platz übrig haben (nur $32 \mathrm{~cm} \times 32 \mathrm{~cm}$ ),

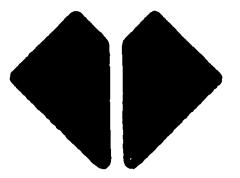

\section{Wir sind sicher:}

\section{Das VITATRON UC 200} PRÄZISIONS-COLORIMETER ist eines der stabilsten Ein-Strahl-Photometer der Welt. dann führen wir es Ihnen gern vor.

Sollten Sie noch etwas mehr Platz haben ( $30 \mathrm{~cm} \times 43 \mathrm{~cm})$, dann bringen wir auch unseren VITATRON-DIGITALWANDLER mit. Er druckt automatisch die Photometeranzeige als Konzentration oder Extinktion'aus, zusammen mit der Proben-Nummer. Fordern Sie bitte weitere Informationen an! Unsere Service-Station ist in Ihrer Nähe.

\section{vitatron}

Vitatron $\mathrm{GmbH}$

5024 Pulheim, Postfach 9 - Ruf: Stommeln $02238 / 7312$ 
439 (1961). - 125. KraffczyK, F. und R. Helger, Z. analyt. Chem. 243, 536 (1968). - 126. HAIs, I. M. und K. MACEK, Handbuch der Papierchromatographie, VEB Gustav Fischer Verlag Jena, (1958) und (1963). - 127. StahL, E., Dünnschichtchromatographie, Springer-Verlag, Heidelberg (1962) und (1968). 128. Wadman, S. K., F. J. van Sprang, G. J. van Stekelendurg und P. K. DE BreE, Acta Paediatr. Scand. 56, 485 (1967). 129. Brenner, M. und A. Niederwieser, Experientia Basel 16, 378 (1960). - 130. Opienska-Blauth, J., H. KRACZkowsKi und H. Bruszkrewicz, in G. B. Marini-Bettolo, Thin-Layer Chromatography, Elsevier, Amsterdam (1964). - 131. BAron, D. N. und J. Economidis, J. Clin. Path. London 16, 484 (1963). - 132. Fafrir, A. R., A. Niederwieser, G. Pataki und M. BrenNer, Helv. chim. Acta 44, 2022 (1961). - 133. Rokkones, T., Scand. J. Clin. Laborat. Invest. 16, 149 (1964). - 134. WhITE, H. H., Clin. Chim. Acta Amsterdam 21, 297 (1968). - 135. SAmuels, S. und S. S. WARD, J. Laborat. Clin. Med. S. Louis 67, 669 (1966). 136. Walker, W. H. und M. Bark, Clin. Chim. Acta Amsterdam 13, 241 (1966). - 137. Troughton, W. D., Techn. Bull. Regist. Med. Techn. 36, 137 (1966). - 138. Troughton, W. D., R. S. Brown und N. A. Turner, Amet. J. Clin. Path. 46, 139 (1966). 139. Farrelly, R. O. und W. B. Watkins, Clin. Chim. Acta Amsterdam 20, 291 (1968). - 140. Ambert, J., C. PeChery und C. Carpentier, Ann. biol. clin. Paris 24, 17 (1966). - 141. SanGER, F., Biochem. J. 39, 507 (1945); 40, 261 (1946); 45, 562 (1949). - 142. Biserte, G. und R. Osteux, Bull. Soc. Chim. biol. Paris 33, 50 (1951). - 143. NIEDERTIESER, A., Dissertation Universität Basel (1962). - 144. WALZ, D., A. R. FAHMY, G. PATAKI, A. NIEDERWIESER und M. BrenNER, Experientia Basel 19, 213 (1963). - 145. BrenNer, M., A. Niederwieser und G. PATAK, I, in "New Biochem. Separations" (A. T. James and L. J. Morris, Editors), van Nostrand, London (1964). - 146. Patakr, G. und M. Keller, diese Z. 1, 157 (1963). - 147. Pataki, G., diese Z. 2, 129 (1964). - 148. Pataki, G. und M. Keller, Helv. chim. Acta 47, 787 (1964). - 149. Bürgr, W., J. P. Colombo und R. RICHTERICH, Klin. Wschr. 43, 1202 (1965). - 150. TANCREDr, F. und H.-Ch. Curtius, unveröffentlicht. - 150a. FrgGe, K., Clin. Chim. Acta Amsterdam 12, 605 (1965). - 151. Patakr, G. und M. KeLler, Helv. chim. Acta 47, 787 (1964). - 152. Keller, M. und G. Pataki, Helv. chim. Acta 46, 1687 (1963). 153. Tancredi, F. und H.-Ch. Curtius, diese Z. 5, 106 (1967). 154. Palmork, K. H., Acta Chem. Scand. 17, 1456 (1963). 155. Pitt-Rivers, R. und J. R. Tata, ,The Chemistry of Thyroid Diseases", Charles Thomas Publ., Springfield, Illinois, USA (1960). - 156. RHodes, B. A. und H. N. WAGNER, Nature London 210, 647 (1966). - 157. Weinert, H., H. Masur, I. RadichewICH und S. C. Wernek, J. Clin. Invest. 46, 1264 (1967). 158. Zappi, E., G. Hoppe, M. Schmidt und F. Prange, diese Z. 6, 286 (1968). - 159. Oberdisse, K. und E. KLeIN, „Die Krankheiten der Schilddrüse", Georg Thieme Vetlag, Stuttgart (1967). 160. Földes, J., G. Gyertyánfy, G. TAmás, E. GesztesI und J. Takács, Nuklearmedizin 6,400 (1967). - 161. Shalom, E. S., J. Endocr. 36, 1 (1966). - 162. MEANS, J. H., L. J. DeGroot und J.B. Stambury, "The Thyroid and its Diseases", McGrawHill Book Co., New York, Toronto (1963). - 163. Zappr, E. und G. HopPE, Nuklearmedizin 6, 420 (1967). - 164. FaIrCLOTH, M. A., A. D. Wirliams und W. H. Fiorshetm, Analytic. Biochem. 12, 437 (1965). - 165. ZAppr, E., J. Chromatog. 30, 611 (1967). 166. SCFINEIDER, G. und C. SCHNEIDER, Hoppe-Seyler's Z. physiol. Chem. 332, 316 (1963). - 167. ZAppr, E., in „Progress in Thin-Layer Chromatography and Related Methods" (A. Niederwieser, G. Pataki, Editors), Ann Arbor Science Publ. Inc., Ann Arbor, Michigan (im Druck). - 168. Bowden, C. H., N. F. MCLAGAN und J. H. Wilkinson, Biochem. J. 59, 93 (1955). 169. MaNdr, R. H. und R. J. Block, Arch. Biochem. Biophysics 81, 25 (1959). - 170. Gmelin, H. und A. I. Virtanen, Acta Chem. Scand. 13, 1469 (1959). - 171. Barker, S. B., in "Methods in Hormone Research" (R. Dorfman, Editor), Academic Press, New York (1962). - 172. BARKer, S. B., Biochem. J. 90, 214 (1964). - 173. Posrmes, Tr., Clin. Chim. Acta Amsterdam 10, 581 (1964). - 174. Row, V. V., R. Volpé und C. Ezrin, Clin. Chim. Acta Amsterdam 13, 666 (1966). - 175. Stahl, E. und
J. Pferfle, Z. analyt. Chem. 200, 377 (1964). - 176. Prescott, B. A., E. Borek, A. Brecher und H. Waelsch, J. biol. Chemistry 181, 273 (1949). - 177. GunNESS, M., I. M. DWYER und J. L. Stokes, J. biol. Chemistry 163, 159 (1946). - 178. BrCkel, H., J. Gerrard und E. M. Hickmans, Lancet London 1953 II 812. - 179. Schweigert, B. S. und E. E. SNell, Nutrit. Abstr. Rev. 16, 497 (1947). - 180. SChWERDTFEGER, E., Z. analyt. Chem. 243, 501 (1968). - 180a. Gerke, J. R., T. A. Haney, J. F. Pagano und A. Ferrari, Ann. N. Y. Acad. Sci. 87, 782 (1960). - 180 b. Shaw, W. H. C. und R. E. Duncombe, Analytic. Chem. 88, 694 (1963). - 181. Block, R. J. und D. Bolling, The Amino Acid Composition of Proteins and Foods, C.C. Thomas, Springfield, Ill., (1951). - 182. in 4, Vol. 2. - 183. BERGMEYER, H. U., Methoden der enzymatischen Analyse, Verlag Chemic, Weinheim (1962). - 184. McCaman, M. W. und E. RoBINs, J. Laborat. Clin. Med. S. Louis 59, 885 (1962). - 185. Wong, P. W. K., T. InOuYe und M. O. FlynN, Clin. Chem. New York 10, 1098 (1964). - 185a. Ambrose, J. A., Clin. Chem. New York 15, 15 (1969). - 186. in 4, Vol. 2, S. 69. - 187. Hill, J. B., G. K. Summer, M. W. Pender und N. O. Roszel, Clin. Chem. New York 11, 542 (1965). - 188. LA Du, B. N. und P. J. Mrchael, J. Laborat. Clin. Med. S. Louis 55, 491 (1960). 189. KNox, W. E. und B. M. Prrt, J. biol. Chemistry 225, 675 (1957). - 190. Gentz, J., B. LindBlad, S. LindstedT und R. Zetrerström, J. Laborat. Clin. Med. S. Louis (1969) im Druck. - 191. Berry, H. K., B. UMbarger und S. B. SutherLAND, J. Pediatr. S. Louis 67, 609 (1965). - 192. BERRY, H. K., Clin. Chim. Acta Amsterdam 20, 299 (1968). - 193. Udenfriend, S. und J. R. Cooper, J. biol. Chemistry 203, 953 (1953). 194. Woolf, L. I., in Adv. Clin. Chem. (H. Sobotka und C. P. Stewart, Editors), Academic Press, New York, Vol. 6, 172 (1963). 195. Gerngross, O., K. Voss und H. Herfeld, Chem. Ber. 66, 435 (1933). - 196. WaAlKes, T. P. und S. UdENFriend, J. Laborat. Clin. Med. S. Louis 50, 733 (1957). - 197. HochedLA, N. J., Analytic. Biochem. 21, 227 (1967). - 198. NeumanN, R. E. und M. A. Logan, J. biol. Chemistry 184, 299 (1950). - 199. StegeMaNN, H., Hoppe-Seyler's Z. physiol. Chem. 311, 41 (1958). 200. Stegemann, H. und K. Stalder, Clin. Chim. Acta Amsterdam 18, 267 (1967). - 201. Prockop, D. J. und S. Udenfriend, Analytic. Biochem. 1, 228 (1960). - 202. StaldER, K., Z. analyt. Chem. 212, 196 (1965). - 203. Rosano, C. L., Analytic. Biochem. 15, 341 (1966). - 204. Piez, K. A., F. Irrevere und H. L. WolfF, J. biol. Chemistry 223, 687 (1956). - 205. Sullivan, M. X., W. C. Hess und H. W. Howard, J. biol. Chemistry 145, 621 (1942). - 206. Hess, W. C. und M. X. Sullivan, Arch. Biochem. Biophysics 3, 53 (1943). - 207. McDonald, W. B. und F. X. Felters, J. Amer. Med. Ass. 197, 396 (1966). - 208. LANGE, J., K. Freund und H. Bürehr, Arzneim.-forsch. Aulendorf 17, 856 (1967). - 209. Matsuura, T. und D. Szafarz, Experientia Basel 21, 737 (1965). - 210. Kurtzman, C. H., P. Smith und D. G. SNYDER, Analytic. Biochem. 12, 282 (1965). - 210a. MEHLER, A. H. und H. TABOR, J. biol. Chemistry 201, 775 (1953). 210b. in 4, Vol. 2, S. 92 . - 211. Benson, J. V., in „New Techniques in Amino Acid. Peptide and Protein Analysis" (Editors: A. Niederwieser and G. Pataki), Ann Arbor Science Publ. Inc., Ann Arbor, Michigan (im Druck). - 212. Hamilton, P. B., in „Advances of Chromatography", Vol. 2, S. 3-62 (Editors: J. C. Giddings and R. A. Keller), Marcel Dekker, New York (1966). 213. Hamrlton, P. B., in "Handbook of Biochemistry, Selected Data for Molecular Biology", S. B-43-B-55 (Editor: H. A. Sober), The Chemical Rubber Co., Cleveland, Ohio (1968). 214. Kirsten, E. und R. Kirsten, Biochem. Biophys. Res. Commun. 7, 76 (1962). - 215. Spackman, D. H., W. H. SteIN und S. Moore, Analytic. Chem. 30, 1190 (1958). - 215a. CrestFIELD, A. M., Analytic. Chem. 35, 1762 (1963). - 215 b. Dus, K., S. LindRoth, R. PAPST und R. M. SMIth, Analytic. Biochem. 18, 532 (1967). - 215c. Dymond, B., Analytic. Chem. 40, 919 (1968). 216. Moore, S. und W. H. Stein, J. biol. Chemistry 176, 367 (1948). - 217. Oreskes, I., F. Cantor und S. Kupfer, Analytic. Chem. 37, 1720 (1965). - 218. Technicon (Instruction Manual). 219. Rosen, H., C. W. Brrard und S. M. Levenson, Analytic. Biochem. 4, 213 (1962). - 220. PIEZ, K. A. und L. Morris, 
Analytic. Biochem. 1, 187 (1960). - 221. Borner, K., diese Z. 4, 212 (1966). - 222. Burtis, C. A. und K. S. Warren, Clin. Chem. New York 14, 290 (1968). - 223. S Jostrom, E., Svensk. Kem. Tidskr. 64, 150 (1952). - 224. HedfFerich, F., Nature London 189, 1001 (1961). - 225. HelfFerich, F., J. Amer. chem. Soc. 84, 3237, 3242 (1962). - 226. LoEwENSCHuss, H. und G. SchmuCkLER, Talanta 11, 1399 (1964). - 227. Sieger, A. und E. T. Degens, Science Washington 151, 1098 (1966). - 228. Helfferich, F., „Ion Exchange" McGraw-Hill, New York (1962). - 228 a. Oepen, H., I. Oepen und N. Langbein, Klin. Wschr. 43, 622 (1965). - 229. Gerritsen, T., M. L. RehberG und H. A. Warsman, Analytic. Biochem. 11, 460 (1965). 230. Gerritsen, T., Privatmitteilung. - 231. Khachadurian, A., W. Knox und A. Cullen, J. Laborat. Clin. Med. S. Louis 56, 321 (1960). - 231 a. De Marco, C., M. Coletta und C. CavalLINI, J. Chromatog. 20, 500 (1965). - 232. Hamilton, P. B., Analytic. Chem. 35, 2055 (1963). - 233. Anders, P. W., Firma Bio-Cal, München, Privatmitteilung. - 234. Spackman, D. H., in "Methods in Enzymology" (Editors: S. P. Colowick, N. O. Kaplan), Vol. 11, S. 3-15 (Editor: C. H. W. Hirs), Academic Press, New York (1967). - 235. Orten, A. U., H. J. Doppke und H. H. Spurrier, Analytic. Chem. 37, 623 (1965). - 236. Curtius, H.-Ch., A. C. Martenet und P. W. Anders, Clin. Chim. Acta Amstełdam 19, 469 (1968). - 237. Benson, J. V., J. CorMICK und J.'A. Pattersox, Analytic. Biochem. 18, 481 (1967). 238. Shin, V. E., M. L. EFron und G. L. Mechanic, Analytic. Biochem. 20, 299 (1967). - 239. SCHROEDER, W. A., W. R. Holmquist und J. R. Shelton, Analytic. Chem. 38, 1281 (1966). 240. Yonda, A., D. L. Filmer, H. Pate, N. Alonzo und C. H. W. Hirs, Analytic. Biochem. 10, 53 (1965). - 241. Starbuck, W. C., C. M. Mauritzen, C. McClmans und H. Busch, Analytic. Biochem. 20, 439 (1967). - 242. Coulter, J. R. und C. S. HANN, in „New Techniques in Amino Acid, Peptide and Protein Analysis" (Editors: A. Niederwieser and G. Pataki), Ann Arbor Science Publ. Inc., Ann Arbor, Michigan (im Druck). - 243. GeHRKE, Ch. W., D. Roach, R. W. Zumwalt, D. L. Stalling und L. L. WALL, "Quantitative Gas-Liquid Chromatography of Amino Acids in Proteins and Biological Substances", Analytical Biochemistry Laboratories, Inc., Columbia, Missouri (1968). -
244. BLAU, K., in „Biomedical Applications of Gas Chromatography" (Editor: H. A. Szymanski), Plenum Press (1968). 245. Weinsten, B., Meth. Biochem. Analysis 14, 203 (1966). - 246. Coulter, J. R. und C. S. HanN, J. Chromatog. 36, 42 (1968). - 247. Darbre, A. rund A. Islam, Biochem. J, 106, 923 (1968). - 248. Stefanovic, M. und B. L. Walker. Analytic. Chem. 39, 710 (1967). - 249. BreUER, J., .G. KAESE und H. Breuer, diese Z. 6, 298 (1968). - 250. RYAN, W. L. und A. B. Lorinzc, Nebraska State Med. J. 49, 321 (1964). - 251. Peisakgov, B. I., Klin. med. Moskva 43, 83 (1964). - 252. Brock, W. D. und M. H. Westhopp, Metabolism Baltimore 15, 46 (1966). - 253. Dus, K., M. DEKKER und R. M. SMITH, Analytic. Biochem. 11, 312 (1965). - 254. HACKET, N., A. P. MAThias und F. PENinington, Analytic. Biochem. 12, 367 (1965). 255. Drawert, F. und O. Bachmann, Angew. Chem. 75, 717 (1963). - 256. Simon, H., G. MüLLhofer und R. MEdinA, „Radioisotope Sample Measurement Techniques in Medicine and Biology“", S. 317, International Atomic Energy Agency Vienna (1965). - 257. Holmes, J. C. und F. A. Morel, Appl. Spectroscopy 11, 86 (1957). - 258. GohtKE, R. S., Analytic. Chem. 31, 535 (1959). - 259. Beynon, J. H., R. A. Saunders und A. E. WILLIAMs, J. Sci. Instr. 36, 375 (1959). - 260. BrEMANN, K. und J. T. Watson, Analytic. Chem. 36, 1135 (1964). - 261. Rrhage, R., Analytic. Chem. 36, 959 (1964). - 262. Currius, H.-Ch., diese Z. 6, 122 (1968). - 263. HARper, H. A., M. E. HutchIN und J. R. Krmmex, Proc. Soc. Exper. Biol. Med. N.Y. 80; 768 (1952). 264. Whelan, D. T. und Ch. R. Scriver, Pediat. Res. 2, 525 (1968). - 265. Ambrose, J. A., A. Crimm, J. Burton, K. Paullin und CF. Ross, Clin. Chem. New York 15, 361 (1969). - 266. Shore, P. A., A. Burkhalter und V. H. Cohn, J. Pharmacol. Exper. Therap. Baltimore 127, 182 (1959). - 267. SruBER, A., Clin. Chim. Acta, Amsterdam 24, 221 (1969). - 268. Koevoet, A. L. und J. D. BaArs, Clin. Chim. Acta Amsterdam 25, 39 (1969). - 269. WADMAN, S. K., H. FABERY DE JONGE Und P. K. de Bree, Clin. Chim. Acta Amsterdam 25, 87 (1969). - 270. Perry, Th. L., D. Stedman und S. Hansen, J. Chromatog. 38, 460-466 (1968). - 271. Benson, J. V., M. J. Gordon und J. A. Patterson, Analytic. Biochem. 18, 228 (1967): - 272. Perry, Tr. L. und S. Hansen, Clin. Chim. Acta Amsterdam 25, 53 (1969).

Dr. A. Niederwieser und Priv.-Doz. Dr. H.-Ch. Curtius $\mathrm{CH} 8032$ Zürich Steinwiesstr. 75 . 